\title{
Application of Field-Modulated Generator Systems to Dispersed Solar Thermal Electric Generation
}

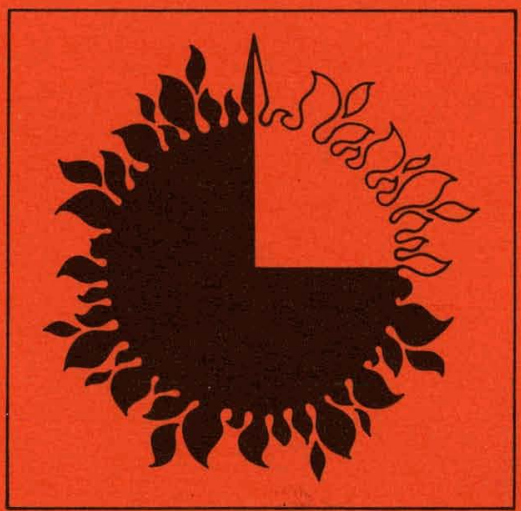

August 15, 1979

Prepared tor

U.S. Department of Energy

Through an agreement with

National Aeronautics and Space Administration

by

Jet Propulsion Laboratory

California Institute of Technology

Pasadena, California 


\section{DISCLAIMER}

This report was prepared as an account of work sponsored by an agency of the United States Government. Neither the United States Government nor any agency Thereof, nor any of their employees, makes any warranty, express or implied, or assumes any legal liability or responsibility for the accuracy, completeness, or usefulness of any information, apparatus, product, or process disclosed, or represents that its use would not infringe privately owned rights. Reference herein to any specific commercial product, process, or service by trade name, trademark, manufacturer, or otherwise does not necessarily constitute or imply its endorsement, recommendation, or favoring by the United States Government or any agency thereof. The views and opinions of authors expressed herein do not necessarily state or reflect those of the United States Government or any agency thereof. 


\section{DISCLAIMER}

Portions of this document may be illegible in electronic image products. Images are produced from the best available original document. 


\section{Application of Field-Modulated Generator Systems to Dispersed Solar Thermal Electric Generation}

R. Ramakumar

K. Bahrami

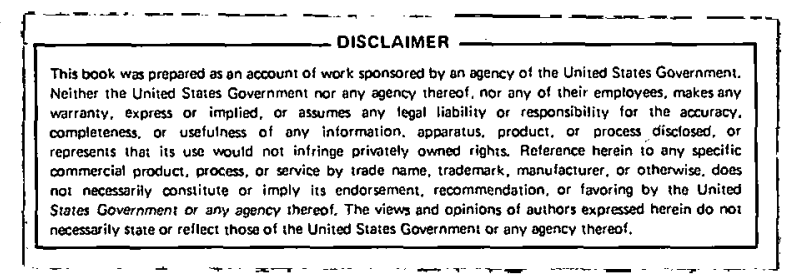

August 15, 1979

Prepared tor

U.S. Department of Energy

Through an agreement with

National Aeronautics and Space Administration

by

Jet Propulsion Laboratory

California Institute of Technology

Pasadena, California 
Prepared by the Jet Propulsion Laboratory, California Institute of Technology, for the U.S. Department of Energy through an agreement with the National Aeronautics and Space Administration.

The JPL Solar Thermal Power Systems Projeot is spunsured by the U.S. Department of Enorgy and furus a part of the Solar Thermal Program to develop low-cost solar thermal electric generating plants.

This report was prepared as an account of work sponsored by the United States Government. Neitlier the United States nor the United States Department of Energy, nor any of their employees, nor any of their contractors, subcontractors, or their employees, makes any warranty, express or implied, or assumes any legal liability or responsibility for the accuracy, completeness or usefulness of any information, apparatus, product or process disclosed, or represents that its use would not infringe privately owned rights. 


\section{FOREWORD}

This report summarizes the results of a study conducted by The Jet Propulsion Laboratory for The Department of Energy to analyze the feasibility of Field Modulated Generator Systems (FMGS) for dispersed solar thermal electric conversion system application.

As part of the Solar Thermal Project at The Jet Propulsion Laboratory (JPL) attention is being focused on the generation of electricity from dispersed solar collectors. One approach is to use small dish electric suntracking generation units to generate electricity. Subsequently, the energy is collected electrically to feed into the electric utility line and/or load.

Various approaches are possible for the conversion of mechanical shaft energy output of the heat engines to electricity. These include the use of $A C$ alternators, DC generators, cycloconverters, and Field Modulated Generators (FMG). The use of FMG allows the generation of electricity at constant frequency $(60 \mathrm{~Hz})$ from a variable mechanical shaft output. FMGS is a variablespeed constant (or adjustable)-frequency power system. It is based on modulating the field of an alternator by exciting it with alternating current at the required output frequency rather than with direct current. The constant frequency output at the modulation frequency is obtained by demodulation techniques employing a low frequency switching scheme. This is a very attractive feature, and it subsequently led to the initiation of the study to investigate the Application of Field Modulated Generator Systems to Dispersed Thermal Electric Generation.

JPL sought expertise in the FMG field from industrial and academic domains. It found such an expertise in Dr. R. Ramakumar, Professor of Electrical Engineering, Oklahoma State University, Stillwater, Oklahoma 77074. He served as a consultant to JPL for the duration of this study.

The study of the dish-electric transport with FMGS started in Mid-September of 1978. Some preliminary ideas were presented during the review of advanced solar thermal power systems entitled "Focus on Solar Technology", held at Denver during November 15-17, 1978. This final report documents the findings and suggests areas for further work needed to judiciously apply FMGS in advanced solar thermal electric plants of the future. It is hoped that this study will expose the attractive features of the application of FMGS, without hiding the shortcomings. This report should open the door for further detailed studies and stimulate prototype design and development to positively demonstrate the applicability of the FMGS in advanced dispersed solar thermal electric conversion systems of the future. 


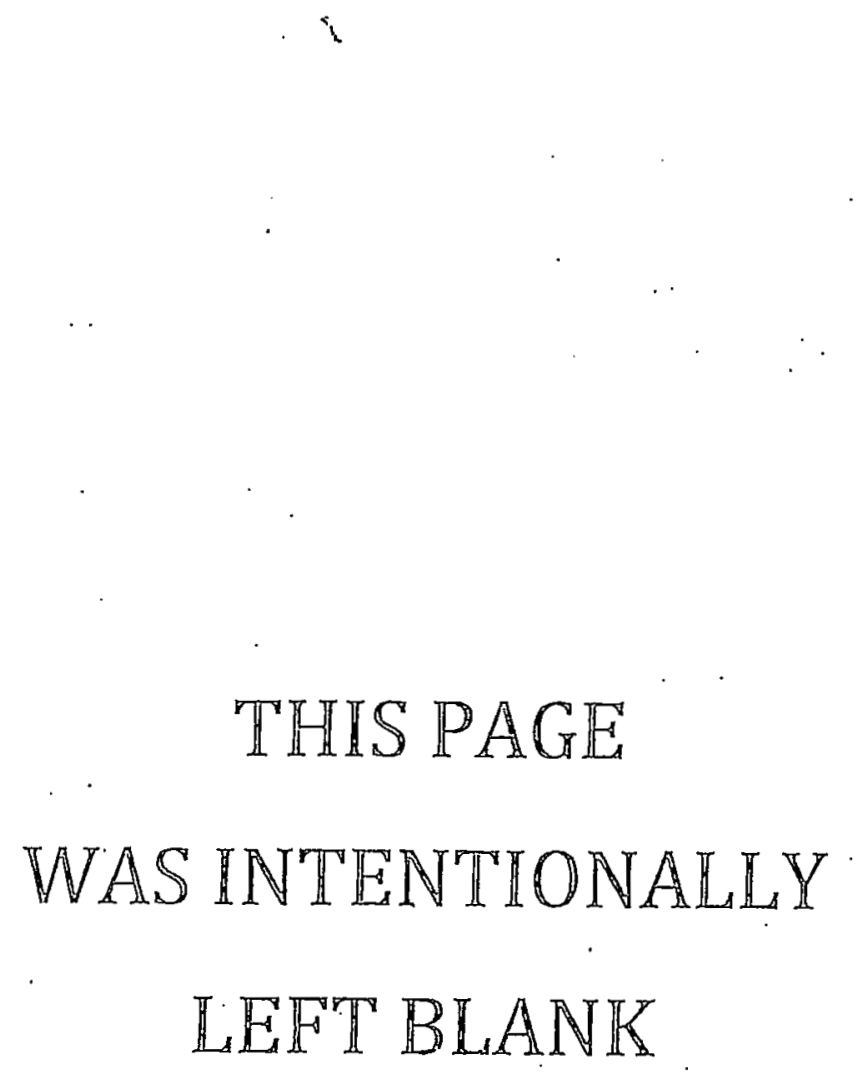




\section{ABSTRACT:}

A Parabolic Dish-Electric Transport concept for dispersed solar thermal generation is considered. In this concept the power. generated by $15 \mathrm{kWe}$ Solar Generation Units is electrically collected in a large plant.

Various approaches are possible for the conversion of mechanical shaft output of the heat engines to electricity. This study focuses on the Application of Field Modulated Generation System (FMGS) for that purpose.

Initially the state-of-the-art of FMGS is presented, and the application of FMGS to dispersed solar thermal electric generation is investigated. This is followed by the definition of the control and monitoring requirements for solar generation system. Then comparison is made between FMGS approach and other options. Finally, the technology developmental needs are identified. 


\section{ACKNOWLEDGMENTS}

The authors wish to acknowledge the efforts of Mr. John Becker, Manager, Advanced Solar Thermal Technology Project for sponsoring this study. 
CONTENTS

Section

Page

I. INTRODUCTION AND PROBLEM STATEMENT . . . . . . . . . . . . . . . . 1

II. FIELD MODULATED GENERATOR SYSTEMS - A REVIEW OF THE STATE-OF-THE-ART 7

III. APPLICATION OF FMGS TO DISPERSED SOLAR THERMAL ELECTRIC GENERATION. 26

IV. CONTROL INTERFACE AND MONITORING REQUIREMENTS . . . . . . . . . . . . 41

V. NEEDED TECHNOLOGY. . . . . . . . . . . . . . . . . . 53

VI. COMPARISON WITH OTHER OPTIONS. . . . . . . . . . . . . . 56

VII. SUMMARY AND CONCLUDING REMARKS . . . . . . . . . . . . . . . 64

FIGURES

2-1 Functional Block Diagram of the Basic Field Modulated Generator System (FMGS) .......................... 9

2-2 Simplified Single-Phase Schematic of the Field Modulated Generator System . . . . . . . . . . . . . . . . . . 10

2-3 Photograph of the $10 \mathrm{~kW}$ Experimental Prototype . . . . . . . . . 14

2-4. Functional Block Diagram of an Alternate Scheme With Field Modulation and no SCRs.................... 19

2-5 Excitation Circuit for the Scheme Shown in Figure 4. . . . . . . . 21

2-6 An Implementation of the Alternate Scheme Shown in Figure 4. . . . 21

2-7 Inductor-type Magnetic Circuit Structure for FMGS to Eliminate Si ip Rings ...................... . . 22

3-1 Schematic of Dish-Electric Transport with FMGS . . . . . . . . . . . 27

3-2 Phasor Relationships Between Excitation and Output Voltages. . . . . 28

3-3 Block Diagram of a Solar Generation Unit Employing FMGS. . . . . . 30

3-4 Typical Efficiencies of the Components of Dish-Electric Transport with FMGS. . . . . . . . . . . . . . . . . . 32 


\section{CONTENTS (Continued)}

FIGURES

Page

3-5 Power Flows for a Solar Generation Unit Employing FMGS . . . . . . 33

3-6 Schematic of Paralle1 Operation of Solar Generation Units with Common Power Processing for each Phase of a Three-Phase System . . . 34

3-7 Power Flows for the Parallel Group of Solar Generation Units for each Phase of a Three-Phase System . . . . . . . . . 36

3-8 Conceptual Block Diagram of a 10 MWe Plant Employing Dish-Electric Transport with FMGS. . . . . . . . . . . . . . 37

3-9 Power Flows with Standardized $10 \mathrm{~m}$ dia Dishes for an Electrical Output of 1.125 MWe (one group of a Three-Group Module for ThreePhase generation) .............. . . 40

4-1 Simplifled Schematic of Individual Control . . . . . . . . . 43

4-2 Circuitry to Obtain $V_{\text {exA }}$ for the Case of Individual Control. . . . 44

4-3 Schematic of Group Control . . . . . . . . . . . . . 45

4-4 Circuitry to Obtain $V_{\text {exA }}$ for the Case of Group Control . . . . . . 46

4-5 Simplified Schematic of the Transformer Interface. . . . . . . 48

4-6 Idealized Circuit Model for an FMGS Pumping Power into a Puwer Grld. bU

6-1 Simp1ified Schematics of VSCF Generation Options for High-Speed

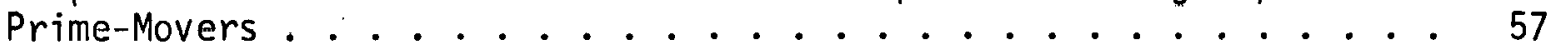

6-2 Sine and Modulated Sine Waveforms. ............... 60 APPENDICES

A. Performance of the $10 \mathrm{~kW}$ FMGS Experimental Prototype . . . . . 66

B. Performance of the Three-Phase $60 \mathrm{~kW}$ FMGS Experimental Prototype 72

C. Application of Field Modulated Generator Systems to Dispersed Sular Thermal Electric Generation. . . . . . . . . . . 


\section{SECTION I}

\section{INTRODUCTION AND PROBLEM STATEMENT}

\section{A. GENERAL}

Solar generated electricity is expected to play an important role in the national energy picture towards the end of this century. Of the various technologies available for the production of electricity, central and dispersed solar thermal electric power systems are receiving considerable attention because of their potential for high efficiencies and cost effective electric power generation.

\section{B. SOLAR THERMAL ELECTRIC CONVERSION}

Electrical energy is generated by collecting (with or without concentration) insolation, converting it to thermal energy first and then to mechanical energy via a thermodynamic cycle to drive an electromechanical energy conversion device. All the syslems identificd so far fall into two broad categories.

1. Distributed Collector with Central or Distributed Generation Systems.
a. Flat-plate distributed receiver systems,
b. Line-focusing distributed receiver systems, and
c. Point-focusing distributed receiver systems.

2. Central Receiver with Central Generation Systems.

Both types of systems have certain basic components. They are listed below.

1. Solar collectors. 
2. Devices to convert insolation into thermal energy.

3. Thermal energy storage component.

4. System to transport thermal energy to the heat engine.

5. Heat engine to convert thermal energy into mechanical energy based on any one of the following thermodynamic cycles:
a. Rankine cycle
b. Stirling cycle
c. Brayton cycle

6. Electromechanical energy conversion device to convert the mechanical energy into electrical energy.

7. Electrical output power conditioning apparatus.

8. Electrical energy storage and reconversion system (if necessary).

9. Monitoring, control and interface equipment.

10. Means to dispose (or utilize) the low-grade thermal energy rejected by the heat engine.

This report deals with point-focusing distributed receiver systems. In particular, a parabolic dish field with electric transport is considered. In the 11 terature, this type of dispersed solar thermal generation cuncept is known as the "Parabolic Dish-Electric Transport." Each solar generation unit is rated at $15 \mathrm{kWe}$ and the power generated by an array of such units is electrically collected for insertion into an existing utility grid.

\section{BASIC FACTORS INVOLVED}

Overall system reliability, efficiency and cost are the three major factors to be considered in selecting candidate system configurations for prntotype development. Obviously, these three are closely intertwined and, often, engineering compromises are necessary. 
The type of heat engine and the associated thermodynamic cycle selected have a bearing on all the key parameters - receiver operating temperature, cycle efficiency, constant or variable speed operation, high, low or medium, speed operation, rotary or reciprocating power converter, cost, reliability, availability and overall efficiency of conversion.

One of the most important design options available is concerned with the choice of maintaining a constant temperature level and reducing the mass flow rate as the insolation varies. This will involve a variable speed operation as compared to constant speed operation resulting from maintaining a constant flow rate and variable temperature. This has a direct bearing on the type of electric generator and the associated power conditioning equipment necessary.

\section{ELECTRIC CONVERSION OPTIONS}

The following factors influence the choice of the electric power-generation and power-conditioning devices necessary.

1. Type of electrical output generated:

a. direct current, constant or variable voltage,

b. variable frequency, variable or constant voltage alternating current, or

c. constant frequency, variable or constant voltage alternating current.

2. Operating mode of the heat engine:

a. Constant speed operation, or

b. Variable speed operation.

3. Operating speed range:

a. Low-speed operation (below $6000 \mathrm{r} / \mathrm{min}$ ),

b. Medium-speed operation (6000 to $18000 \mathrm{r} / \mathrm{min})$, or

c. High-speed operation (above $18000 \mathrm{r} / \mathrm{min}$ ). 
4. Type of electrical output desired at the application end:

a. constant-voltage constant-frequency utility grade ac, or

b. direct current for storage in batteries or as an input to electrolysis units for storage in the form of hydrogen.

It is quite clear that a multitude of options are available for electric power generation, depending on the particular combination of operating parameters required. However, if utility grade ac is of interest for direct insertion into an existing grid without an intermediate energy storage and reconversion system, the choices dwindle down to the following.

1. Constant-speed operation: synchronous generator,

2. Variable-speed-operation: some type of variable-speed constantfrequency (VSCF) generation scheme.

Several VSCF generation schemes are available for use in the dish-electric transport concept. The ones that show the most promise are:

a. $A C-D C-A C$ link employing a conventional or a permanent-magnet variablefrequency al ternator.

b. Cycloconverter.

c. Field modulated generator system.

The choice of generation scheme is also strongly dependent on the rotational speed of the heat engine. Direct coupling of synchronous generators is $11 \mathrm{mited}$ to a top speed of $3600 \mathrm{r} / \mathrm{min}$ and to certain discrete lower values. Special ac generators for VSCF schemes have a little bit more flexibility. There is always the possibility of employing an appropriate mechanical interface (gear box and coupling) to match the generator to the heat engine. However, this will add weight to the system at a point where it can least afford namely the focal point.

The $A C-D C-A C$ link (otherwise known as static frequency changer) rectifies the variable frequency output of the alternator and employs an inverter to 
obtain a constant-frequency constant-voltage output. This is a mature technology and considerable amount of work has already been done on this approach. Cycloconverter type frequency changers have also been thoroughiy researched and has already reached the small-scale (a few hundreds) commercial market. Drawbacks associated with this scheme are the extensive filtering required to obtain an acceptable waveform, less adaptive to sudden input and speed changes and slightly lower efficiencies because of the harmonic content in the machine currents. Although they have reactive power output capability, they appear to be quite expensive for use in the large-scale harnessing of solar energy.

\section{E. FIELD MODULATED GENERATOR SYSTEMS (FMGS) OPTION}

The rest of this report will be concerned with a specific VSCF option namely the field modulated generator system. If direct coupling of the electrical generator to a high-speed engine operating in the variable-speed mode is required, FMGS appears to provide a viable alternative for constantfrequency utility grade ac power generation.

Field modulation and demodulation techniques use an electromagnetic modulator in the form of exciting the rotating field coil with alternating current at the required low frequency. Output is obtained by demodulation techniques which employ either a high-frequency or a low-frequency switching scheme. By far the most successful FMGS employs low frequency. switching and has been under development at OKlahoma State University since 1970.

The next Chapter summarizes the state-of-the-art of FMGS. Application to dispersed solar thermal electric generation is discussed in Chapter III. Moni= toring, control and interface requirements are outlined in Chapter. IV. The technologies needed for the successful introduction of this device in advanced dispersed solar thermal electric power systems of the future are documented in 
Chapter $V$. The report concludes with a comparison of the FMGS option with other options in terms of overall efficiency, reliability, economics and operational features. 
SECTION II

FIELD MODULATED GENERATOR SYSTEMS

A REVIEW OF THE STATE-OF-THE-ART

The term 'field modulation' refers to varying the magnetic field in the air-gap of a rotating machine as desired by varying the excitation current to obtain a variety of desired outputs. In the case of rotating field machines, replacing the $d c$ excitation by ac (or a combination of $d c$ and ac) excitation necessitates a laminated rotor (instead of the usual solid rotor) to minimize iron losses.

A. BACKGROUND

The concept of employing field modulation techniques to control the output frequency of a generator has been discussed in the literature for at least 20 years [1-4]. However, most of the early attempts were not highly successful either for the lack of high-speed high-powered solid-state switching devices at that time or due to low overall efficiencies resulting from 7 tne-to-line short circuits at the machine terminals during commutation or both.

The first successful multi-kilowatt-scale field modulated generator system (FMGS) was developed, designed, fabricated and tested at Oklahoma State University $[5,6]$ during the early seventies. The scheme employs a parallel-bridge rectifier system (PBRS), thus eliminating the line-to-line short-circuits at the machine terminals. This feature, coupled with the use of capacitors at the bridge-inputs, reduce the excitation requirements, improve the regutation and the overall efficiency. 


\section{B. DESCRIPTION OF THE FMES}

A functional block diagram of the field modulated generator system is shown in Figure 2-1. The prinicpal components of the system are (i) field modulated alternator, (ii) parallel-bridge rectifier system with bridge-input capacitors, (iii) SCR switching circuit and (iv) low-pass filter. Assuming the basic machine waveform to be sinusoidal, voltage waveforms at various points and their phase relationships are shown in the block diagram. It can be seen that the cutput voltage of the PBRS is essentially a full-wave rectified waveform (with a small amount of high-frequency harmonics superimposed). This is then switched by a thyristor-bridge inverter at the nearly zero-voltage points to obtain a constant frequency output. The scheme described here belongs to the class of systems employing low-frequency envelope switching for demodulation.

Figure 2-2 shows a simplified single-phase schematic of the field modulated generator (frequency down converter) system. It is built around a highreactance high-frequency (approximately 10 times the output frequency required or higher) three-phase alternator. Rotor winding terminais of the wound-rotor are brought out through a conventional slip ring arrangement. Both cylindrical rotor and salient-pole configurations are suitable for field modulation. The. rotor and the stator are laminated to minimize iron losses. The six stator: leads are connected to three full-wave bridges as shown, one acrnss each of thc phases. Outputs of the bridges are tied in parallel dcross the load through a silicon controlled rectifier switching system. Stator tuning capacitors $C$ are connected across each of the stator windings to decrease the excitation requirements (both watts and vars). The small capacitor $C_{1}$ and the inductor $L_{1}$ prevent any rapid voltage variations that may occur at the machine terminals 


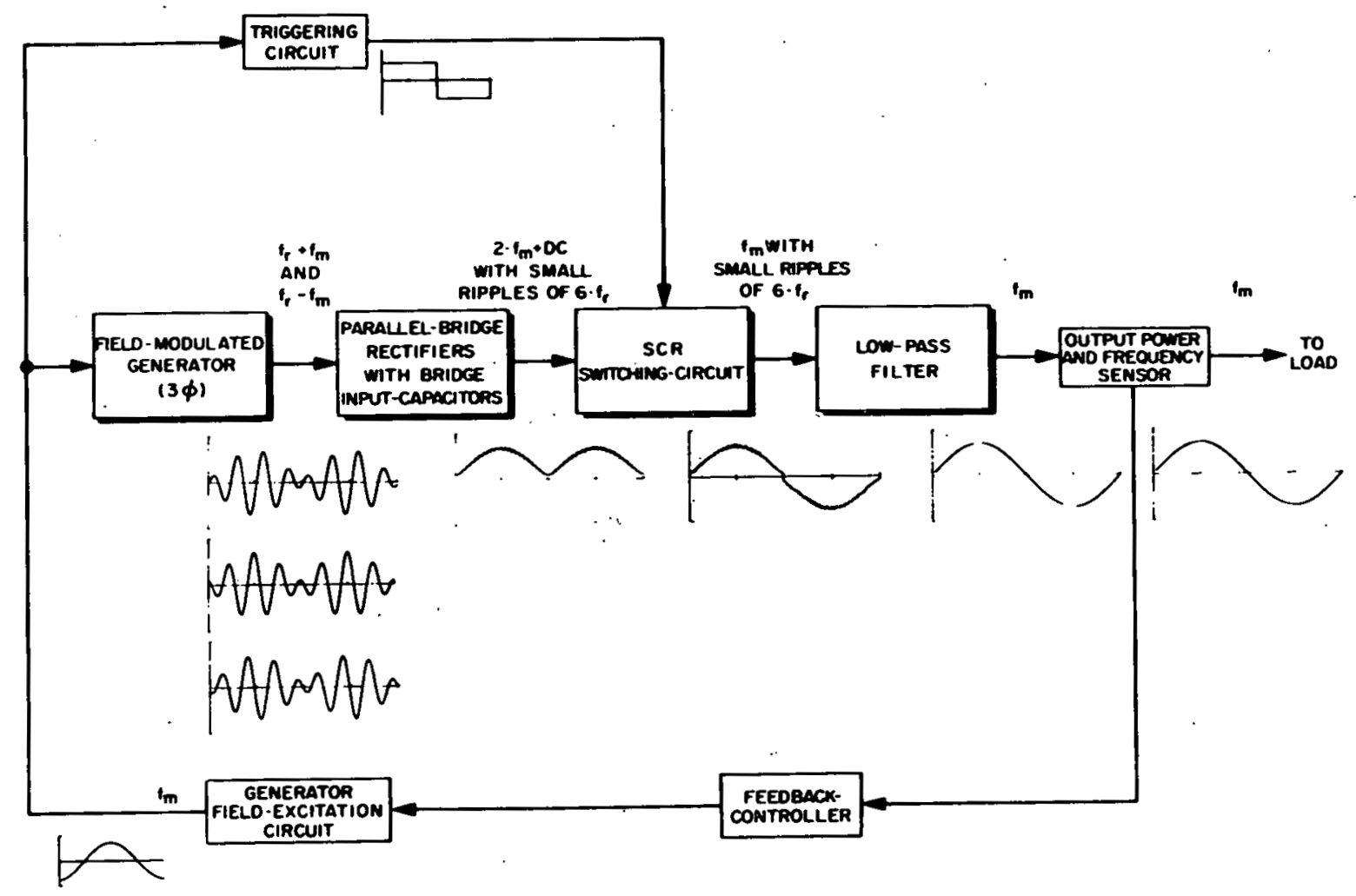

Figure 2-1. Functional Block Diagram of the Basic Field Modulated Generator System (FMGS). 


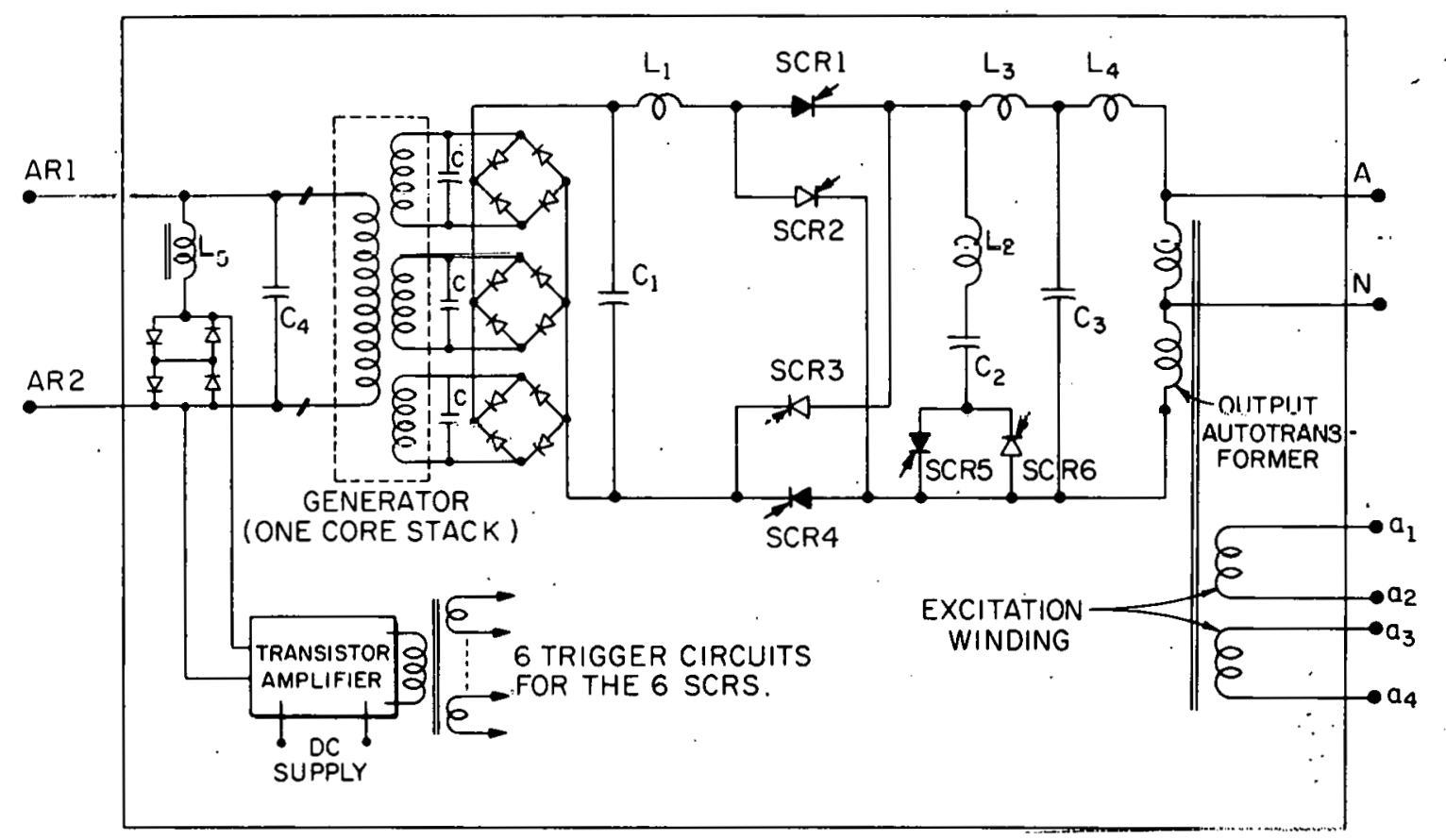

Figure 2-2. Simplified Single-Phase Schematic of the Fiold Modulatcd Generator. System 
from damaging the silicon controlled rectifiers. The main switching process is accomplished by the four controlled rectifiers, SCR1 through SCR4. The commutating circuit consisting of $\mathrm{L}_{2}, \mathrm{C}_{2}$ and the controlled rectifiers SCR5 and SCR6 aid in this switching process, especially when the load is not purely resistive.

At the start of one half of the low frequency cycle, SCR1, SCR4 and SCR5 are triggered together. Capacitor $\mathrm{C}_{2}$ charges up to the peak value of the fullwave rectified voltage appearing across the parallel bridge arrangement. At the end of this half cycle, SCR2, SCR3 and SCR6 are triggered together and simultaneous Ty SCR1, SCR4 and SCR5 are shut off. The voltage across capacitor $C_{2}$ now is of such a polarity (top + and bottom -) as to help turn off SCRI and SCR4. In this process, capacitor $C_{2}$ discharges and starts to recharge in the opposite direction through SCR6 to the peak value of the voltage as before. At the end of this second half cycle, the voltage across capacitor $c_{2}$ (top -, bottom + ) will aid in shutting off SCR2 and SCR3. This charging and discharging of $C_{2}$ is repeated once every half cycle corresponding to the modulation (10w) frequency. The size of $C_{2}$ depends on the accuracy of the timing of the SCR trigger signals and on the reactive nature of the load. The small inductance $L_{2}$ is provided as a safeguard against sudden voltage variations from appearing acrosS SCR5 and SCR6. Filtering the switched output is performed by the tuned circuit consisting of filter capacitor $C_{3}$, inductors $L_{3}$ and $L_{4}$ and the output autotransformer. In addition to filtering, capacitance $\mathrm{C}_{3}$ aids the system in handling lagging power factor loads.

The field winding is excited by an ac power source of (modulation) frequency $f_{m}$. Since the excitation fixes the output frequency, care must be exercised in the design of this part of the system. In case the system is required to be cumpletely independent (standalone system), an inverter-dc 
source combination must be used to excite the field. The dc power might come from an exciter alternator-rectifier unit mounted on the same shaft as the main generator. The volt-ampere capacity required of the excitation source can be greatly decreased by partial tuning of the field circuit by properly choosing the capacitor $C_{4}$. In series with inductance $L_{5}$, a back-to-back diode combination is used to obtain the triggering signals. The rotor input current lags the rotor applied voltage by nearly $\pi / 2$. The current through $L_{5}$ and the diodes also lags the input voltage by nearly $\pi / 2$. Thus the current through the back-to-back diode combination is nearly in phase with the rotor input current. The voltage picked up across this diode combination is a square wave with zero crossings coincident with the zeros of the rotor winding current. This square wave is fed to a high-frequency transformer with six secondaries. The output of each secondary is used to trigger one of the six controlled rectifiers.

The system takes the modulated output of a three-phase machine (on one core stack) and converts it into a single-phase output at the modulation frequency. Therefore, generation of (two) three-phase power requires (two) three separate core stacks (magnetic circuits) on a single shaft, each modulated separately with the proper phase differences between the corresponding singlephase outputs. The electronics associated with each of the phases is identical to the single-phase system discussed earlier. The excitation source will itself have to be a (two) three-phase power supply or a dc to (two) three-phase Inverter (for standalune systems). It should be noted at this point that a single-phase load on a polyphase FMGS becomes a three-phase load on one of the core stacks. 


\section{EXPERIMENTAL PROTOTYPES}

The first experimental prototype designed and built was rated at $10 \mathrm{~kW}$, $220 \mathrm{~V}$, single-phase, $60 \mathrm{~Hz}$. It had sixteen poles and at a speed of $7000 \mathrm{r} / \mathrm{min}$, the basic machine frequency was around $930 \mathrm{~Hz}$. The rotor diameter was 6 inches and the active iron length was 2.5 inches. Overall dimensions of the alternator were 9.75 inches diameter and 7.75 inches axial length. A photograph of the complete system is shown in Figure 2-3. With properly chosen stator tuning capacitors, the overall efficiency (ratio of $60 \mathrm{~Hz}$ output to mechanical input, accounting for excitation losses) of the system was constant at about $82 \%$ from $110 \%$ of rated output down to $40 \%$ of rated output. For the purpose of comparison, it should be noted that, in the case of an AC-DC-AC system, if the alternator has an efficiency of $90 \%$ and if the rectifier-inverter system also has an efficiency of $90 \%$, then the overall efficiency is only $81 \%$. Other details and experimentally obtained performance characteristics of this prototype are documented in a paper attached as Appendix A.

The next single-phase prototype $(20 \mathrm{~kW}, 120 \mathrm{~V}, 6000 \mathrm{r} / \mathrm{min})$ was designed for eventual use as one of the three core-stacks in a three-phase $60 \mathrm{~kW}$ system $[7,8]$. The United States Air Force (Aeronautical Systems Division, WrightPatterson Air Force Base), sponsors of this phase of the FMGS work, was interested in supplying electric power at two different frequencies - $400 \mathrm{~Hz}$ and $60 \mathrm{~Hz}$ - from one machine (with an electronic subsystem as needed) for their Bare-Base concept. This restriction automatically fixed the basic machine frequency at $400 \mathrm{~Hz}$ and the rotational speed at $6000 \mathrm{r} / \mathrm{min}$. In addition, both the $60 \mathrm{~Hz}$ and the $400 \mathrm{~Hz}$ sinusoidal outputs were to be delivered at threephase star 120/208 Volts. All these specifications severely limited the design of the machine and the associated electronics. The ratio of the basic machine frequency to the modulation frequency was only $400 / 60=6.66$, lower than the 


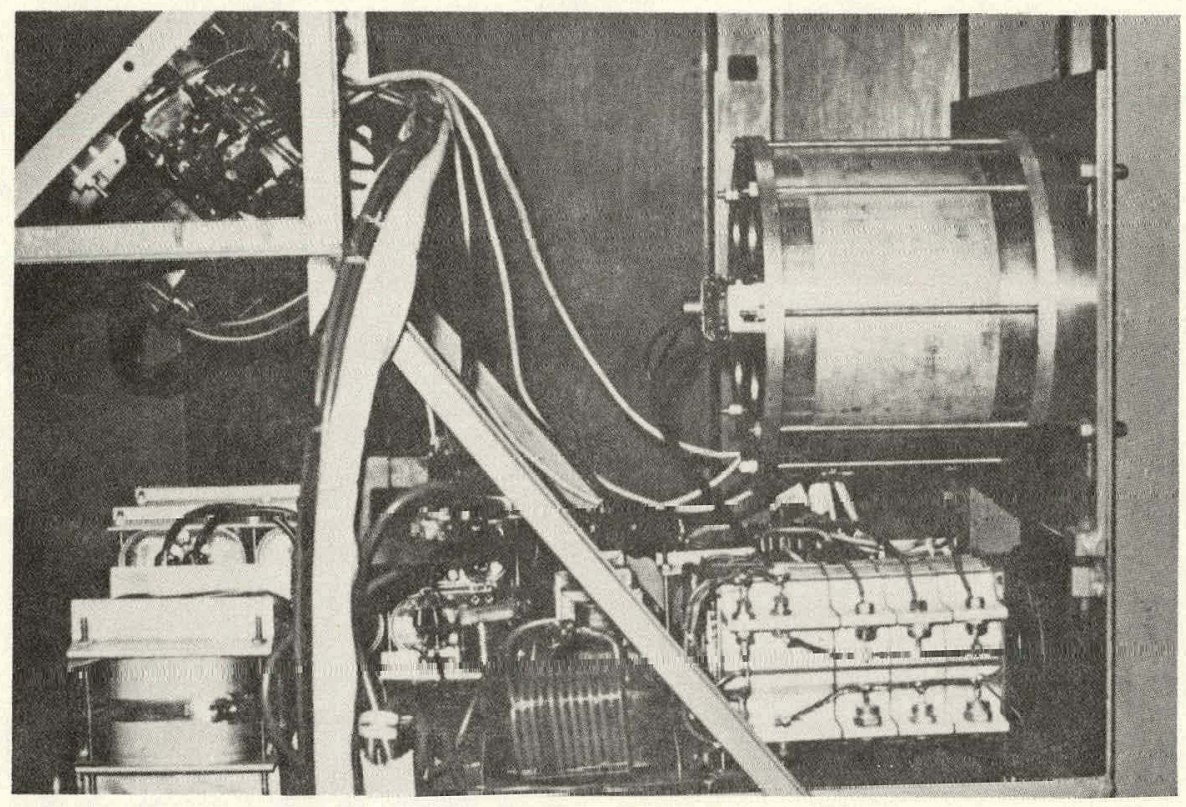

Figure 2-3. Photograph of the $10 \mathrm{~kW}$ Experimental Prototype. 
desired value of 10 (or higher). The net result of all these design. specifications was an electronics subsystem that was bulkier than expected. The final version of the prototype incorporated several interesting features such as self-excitation and self-regulation. The system was tested and found satisfactory both under steady-state and transient (sudden application of full load, motor starting, three-phase fault, etc.) operating conditions. Appendix $B$ contains a paper describing this system and the performance of the prototype in detail. The overall efficiency of this three-phase system-ratio of $60 \mathrm{~Hz}$ output to the mechanical input, accounting for excitation losses - was estimated to be slightly over 90 percent.

The latest FMGS prototype was designed and fabricated using the laminations developed for the Air Force project. The machine was designed for variable speed operation in the nominal speed range of 3000 to $6000 \mathrm{r} / \mathrm{min}$, with the rated output varying from 10 to $20 \mathrm{~kW}$, single-phase, $60 \mathrm{~Hz}, 120 \mathrm{~V}$. The effort was a part of an ERDA/NSF (now DOE) sponsored project entitled "Development and Adaptation of Field Modulated Generator Systems for Wind Energy Applications." Further details can be found in the final report [9] submitted at the end of this contract.

\section{STATUS OF FMGS THEORY}

Analysis and modeling of FMGS is complicated by the innerent rectification, inversion and filtering processes involved and the manner in which their effects are reflected back into the machine and affect its behavior. Presence of stator and rotor tuning capacitors further complicates the problem by providing closed paths for harmonic currents to circulate. Factors such as the accuracy of timing of thyristor triggering signals, power factor of the load, design of the magnetic circuit, range of rotor speed variations and nonlinearities introduced by circuit elements, all influence the overall performance of the system. 
The first step in the analysis of any complicated system is to develop an idealized model under certain simplifying assumptions. These assumptions can then, be relaxed one by one or in groups in later investigations to study the ensuing modifications and improvements in the model. An idealized model should, however, lead to a basic understanding of the interaction of the various parameters in the operation of the system.

The task of modeling FMGS is approached by dividing the system into several subsystems for separate studies. The results of all these analyses are then combined to obtain the model sought for. Following this procedure, an idealized model has been developed for the FMGS. In the following paragraphs, brief descriptions of the procedures used to study the subsystems and the manner in which the model was synthesized are given.

\section{(i) Parallel-Bridge Rectifier System Studies}

The nucleus of the field modulated generator system is a high-frequency alternator feeding into a parallel-bridge rectifier system with bridge-input capacitors. Therefore, as the first step in the model development, this part or the system was studied thoroughly.

Both experimental and analytical techniques were employed in developing understanding of the operation of PBRS with bridge-input capacitors. Following the work of Ramakumar et a1. [10], circuit differential equations were set up for various voltages and currents in the idealized model of this subsystem. These equations were solved using proper initial values and boundary conditions. In this process, two angles, $\gamma$ and $\beta$, related to the "on" and "off" conditions of various diodes, were found to play a key role. Values of these angles were numerically evaluated by solving a set of non-linear algebraic equations obtained by the application of proper boundary conditions. Theoretical values of $\gamma$ and $\beta$ 
were evaluated for different values of non-dimensional circuit parameters. Experimental verification of these theoretical results provided good correlation and confidence in the theory developed [11-13].

Incorporating solid-state power conditioning devices at the outputs of conventional rotating machines distorts the waveforms and introduces harmonics in various parts of the system. Harmonic analysis of key waveforms would provide vital information leading to proper approximations in the development of the model. For the PBRS with bridge-input capacitors, this task has been completed and the results (phase angles and normalized magnitudes of different harmonic components) are documented (see Reference 9) in graphical form for a range of values of non-dimensional circuit parameters.

\section{(ii) Synthesis of Idealized Model of FMGS}

By synthesizing parallel-bridge rectifier analysis and rotating machine analysis, an idealized model has been developed for the FMGS [14]. The model is built on several simplifying assumptions which include consideration of only fundamental components of currents and magnetomotive forces, ideal switching and filtering, infinitely permeable iron and the exclusion of transformer voltages in the stator windings in comparison with speed voltages.

With only fundamental components considered, phase relationships can be expressed in vector diagram form, both at the modulation frequency and at the basic machine frequency. Such vector diagrams have been developed and relationships between various voltages and currents have been established.

The idealized model discussed above has been verified experimentally. Fesults obtained from the model agreed with experimental observations within acceptable limits [15]. The first. step in the development of a mathematical model for the FMGS has been completed [16]. 


\section{E. OTHER SCHEMES EMPLOYING THE FIELD MODULATION PRINCIPLE}

The field modulated generator system discussed until now is only one of several possibilities $[17,18]$ proposed in the literature to generate constant frequency output power from a variable speed shaft by employing the field modulation principle.

Functional block diagram of an interesting alternative scheme proposed is shown in Figure 2-4. It requires two identical machines and an excitation source made up of a combination of dc and modulation-frequency ac. The field winding of one of the machines is excited with a current of the form (I+ I $\left.\cos \omega_{m} t\right)$. Then, the high-frequency outputs of the three phases of this alternator will exhibit the characteristics of an amplitude modulated carrier with a modulation index of unity (100\% modulation). The envelopes of all the three outputs will be in-phase and sinusoidal (with a frequency equal to the modulation frequency). When the outputs of the three phases are processed through a PBRS, the resulting voltage will be of the form $\left(E+E \cos \omega_{m} t\right)$ with a small amount of ripple (at six times the basic machine frequency) superimposed. In this, only the sinusoidal component is of interest and the do component should be eliminated in an efficient manner. This is the major problem with this scheme. One idea suggested in Reference 18 is to excite the field winding of the other (identical) machine with a current of the form (I - I $\cos \omega_{m} t$ ), processing the outputs of the three phases of this machine through a second PBRS to obtain a voltage of the form ( $E-E \cos \omega_{m} t$ ), with a small amount of ripple superimposed, and subtracting the second PBRS output from the first PBRS output as illustrated in Figure 2-4. The final output of the two-machine system is presumably equal to $\left(E+E \cos \omega_{m} t\right)-\left(E-E \cos \omega_{m} t\right)$ or $2 E \cos \omega_{m} t$, with a small amount of high-frequency ripple which can be smoothed out using a low-pass filter. But, unfortunately, the PBRS circuitry allows current flow 


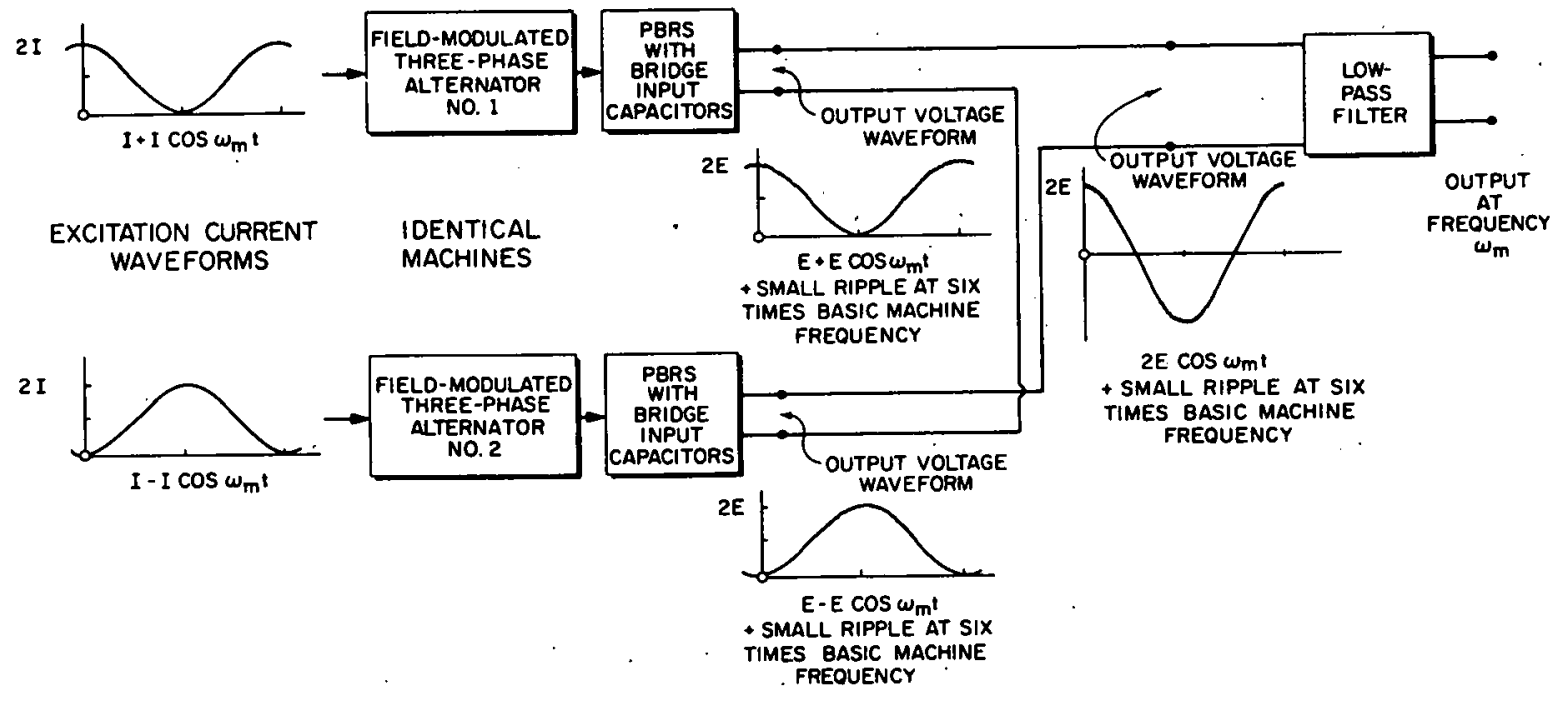

Figure 2-4. Functional Block Diagram of an Alternate Scheme With Field Modulation and no SCRs. 
only in one direction. An examination of Figure 2-4 shows that this characteristic alone will make this scheme unworkable. One may consider employing a transformer with two primaries and one secondary with the primaries supplied by the two PBRS outputs. Even this is not practical since the primary windings will, in effect, short-circuit the dc components and result in excessive current flows and losses in the machine. If a clever way is found to circumvent this problem, this alternate scheme will become attractive.

Exciting the two machines as discussed above is not a problem. A variable voltage dc power source and an adjustable ac source can be combined as shown in Figure 2-5 to supply the excitation currents. The two identical alternators required can be two core-stacks mounted on the same shaft and excited as shown in Figure 2-6. Each core-stack will have its own three-phase stator winding and PBRS with bridge-input capacitors.

This scheme is obviousiy not useful until the basic problem discussed above is solved.

Elimination of Slip Rings,

When the rotational speeds of machines approach and exceed the value of $20,000 \mathrm{r} / \mathrm{min}$, it is not realistic to employ wound rotors, connected to external circuits via slip rings and brushes. An approach to eliminate slip rings is shown in Figure 2-7. This type of magnetic circuit arrangement is commonly found in 'inductor' and 'homopolar' alternators. However, because of the need to modulate the field, the magnetic circuit becomes slightly more involved. The flux is set up by the stationary field coil and the fluxpaths are completed by axial flux flows through the laminations near the casing and near the shaft. The stator winding will be in two halves, one on each side of the exciting coil and they can be connected in series or in parallel as desired. Since a varying 


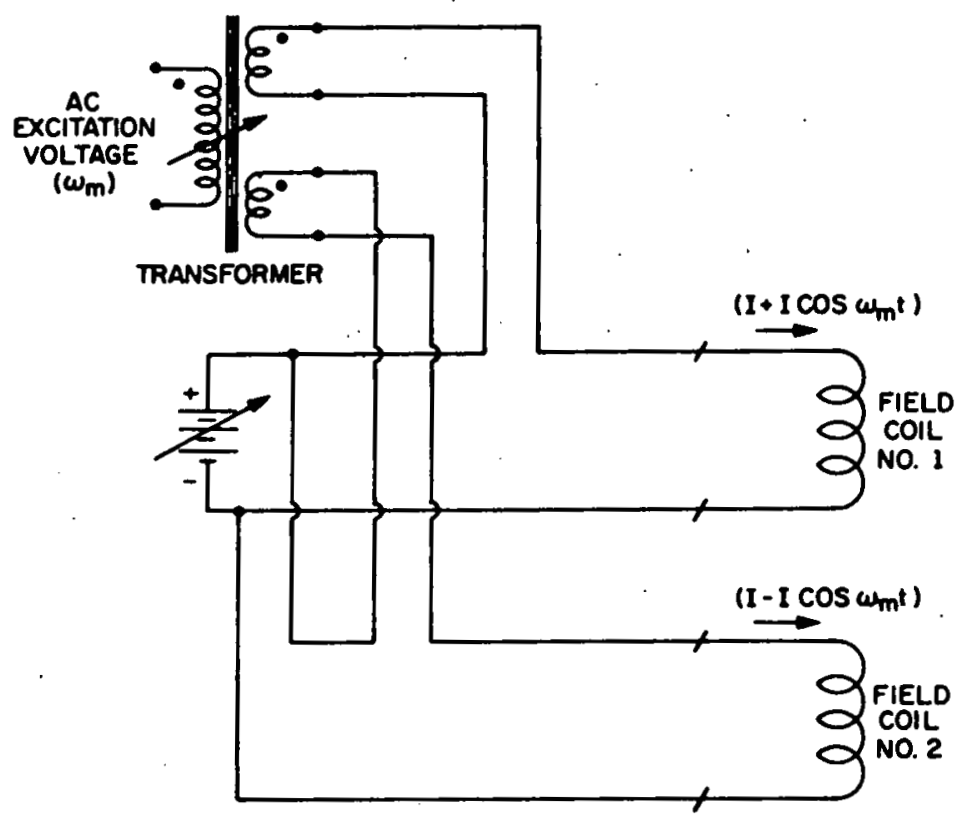

Figure 2-5. Excitation Circuit for the Scheme Shown in Figure 4.

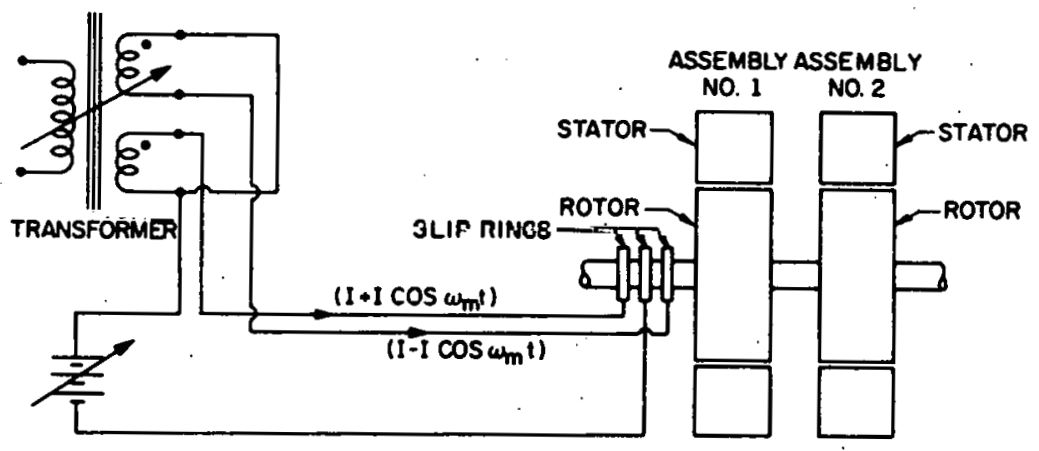

Figure 2-6. An Implementation of the Alternate Scheme Shown in Figure 4. 


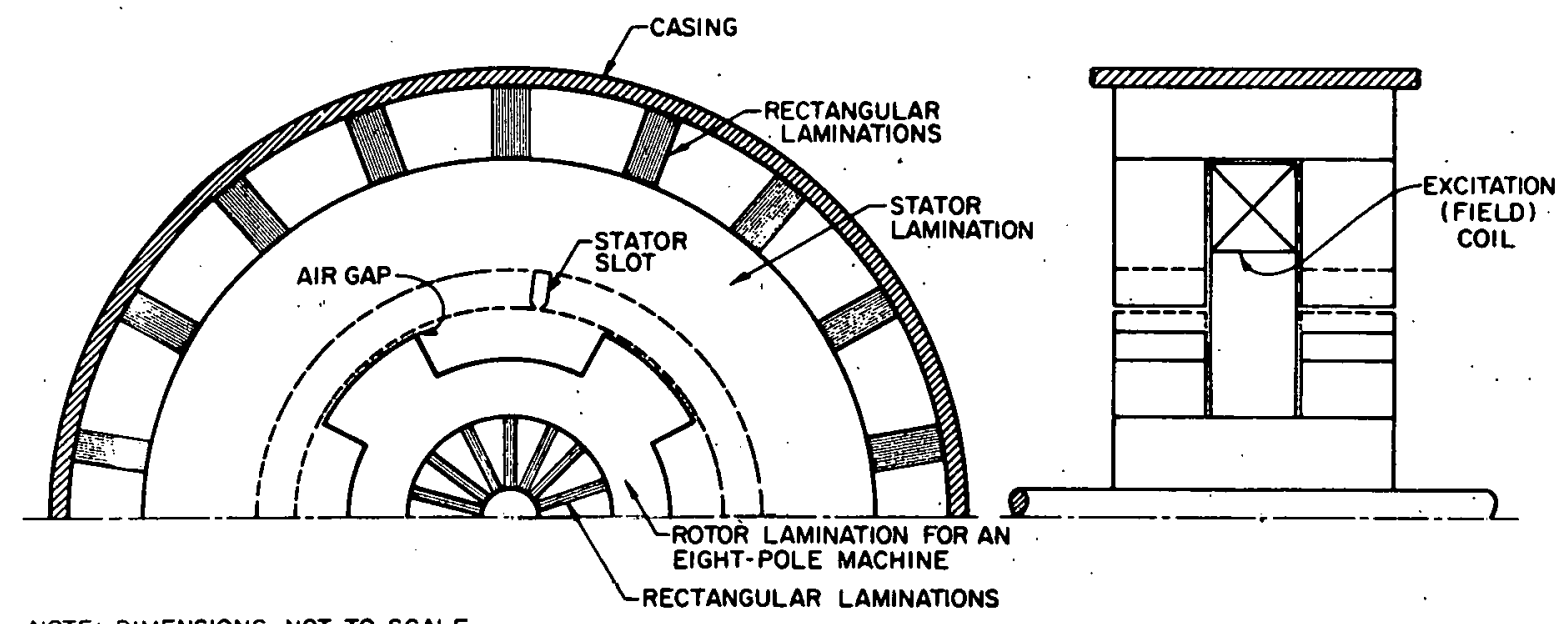

NOTE: DIMENSIONS NOT TO SCALE

Figure 2-7. Inductor-type Magnetic Circuit Structure for FMGS to El iminate Slip Rings.

air-gap is used instead of the conventional alternate north and south pole structure, magnetic circuit utilization is poor, resulting in larger machines for a given speed and output power.

\section{F. APPLICATIONS}

Field modulated genarator systems are variable-specd adjustatie-frequency (VSAF) power sources. There are many important practical applications for such systems. They can serve as variable-voltage variable-frequency power supplies for electric drives and in ground transportation, deriving their mechanical input from an unregulated shaft $[19,20]$. Operated as variable-speed constantfrequency (VSCF) systems, they can be used with non-synchronous prime-movers such as aeroturbines [21-24] and in aircraft power generation [25,26]. In addition, VSCF generation systems are ideally suited as interfaces between flywheel energy storage systems and conventional utility grids [27]. Recentiy, FMGS is being considered as an alternative power generation scheme for application in the DOE/NASA-LERC/JPL's point-focused distributed receiver advanced solar-thermal-electric power systems program. 


\section{G. REFERENCES}

1. B. M. Benton and R. P. Judkins, "Frequency Control Device for Generators," U.S. Patent No. 2,896,150, dated July 21, 1959.

2. L. J. Johnson, "Apparatus for Producing Alternating Current," U.S. Patent No. 3,001,124, dated September 19, 1961.

3. A. K. Wickson; "A Simple Variable Speed Independent Frequency Generator," AIEE Conference Paper No. CP 59-915, presented at the Summer and Pacific General Meeting and Air Transportation Conference, Seattle, Washington, June 1959.

4. T. Bernstein and N. L. Schmitz, "Variable Speed Constant Frequency Generator Circuit Using a Controlled Rectifier Power Demodulator," AIEE Conference Paper No. CP 60-1053, presented at the Pacific General Meeting, San Diego, California, August 1960.

5. R. Ramakumar, H. J. Allison and W. L. Hughes, "Description and Performance of a Field Modulated Frequency Down Converter," 1972 SWIEEECO Record, IEEE Catalog No. 72 CHO 595-9 SWIECO, Dallas, Texas, pp. 252256, Apri1 1972.

6. H. J. Allison, R. Ramakumar and W. L. Hughes, "A Field Modulated Frequency Down Conversion Power System," IEEE Conference Record of 1972 Seventh Annual Meeting of the IEEE Industry Applications Society, IEEE Catalog No. 72 CHO 685-8-IA. Philadelphia, Pennsylvanía, pp. 769-774, October 1972; IEEE Tránsactions on Industry Applications, Vol. IA-9, No. 2, pp. 220-226, March/April 1973.

7. R. Ramakumar and H. J. Allison, "Design-Fabrication and Layout of a $60 \mathrm{~kW}$ Three-Phase Field Modulated Generator System," Proceedings of the Frontiers of Power Technology Conference, OKlahoma State University, Stillwater, OkTahoma, pp. 16-1 to 16-9, October 1972.

8. R. Ramakumar, H. J. Allison and W. L. Hughes, "A Self-Excited FieldModulated Three-Phase Power System," IEEE Summer Power Meeting and Energy Resources Conference, Paper No. C 74 318-2, Anaheim, California, JuTy 1974.

9. R. Ramakumar et al., Final Report, "Development and Adaptation of Field Modulated Generator Systems for Wind Energy Applications." Submitted to the Energy Research and Development Administration and the National Science Foundation, Washington, D.C., Contract No. ERDA/NSF-AER . 7500647, September 1976. NTIS Accession No. PB 272495/AS.

10. R. Ramakumar, H. J. Allison and W. L. Hughes, "Analys is of the Parallel Bridge Rectifier System," IEEE Transactions on Industry Applications, Vol. IA-9, No. 4, pp. 425-436, JuTy/August 1973. 
11. R. Ramakumar, H. J. Allison and W. L. Hughes, "Operation of Alternators with Parallel-Bridge Rectifier Systems," IEEE Transactions on Power Apparatus and Systems, Vol. PAS-92, No, 5, pp. 1679-1687, September/ October 1973.

12. Chi-Cheng Tsung and R. Ramakumar, "Operation of Parallel-Bridge Rectifier Systems with Capacitors at Bridge-Inputs," '1974 Midwest Power Symposium Conference Record, University of Missouri-RolTa, Rolla, Missouri, October 1974.

13. C. C. Tsung and R. Ramakumar, "A Study of the Parallel-Bridge Rectifier System with Bridge-Input Capacitors," Record of the 10th IAS Annual Meeting, IEEE Catalog No. 75 CHO 999-3 TA, AtTanta, Georgía, pp. 10121019, October 1975.

14. R. Ramakumar and C, C. Tsung, "An Approach to Model Field Modulated Generator Systems," 1975 Midwest Power Symposium Conference Record, Akron, Ohio, October 7975 .

15. C. C. Tsung and R. Ramakumar, "Idealized Model of Field Modulated Generator Systems: An Experimental Study," 1976 Midwest Power Symposium Conference Record, Manhattan, Kansas, October 1976.

16. Chi-Cheng Tsung, "A Study of the Field Modulated Generator System," Ph.D. Thesis, Oklahoma State University, Stillwater, Oklahoma, December 1976.

17. W. L. Hughes, H. J. Allison and R. Ramakumar, "Apparalu's for Providing Ai Electrtcal tnergy at a Preselected Frequency, "U.S. Patent, No. $3,663,945$, May 16, 1972 .

18. W. L. Hughes, H. J. Allison and R. Ramakumar, "Field Modulated Alternator System and Control Therefor," "U.S. Patent, No. 3,727,122, April 10. 1973.

19. W. L. Hughes, H. J. Allison and, R. Ramakumar, "A Variable Frequency Power Source for Ground Transportation," Proceedings of the Seventh Intersociety Energy Conversion Engineering Conference, San Diego,. California, pp. 996-1002, September 1972.

20. R. Ramakumar, H. J. Allison and W. L. Hughes, "Variable Speed Drive Applications of Field Modulated Frequency Down Converters," 1973 SWIEEECO Record, IEEE Catalog No. 73 CHO 719-5-SWIECO, Houston, Texas, pp. 162-165, Apri1 1973.

21. R. Ramakumar, "Development and Adaptation of Field Modulated Generator Systems for Wind Energy Applications," Proceeding of the Second Wind Energy Conversion Systems Workshop, sponsored by ERDA and NSF, Washington, D.C., pp. 279-289, June 1975. 
22. R. Ramakumar, "Harnessing Wind Power in Developing Countries," Proceed-. ings of the Tenth Intersociety Energy Conversion Engineering Conference, IEEE Catalog No. 75 CHO 983-7 TAB, Newark, Delaware, pp. 966-973, August 1975 .

23. R. Ramakumar, "Wind Electric Conversion Utilizing Field Modulated Generator Systems," Sharing the Sun 76-Solar Technology in the Seventies Conference, sponsored by the American Section of the ISES and the Solar Energy Society of Canada, Winnipeg, Manitoba, Canada, Vol. 7, pp. 215229, August 1976. Solar Energy, Vol: 20, No. 2, pp. 109-117, 1978.

24. R. Ramakumar, "Wind Driven Field Modulated Generator Systems," Proc. of the Eleventh Intersociety Energy Conversion Engineering Conference, State Line, Nevada, pp. 1766-1772, September 1976.

25. T. B. Owen, "Variable-Speed Constant-Frequency Devices: A Survey of the Methods in Use and Proposed." AIEE Transactions (Part II. Applications and Industry); Vol. 78, pp. 321-326, November 1959.

26. K. M. Chirgwin and L. J. Stratton, "Variable-Speed Constant-Frequency Generator System for Aircraft." AIEE Transactions (Part II. Applications and Industry), Vo1. 78, pp. 304-310, November 1959.

27. R. A. Fernandes, "Optimum Peak Sharing Mix for Electric Utilities." IEEE Conference Paper No. C 75-143-3, Energy Development II, IEEE Cata$\log$ No. $76 \mathrm{CH} 1102-3-\mathrm{PWR}, \mathrm{pp} .83-91$, 1975. 


\section{SECTION III}

\section{APPLICATION OF FMGS TO DISPERSED SOLAR \\ THERMAL ELECTRIC GENERATION}

\section{A. GENERAL}

The nature of the basic FMGS scheme suggests the use of a single-phase unit with cach dish. The uulputs nf an array of dishes can be paralleled (at the PBRS output terminals) and processed through a common inverter. To obtain a three-phase electrical output from a dish-collector field, the units should be divided into three equal groups, with each group modulated in such a way as to contribute to one of the three three-phase outputs. It is logical to scatter the units belonging to a group throughout the collection rield so that any effect due to cloud cover and other statistical variations can be smoothed out. Figure 3-1 shows a schematic of the parabolic dish-electric transport with FMGS. External energy storage and reconversion, if necessary, can be added as illustrated in Figure 3-1.

The excitation voltages, $V_{\text {exA }}, V_{\text {exB }}$ and $V_{\text {exC }}$, should lead the corresponding output phase-voltages $V_{A}, V_{B}$ and $V_{C}$ by 90 electrical degrees as shown in Figure 3-2. Such a phase relationship is required because of the inductive nature of the field winding and the resulting quadrature phase relationship between the excitation voltage and the rotor winding current, with the current lagging the voltage. To recapitulate, in an FMGS, the output voltage and the rotor winding current are in-phase. 


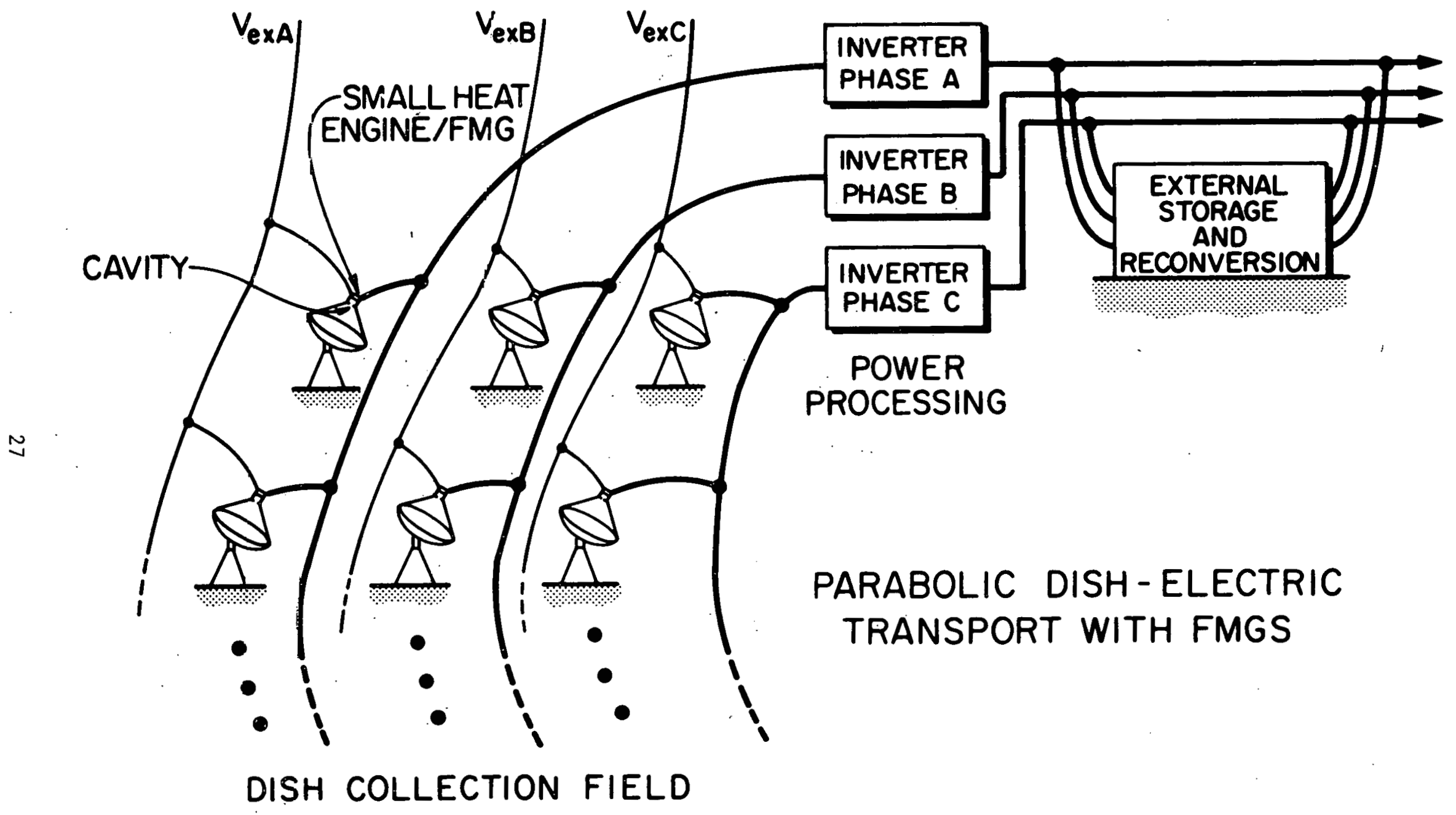

Figure 3-1. Schematic of Dish-Electric Transport with FMGS. 


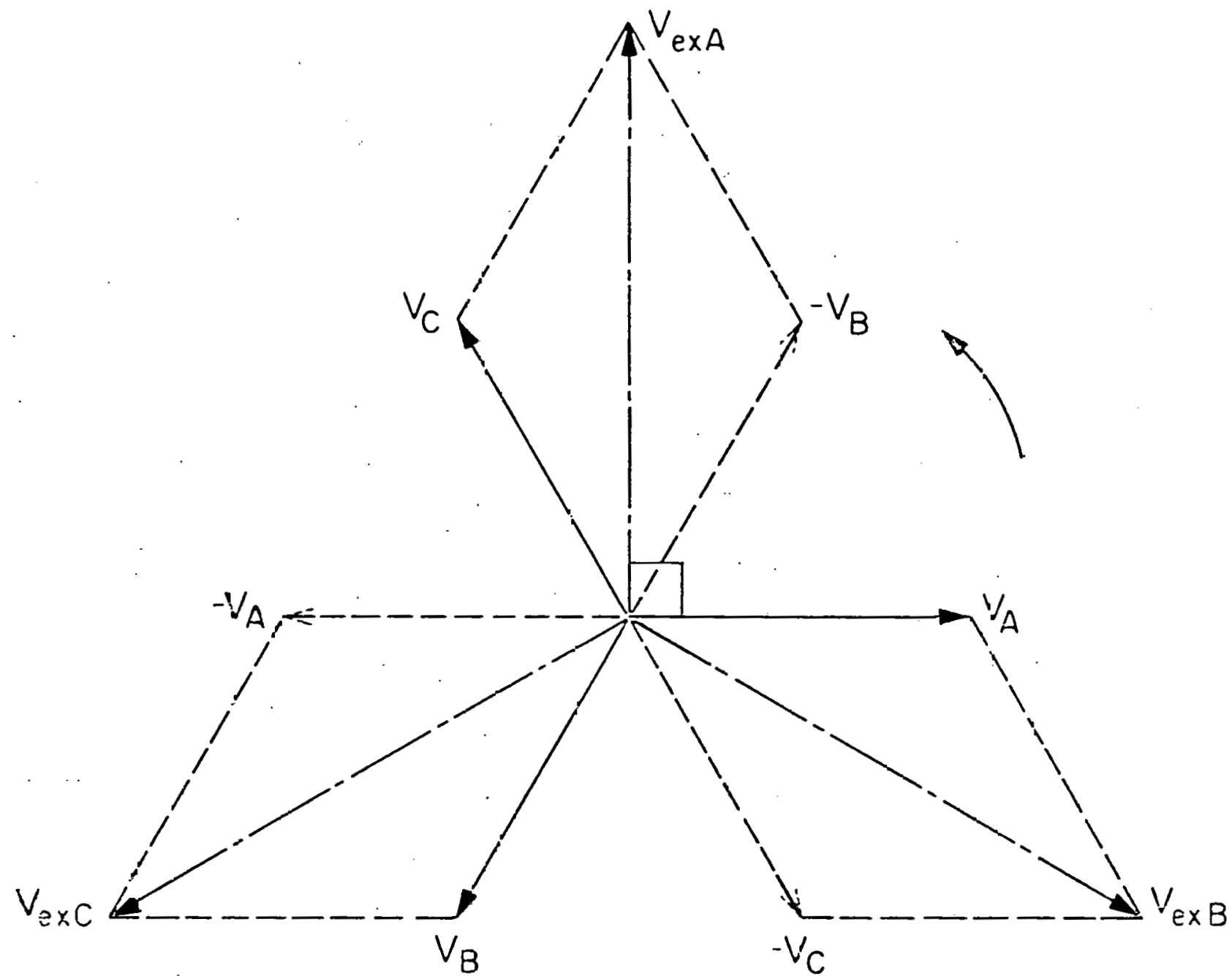

Figure 3-2. Phasor Relationship Between Excitation and Output Voltages. 


\section{B. LOW SPEED OPERATION (1800 to $6000 \mathrm{r} / \mathrm{min}$ )}

To achieve the best results with FMGS, it is necessary for the basic machine frequency to be at least ten times the required output frequency. For a $60 \mathrm{~Hz}$ output, this translates into a basic machine frequency of $600 \mathrm{~Hz}$ or higher. At the low end of the speed range under consideration, a winding arrangement for 40 poles (or 20 pole-pairs) will have to be housed in the stator and rotor. This is impractical in a compact machine and, if attempted, will lead to a heavier than normal machine. At the high end of this speed range, a twelve-pole machine will be sufficient. This is well within the range of possibilities and FMGS is beginning to be attractive for solar thermal electric conversion.

It appears that there is no special advantage in employing FMGS for constant frequency power generation when the engine operating speeds are "low" i.e., in the 1800 to $6000 \mathrm{r} / \mathrm{min}$ range. The heat engines operating in this speed range are based on the Rankine Cycle or the Stirling Cycle. Therefore, Dish-Stirling and Dish-Rankine system concepts do not appear to reap any benefits from integration with FMGS.

\section{MEOIUM SPEED OPERATION (6000 to $18,000 \mathrm{r} / \mathrm{min}$ )}

This speed range is realized with small Brayton cycle engines. If direct coupling of the generator is preferred (to eliminate the need for a gear box), conventional alternators become unsuitable to provide a $60 \mathrm{~Hz}$ output. Some type of special ac generator is required for frequency down conversion to $60 \mathrm{~Hz}$. Under these circumstances, application of FMGS shows considerable promise.

Block diagram of a solar generation unit for the AC-Link approach employing FMGS is shown in Figure 3-3. It consists of a dish collector, receiver (with 


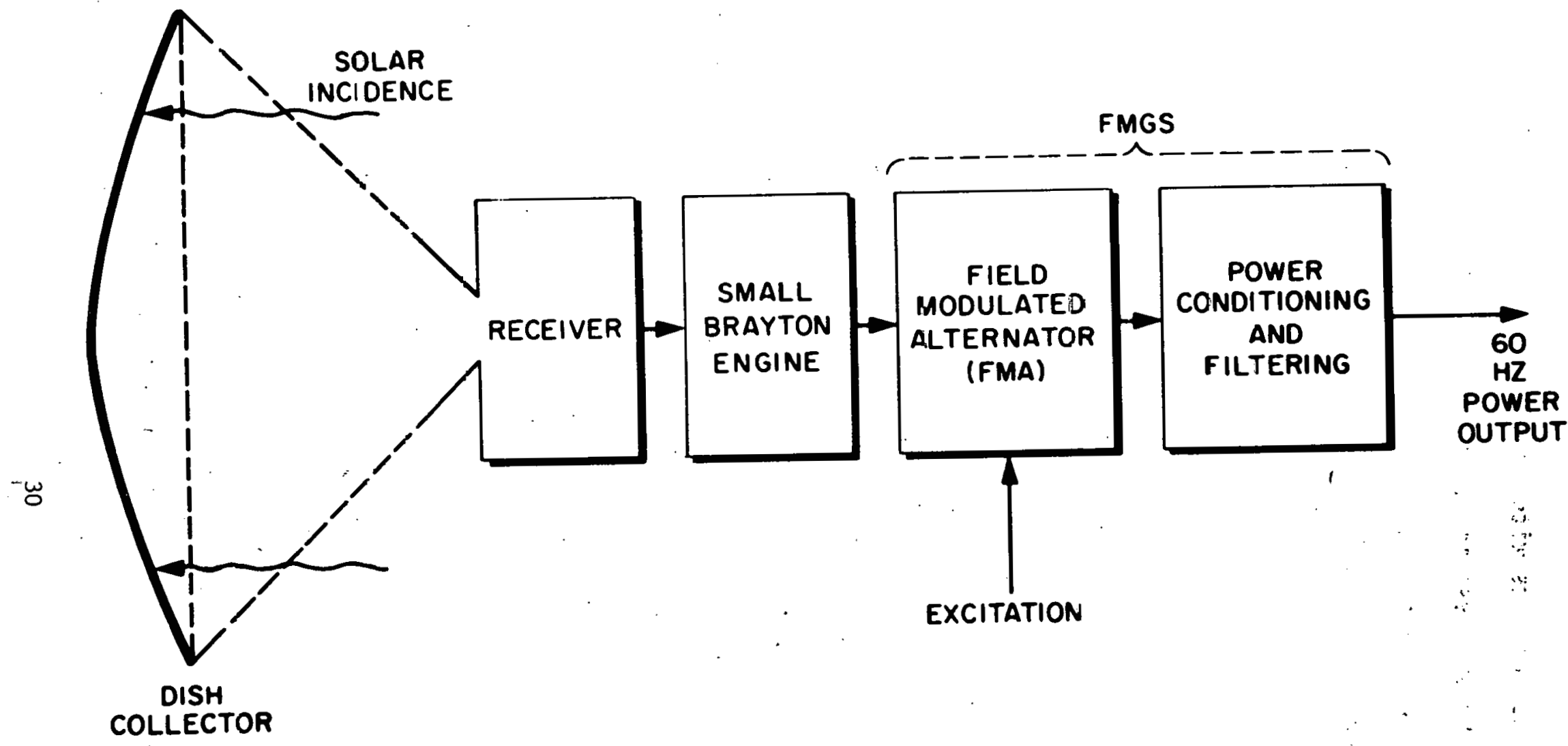

Figure 3-3. Block Diagram of a Solar Generation Unit Employing FMGS. 
thermal storage system, if necessary), small Brayton Cycle engine and an FMGS consisting of a field modulated alternator (FMA) and output power conditioning and filtering circuits. For the FMA, excitation should be provided externally as shown. Typical efficiency values for the various components are given in Figure 3-4. For the Brayton Cycle engine, the assumed efficiency value of $40 \%$ corresponds to nominal performance with a peak cycle temperature of approximately $2000^{\circ} \mathrm{F} . *$ The efficiency figure of $82 \%$ assumed for the FMGS has al ready been achieved with experimental prototypes at Oklahoma State University. It is expected that, with additional study and design optimization, this efficiency may increase by 3 to $5 \%$. However, a conservative value of $82 \%$ is used in this study. The receiver and collector efficiencies correspond to the figures normally assumed in the conceptual design calculations of such systems.

Thermal, mechanical and electrical powers at various points for the unit are shown in Figure 3-5. Based on these, a parabolic dish of diameter $9.74 \mathrm{~m}$ is indicated for a $15 \mathrm{kWe}$ output. The average solar insolation value of $0.845 \mathrm{kWt} / \mathrm{m}^{2}$ corresponds to the conditions at Lancaster, $\mathrm{CA}$, with no cloud cover. With a collector-receiver efficiency of $72 \%$, the overa 11 efficiency works out to be $23.77 \%$.

As discussed earlier, it is advisable (to minimize the complexity and the cost per kWe) to process the outputs of several solar generation units using a common inverter for each of the three phases. Figure 3-6 illustrates a schematic of this approach. Paralleling of the units is done at the output terminals of the parallel-bridge rectifier systems. In the schematic, the block marked FMA represents the field modulated alternator and a parallel-bridge rectifier system. With this arrangement, only two leads will come out of each FMA block and the paralleling bus will need to have only two conductors. In this arrangement, with $N$ solar generation units feeding their power

*Refer to Figure 5-5, page 5-14 in JPL Report No. 5102-67; Semi-Annua1 Progress Report prepared for the US DOE; June 1978. 


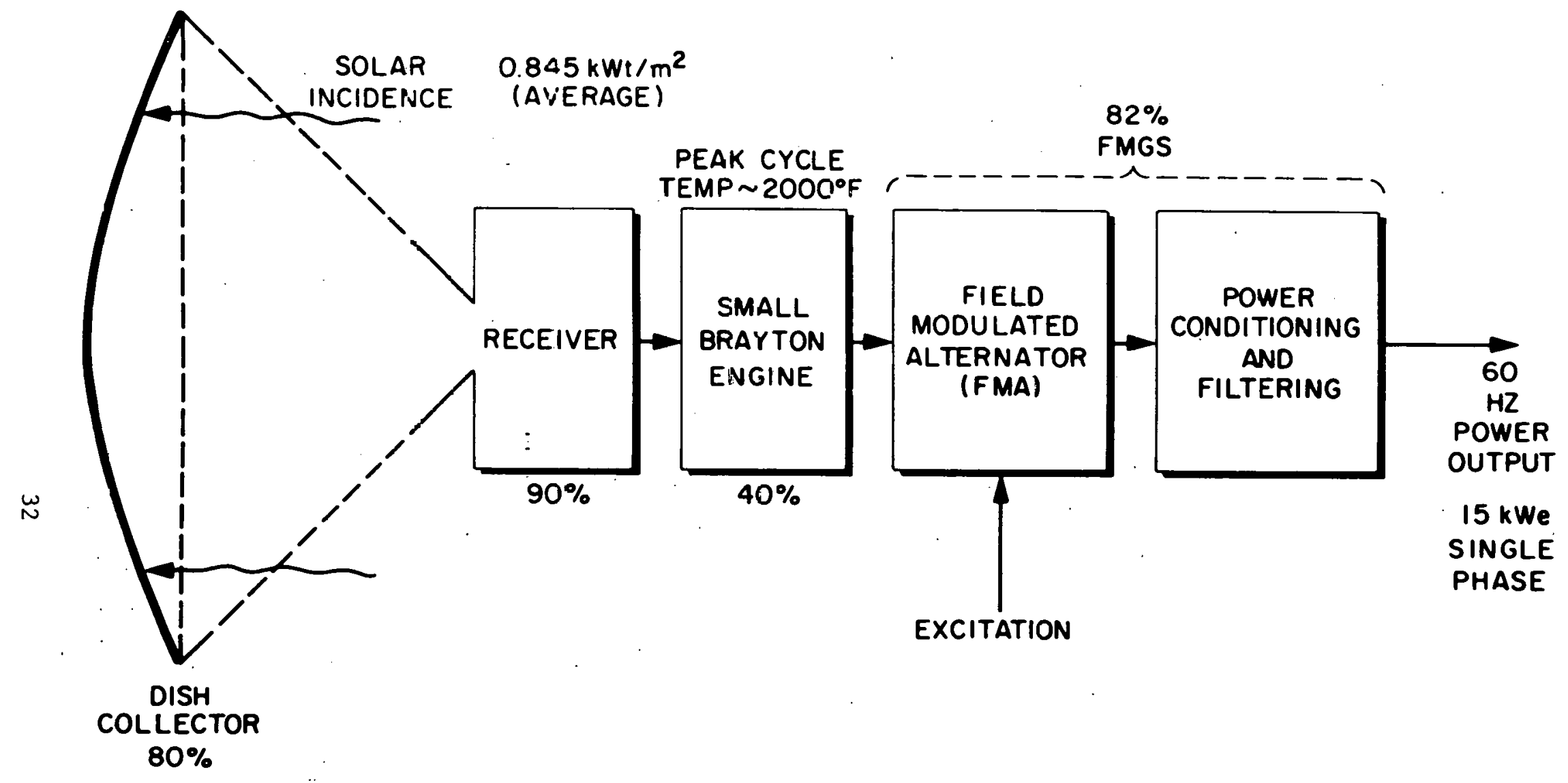

Figure 3-4. Typical Ef Eiciencies of the Compcnents of Dish-Electric Transport with FMGS. 


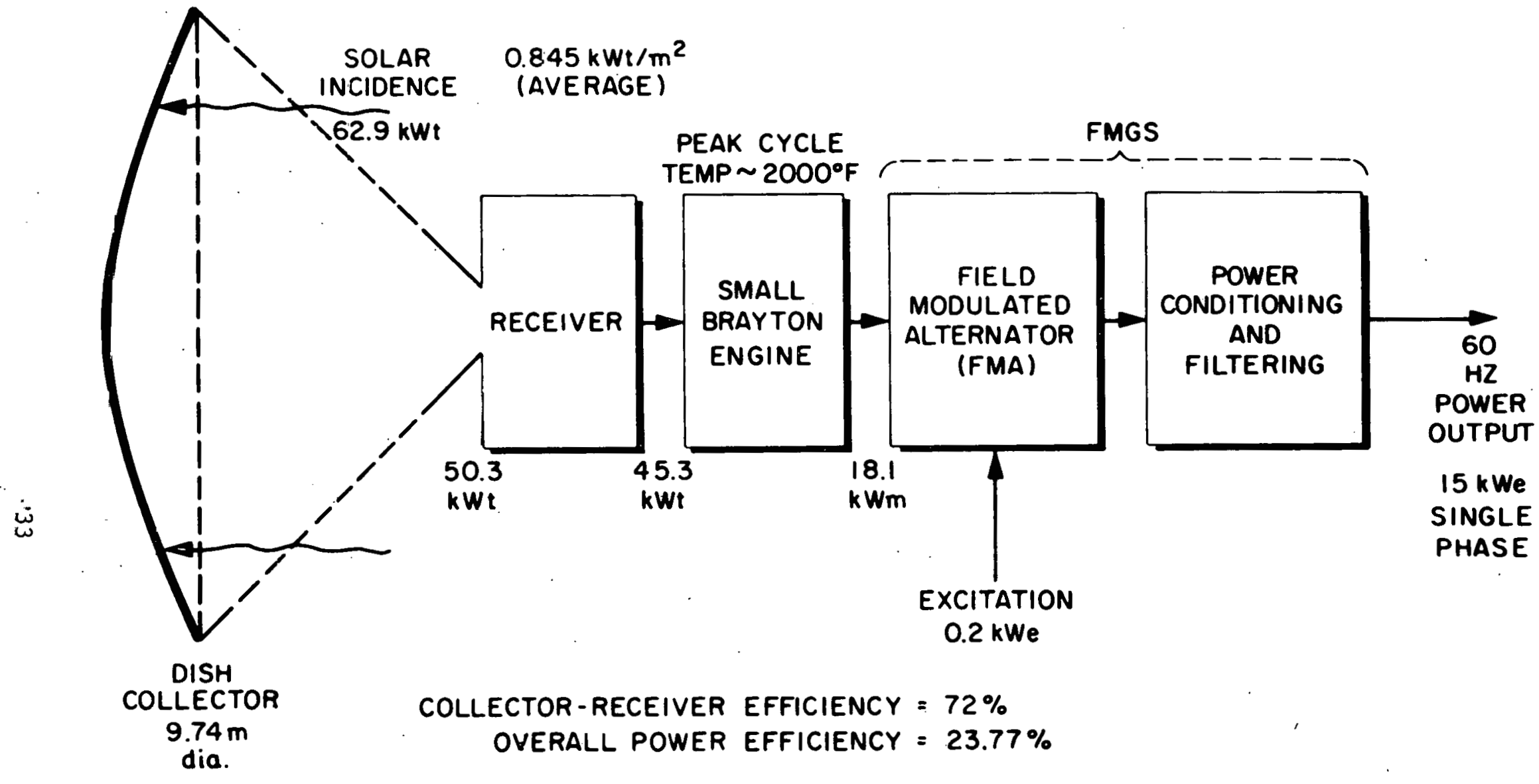

Figure 3-5. Power Flows for a Solar Generation Unit Employing FMGS. 

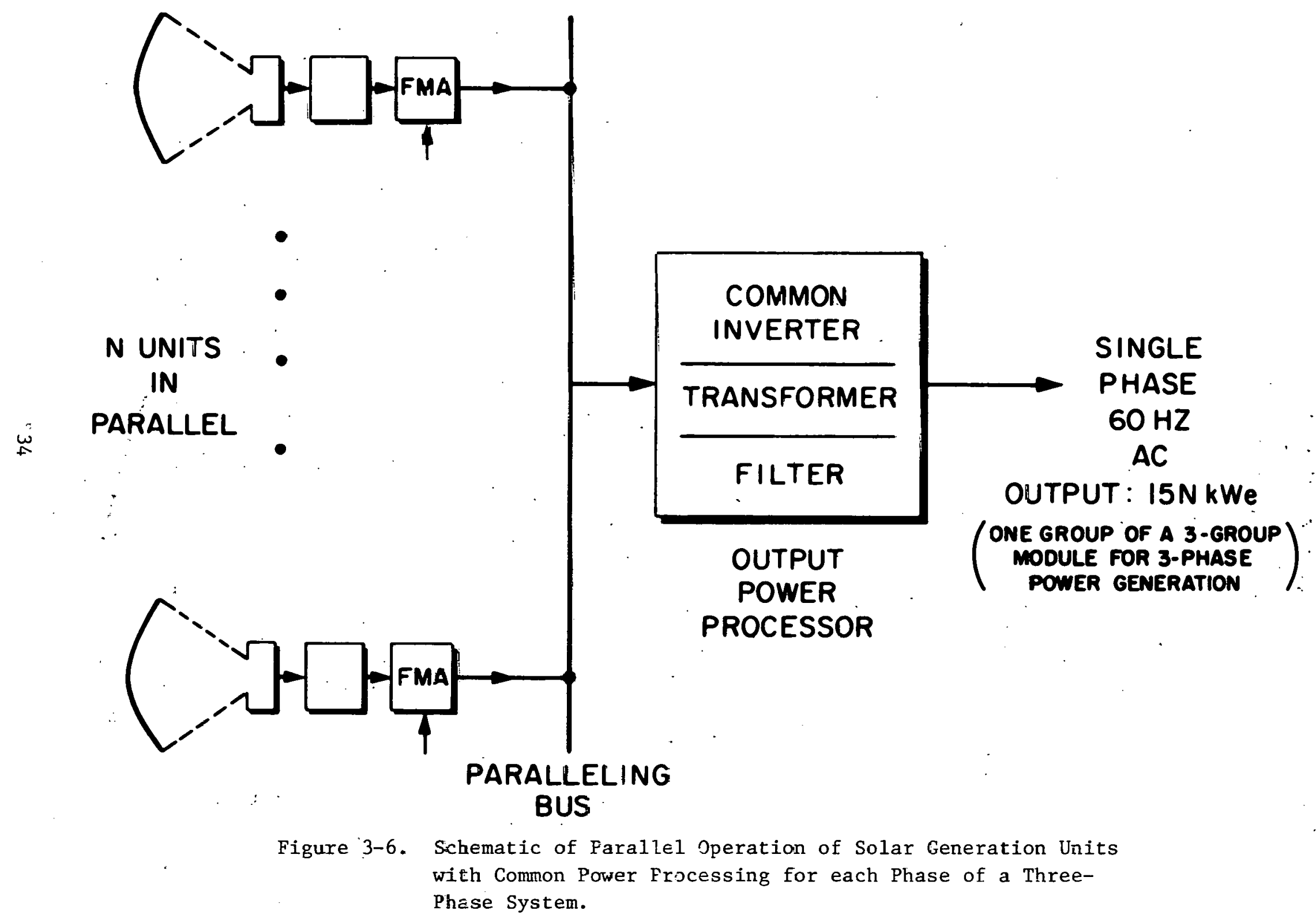
into a common inverter, its rating should be $15 \mathrm{~N}$ kWe. The economics of solidstate power converters is such that the cost of one $15 \mathrm{~N}$ kWe unit is less than the cost of $N$ units of $15 \mathrm{kWe}$ rating each. In addition, the overall efficiency will improve with the common inverter approach.

Assuming an efficiency value of $87 \%$ for the combination of the FMAs and the common inverter, the powers at various points are shown in Figure 3-7. Once again, this is a very conservative efficiency figure and increases of up to $6 \%$ may be expected in the final designs. Because of a slight improvement in the overall efficiency, the diameter of the dish required is calculated to be $9.47 \mathrm{~m}$ as compared to the value of $9.74 \mathrm{~m}$ obtained earlier with individual FMGS for each solar generation unit. With a collector-receiver efficiency of $72 \%$, the overall efficiency for this system is $25.13 \%$.

Figure 3-8 shows a conceptual block diagram of a 10 MWe plant employing dish-electric transport with FMGS. It consists of three identical modules, each providing one-third of the total three-phase output. Paralleling of the modules as shown will contribute towards improving the overall system reliability. Each module has three groups of solar generation units, one for each of the three phases of the three-phase system. Each group has 75 units operating in parallel and feeding into a common inverter and power processor of $1.125 \mathrm{MW}$ capacity. The net rating of the plant is $10 \mathrm{MW}$; the difference from $3 \times 3.375=10.125 \mathrm{MW}$ is very nearly equal to the total excitation power required for the 675 iield modulated alternators constituting this 10 MWe plant.

For a $600 \mathrm{~Hz}$ basic machine frequency, the minimum number of poles required in the FMA ranges from 12 down to 4 for this speed range. Although slip-rings can be used to carry the excitation current to the rotor winding, it may be better (especially towards the top end of this speed range) to avoid them as discussed in the next section. 


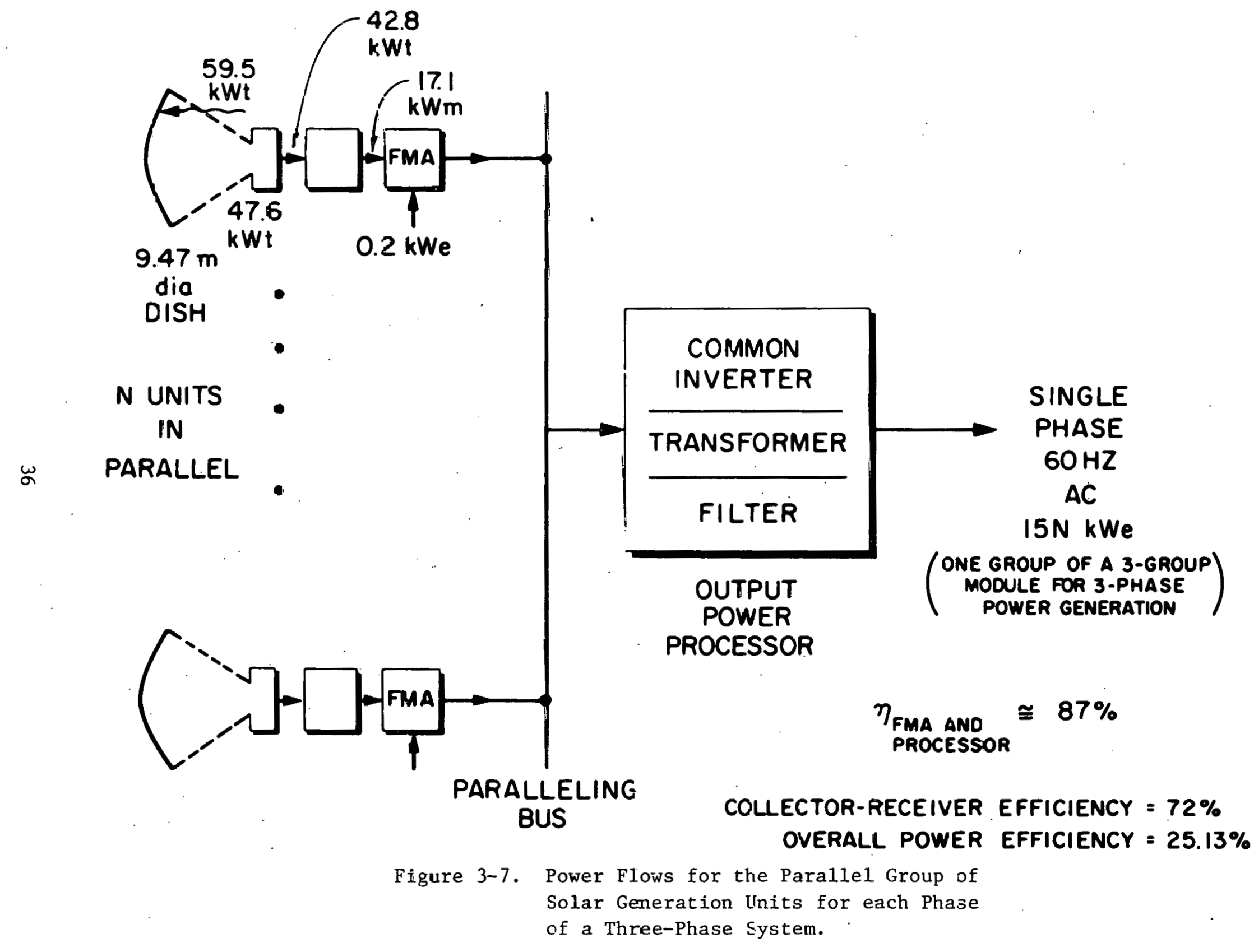




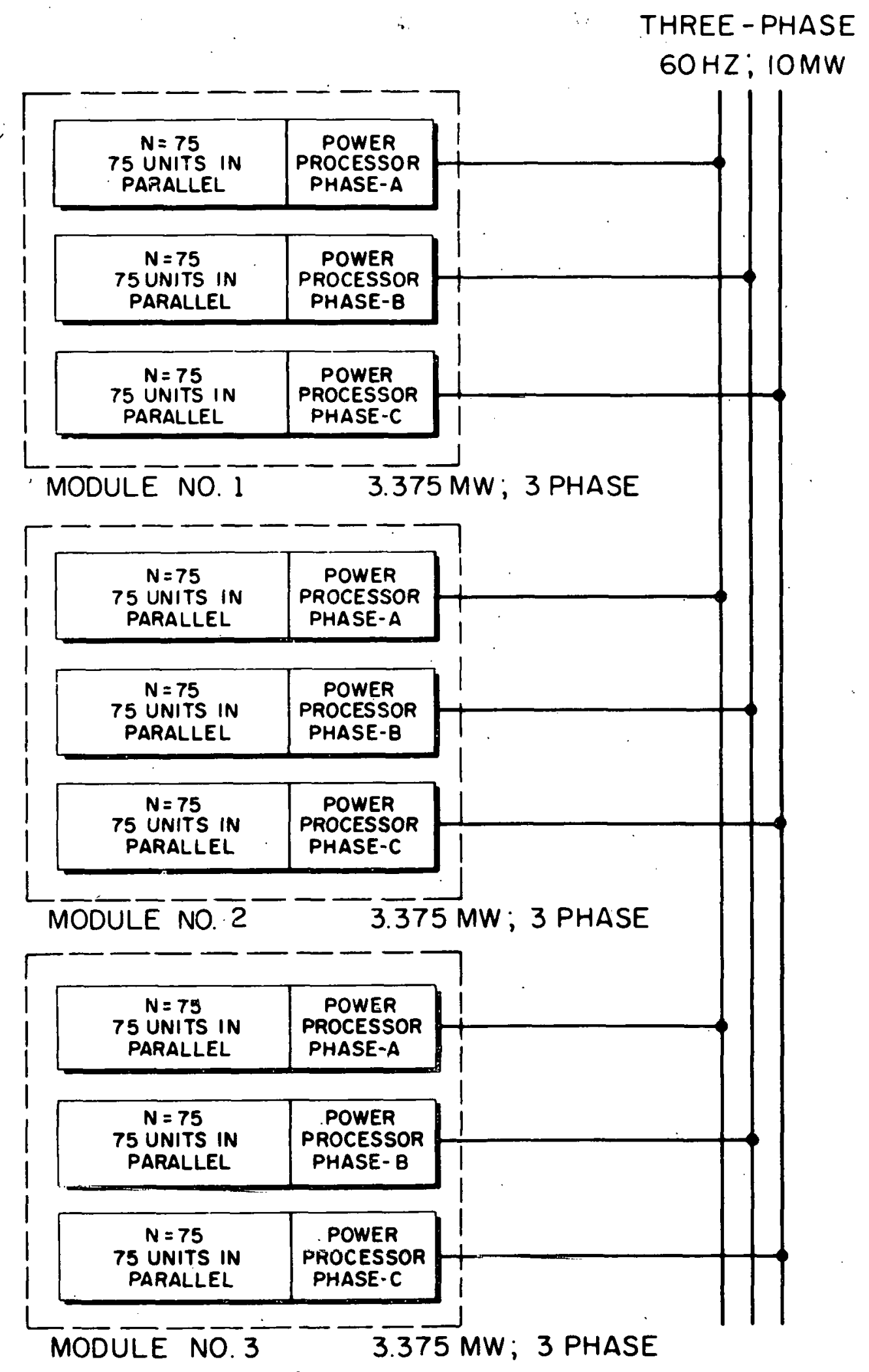

Figure 3-8. Conceptual Block Diagram of a 10 MWe Plant Employing Dish-Electric Transport with FMGS. 


\section{HIGH SPEED OPERATION (Above $18,000 \mathrm{r} / \mathrm{min}$ )}

As the operating speeds of electrical machines increase, the use of wound rotors with slip rings becomes rather tenuous at around 15,000 to $20,000 \mathrm{r} / \mathrm{min}$. The cost begins to increase sharply, coupled with a significant decrease in the reliability.

A review of the literature on Brayton engines shows that a considerable fraction of them operate at shaft speeds ranging from 55,000 to $70,000 \mathrm{r} / \mathrm{min}$. It appears that most of the Brayton engines that are available at present operate at speeds above $18,000 \mathrm{r} / \mathrm{min}$.

Direct coupling of an FMA to a Brayton engine at these high speeds will requite the elimination of slip rings and windings in the rotating part. This is possible and one approach to accomplish this (as discussed in Chapter II) is to employ a "homopolar" or "inductor" structure. Because of poor utilization of the magnetic circuit, larger machines will be necessary. However, at these high speeds, even an increase of 2 or 3 to 1 in size would still result in a very cunpact machine.

All the schematics and the associated discussions presented in connection with medium speed operation are valid for this speed range also. The only difference is the elimination of rotor windings and slip rings and the redesign of the magnetic circuit. A two or four pole structure is sufficient to get the required machine frequencies.

\section{E. STANDARDIZATION OF THE DISH SIZE}

For practical reasons, it may be convenient to standardize the diameter of the dish and adjust the number of dishes to obtain the required power output. In Figure 3-9, power flows at various points are shown with an array of $10 \mathrm{~m}$ diameter dishes. With the parallel connection of solar generating units and a 
common power processor as discussed earlier, an array of 67 dishes is needed for an electrical output of 1.125 MWe. Such an array can form one group of the ninegroup configuration (see Figure 3-8) for a 10 MWe plant. 


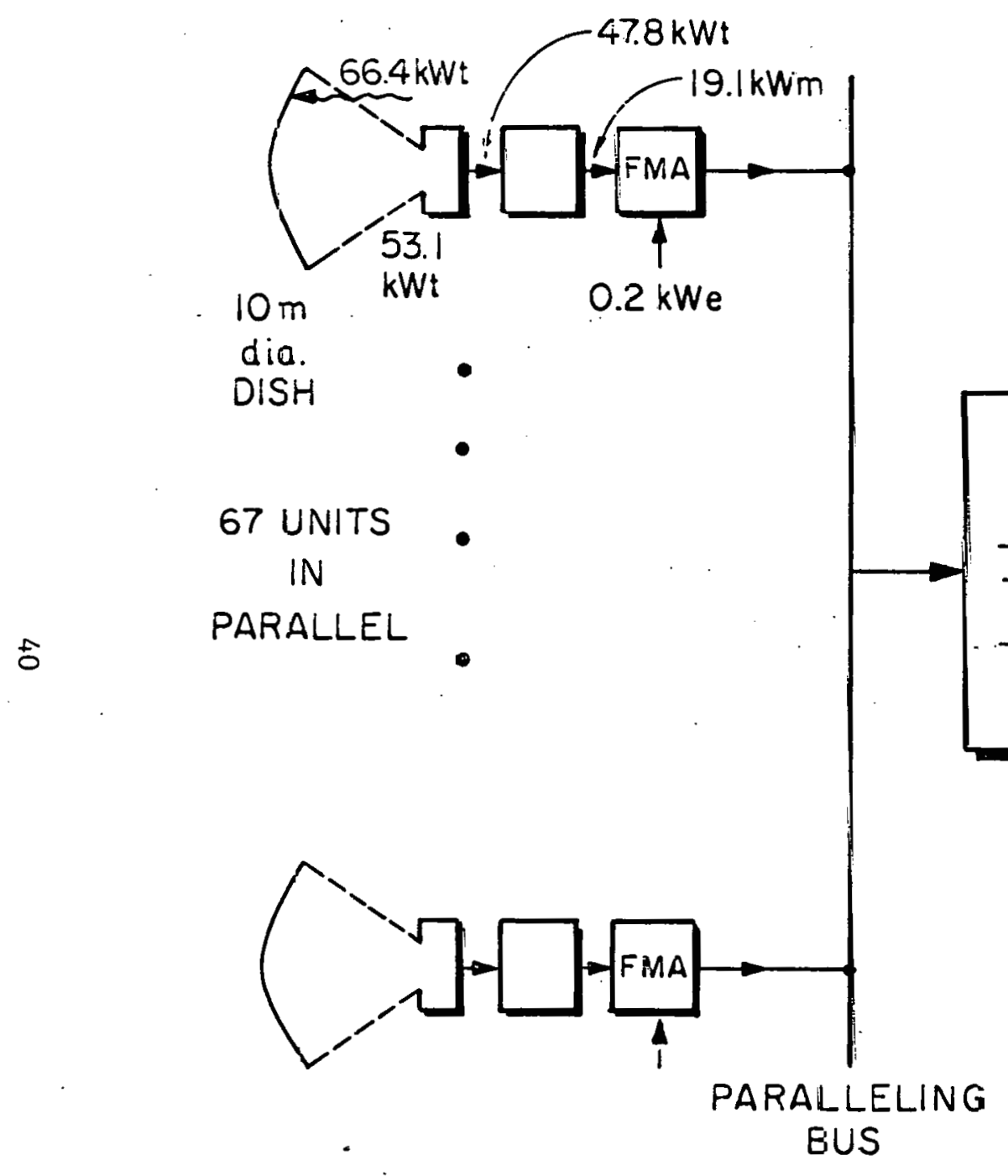

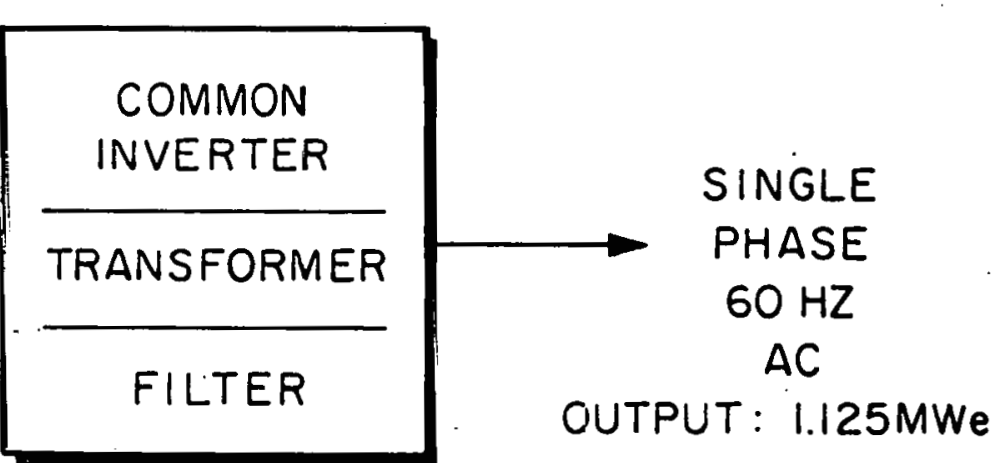

$\left(\begin{array}{c}\text { ONE GROUP OF A 3-GROUP } \\ \text { MODULE FOR 3-PHASE } \\ \text { POWER GENERATION }\end{array}\right)$

POWER

PROCESSOR

COLLECTOR-FECEIVER EFFICIENCY $=72 \%$ OVERALL POWER EFFICIENCY $=25.2 \%$

Figure 3-9. Power Flows with Standardized $10 \mathrm{~m}$ dia Dishes for an Electrical Output of 1.125 MWe (one group of a Three-Groiup Moduie for Three-Phase gereration). 


\section{SECTION IV \\ CONTROL INTERFACE AND MONITORING REQUIREMENTS}

\section{A. GENERAL}

Since the excitation current required by the FMGS is $A C$, both its magnitude and phase are available for controlling the behavior of the system. However, when several FMAs (belonging to one group) are operating in parallel feeding a common inverter, it is imperative that all of their excitation currents be in-phase. The common inverter must switch at instances corresponding to the zeros of this excitation current.

Two philosophies are available for controlling a plant employing dishelectric transport with FMGS.

1. Individual control

2. Group control.

In individual control, the amplitude of the excitation voltage of each of the FMAs is separately varied, while maintaining all the excitation voltages of one group in-phase. In group control, both the magnitude and the phase of all the excitation voltages belonging to one group of.FMAs are varied in unison. Obviously, group control assumes that the excitation needs of all the FMAs belonging to a group are identical. This is not always valid since some dishes belonging to a group may come under the influence of cloud cover. Group control is clearly more economical than individual control and this may justify its adaptation. 


\section{B. INDIVIDUAL CONTROL}

A simplified schematic of this approach is shown in Figure 4-1 for FMAs belonging to one Phase-A group. Excitation to each FMA is supplied by an individual servo-controlled variac so that the amplitudes of the excitation voltages can be controlled separately. However, all the excitation voltages are locked in-phase because they are in parallel. The circuitry (located in the control center) to obtain the voltage $V_{\text {exA }}$ is shown in Figure 4-2. This voltage is equal to the vector suml of $V_{C B}$ and a small controllable voltage in phase-opposition with $V_{A}$. By varying this small voltage, the phase of $V_{\text {exA }}$ can be varied over the required range without significantly altering its amplitude. Thus, while the phase of all the excitation voltages can be varied in unison from the control center, the amplitudes are varied individually. Phase control may be necessary to control the overall output being pumped into the power lines. This approach is obviously expensive because of the need for individual servo-controlled variacs. Also, it is possihle to replasc these variacs by suitable magnetic amplifiers (saturable reactors) to meet the response needs.

C. GROUP CONTROL

In this approach, both the amplitude and the phase are controlled from the control center. Circuit connections to the individual excitation windings are very simple as shown in Figure 4-3. However, the circuitry to obtain V exA should have the capabllity for both amplitude and phase variations. One possibility to achieve this is shown in Figure 4-4. In this, phase control is obtained by varying a small voltage in phase-opposition with $V_{A}$ as before. But, as the amplitude of $V_{C B}$ is varied, this small voltage should also be varied in proportion so that the phase of $V_{\text {exA }}$ will remain the same. This can be 


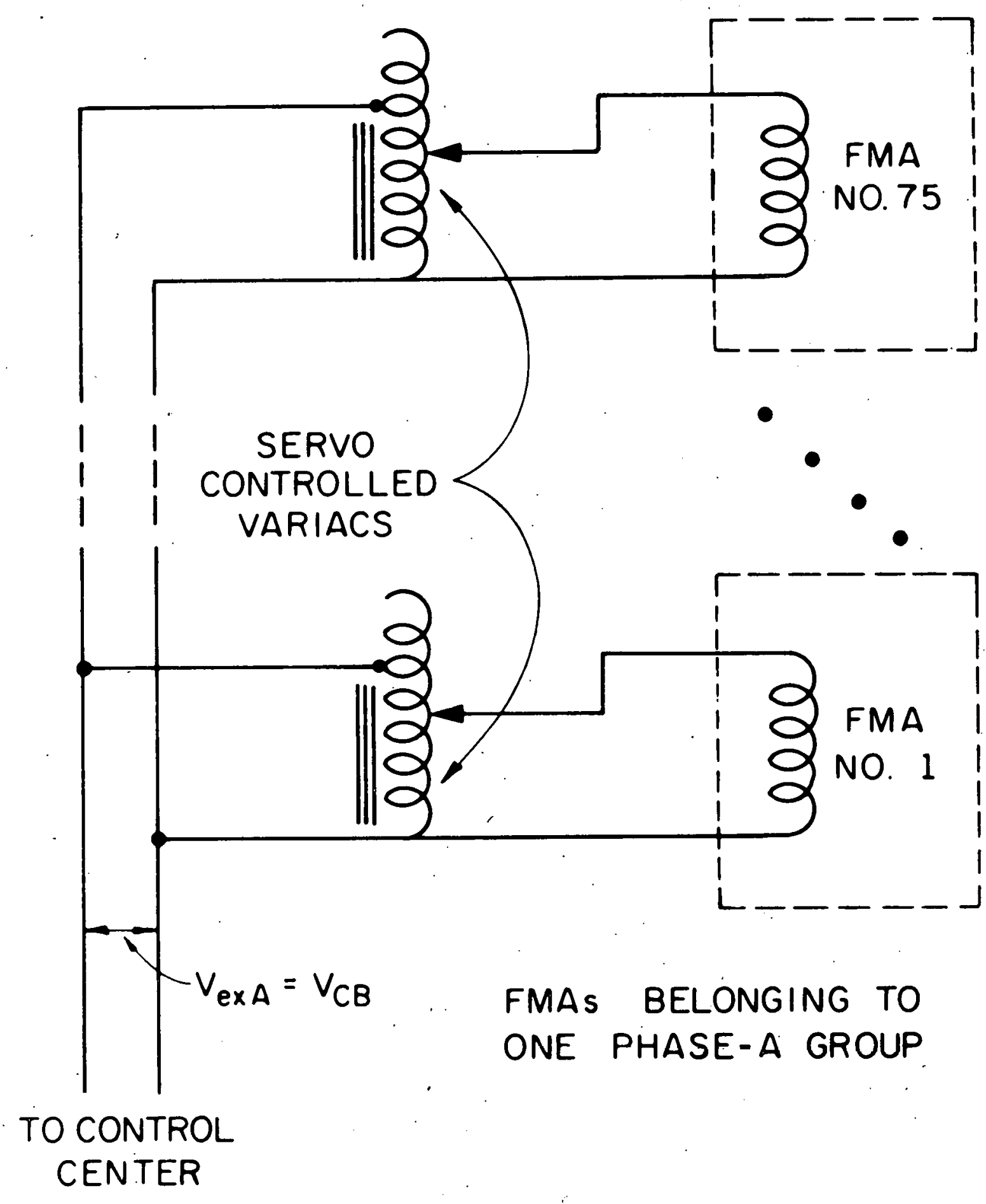

Figure 4-1. Simplified Schematic of Individual Control. 


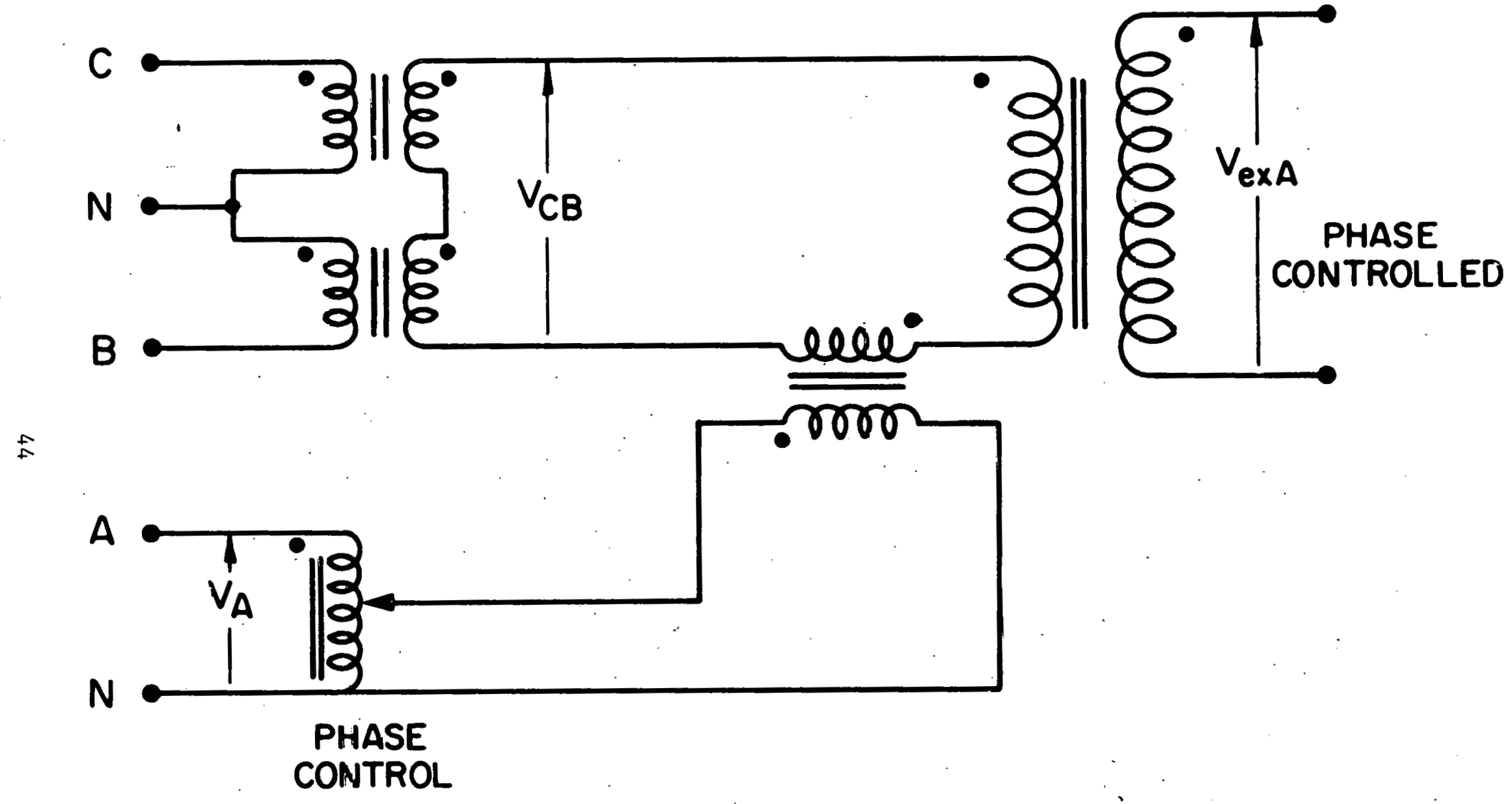
Figure 4-2. Circuitry to Obtain V exA for the
Case of Individual control. 


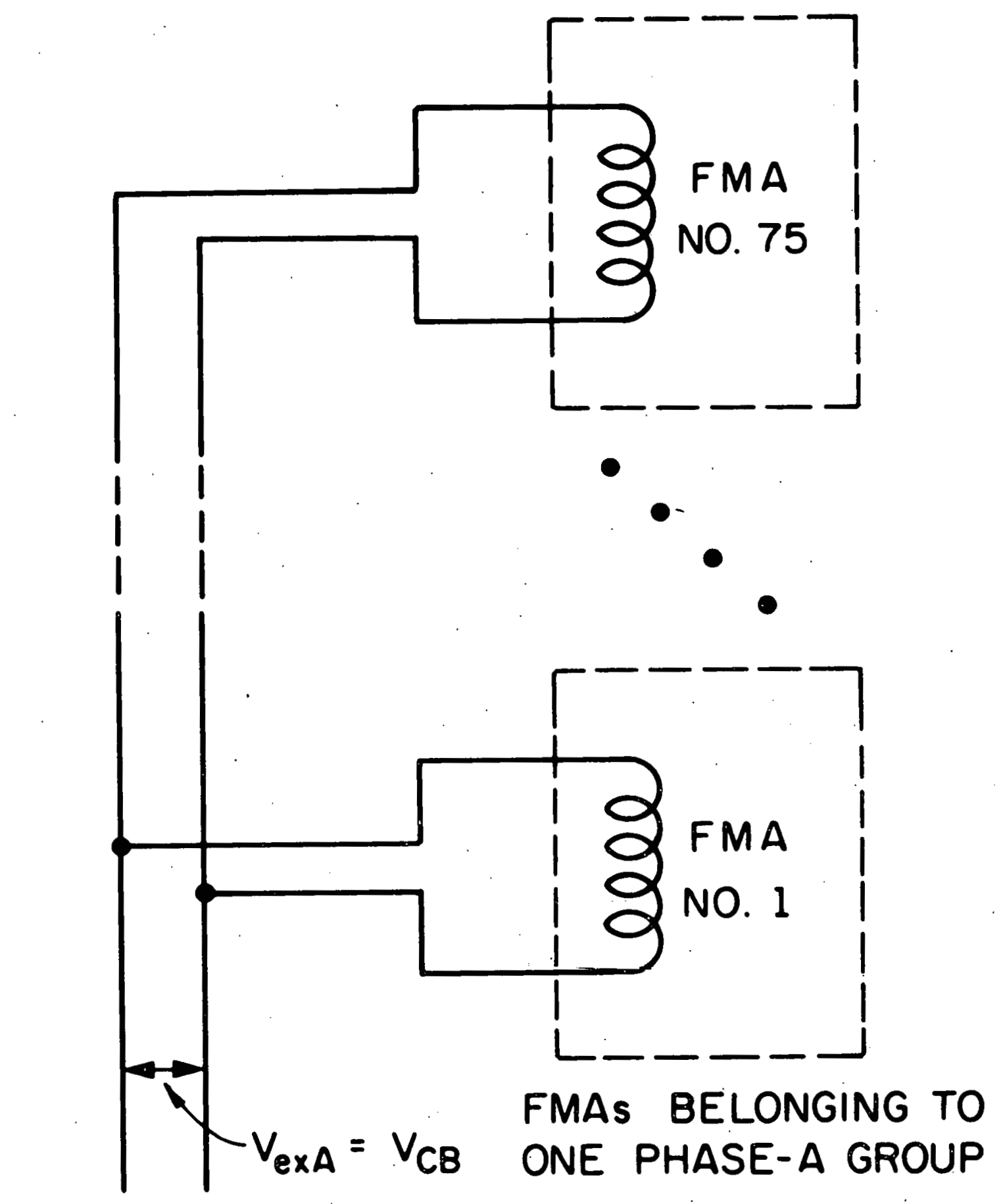

TO CONTROL

CENTER

Figure 4-3. Schematic of Group Control. 


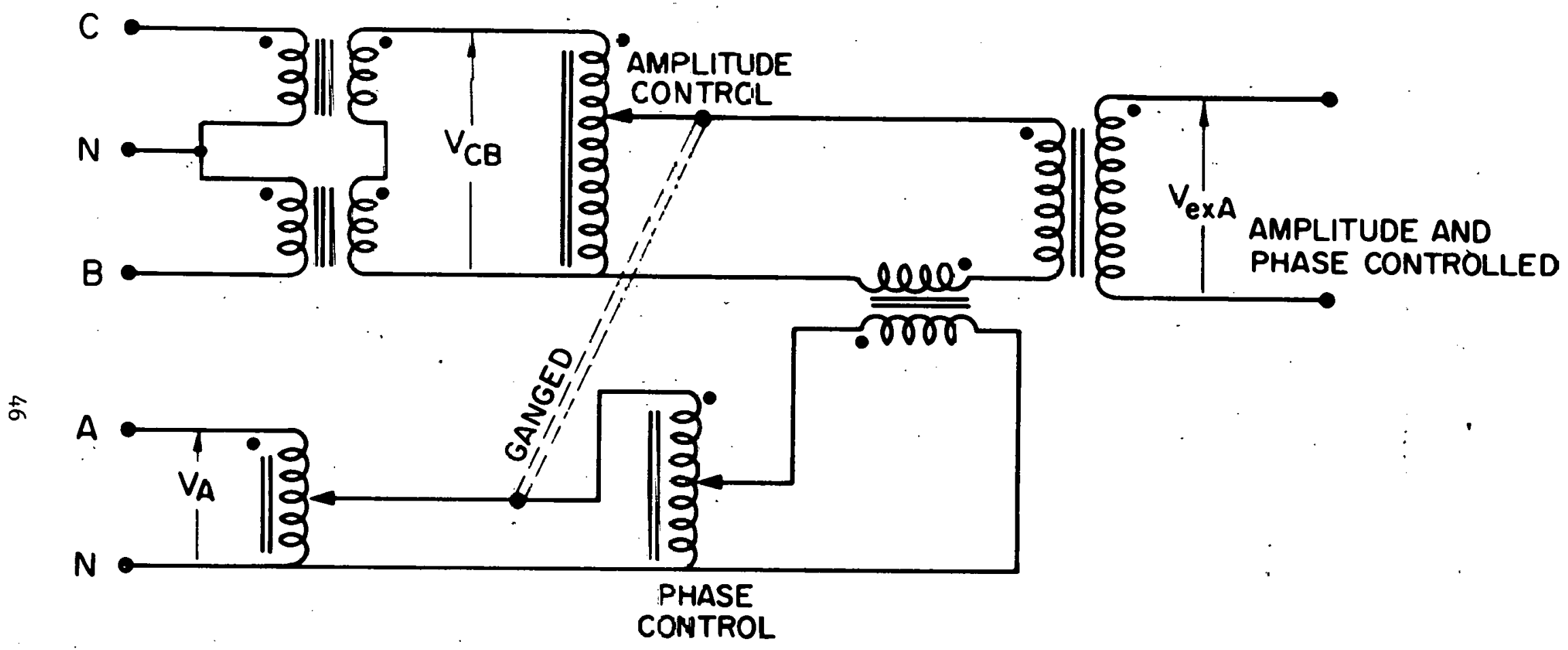

Figure 4-4. Circuitry to Obtain $\mathrm{V}$ exA for the 
done by a ganged-variac system as shown in Figure 4-4. With this arrangement, either the amplitude or the phase or both can be varied as required, since only one such assembly is required per group (consisting of 75 FMAs), the group control approach is less expensive than the individual control approach. The disadvantage with the group control is that all the FMAs belonging to one group will be supplied with the same excitation voltage, irrespective of their individual needs. This may not be very serious if the individual thermal energy storage (TES) systems can smooth out the effect of cloud cover on some dishes for a short duration. D. INTERFACE WITH UTILITY GRID

The simplest possible interface with the utility grid can be realized through a power transformer. This is illustrated in Figure 4-5. Although a $Y-Y$ transformer is shown for simplicity, a $\Delta-Y$ transformer may be preferable in practice. However, slight modifications will then be necessary in the excitation circuits to compensate for the phase-shifts introduced by the $\Delta-Y$ transformer and. maintain the proper phase relationship between the excitation and the output voltages in the FMGS. By employing one transformer per module, overall reliability can be improved. For the arrangement shown in Figure 3-8, each transformer will be rated at $3.375 \mathrm{MW}$. The individual windings on the plant side can, with suitable capacitors in parallel, function as the low-pass filters required at the outputs of the inverters.

Power flow into the grid can be controlled by controlling the relative phase of the plant-side voltages with respect to the grid-side voltages (which are the same as the grid voltages). This is done by varying the phase of the excitation voltages as discussed earlier. It should be remembered that, power supplies for the circuits shown in Figures 4-2 and 4-4 are derived from the very utility grid into which the power generated by the plant is pumped.

Tine frequency of the plant output is slaved to the utility line frequency. The phase and the phase sequence are also determined by the line voltages, except for a small intentional phase variation for control purposes. The net 


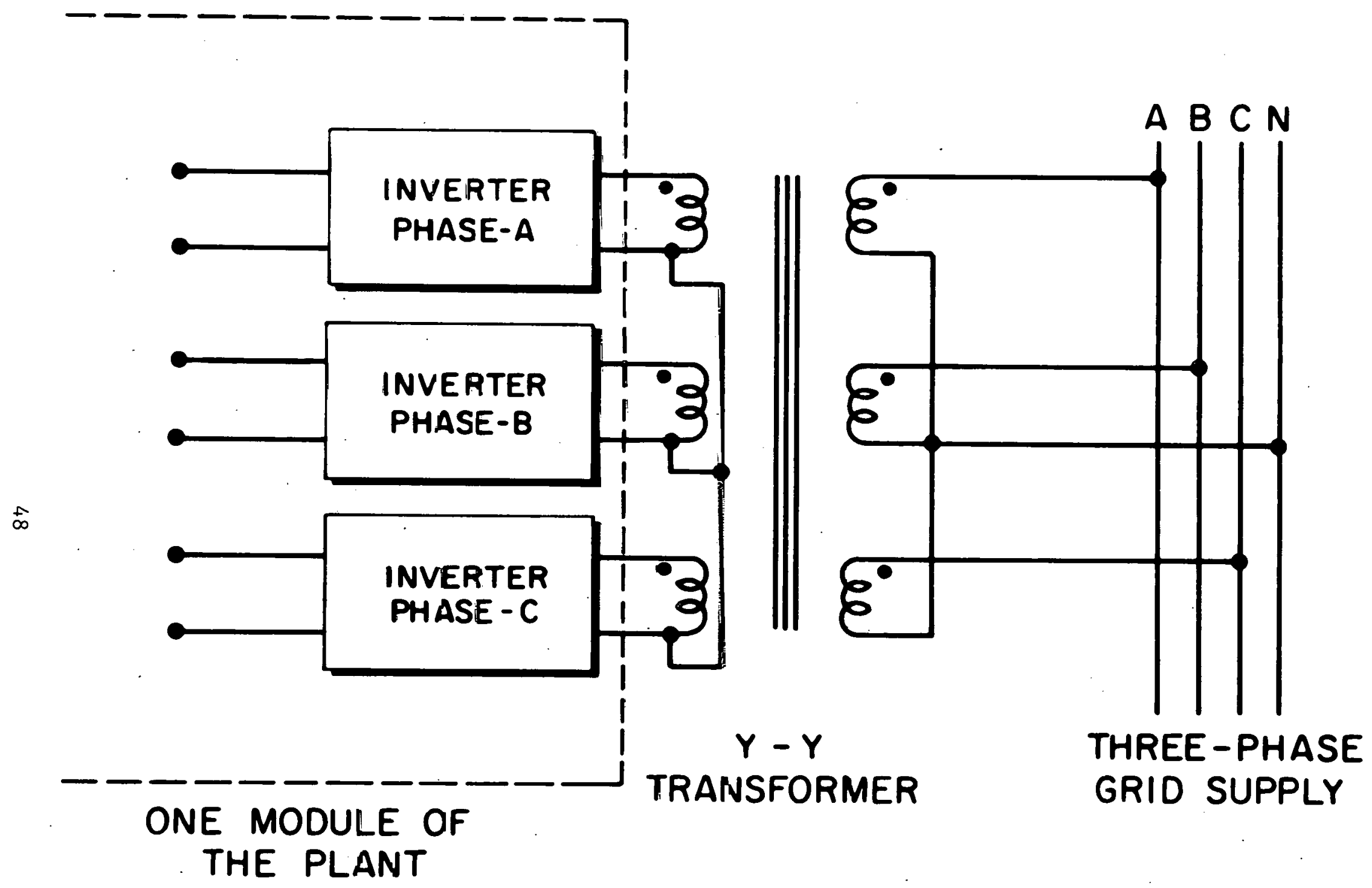

Figure 4-5. Simplified Schematiz of the Transformer Interface. 
effect of all these is that synchronization and parallel operation of the plant with the power grid becomes very simple.

With conventional synchronous machines operating in parallel with power lines, assuming the excitation to be constant, an increase in the prime-mover torque will tend to speed up the rotor. This will automatically increase the torque angle $(\delta)$ and the power delivered to establish a new equilibrium state with speed still remaining synchronous, as long as pull-out conditions are not reached. If the excitation is changed with prime-mover torque remaining constant, both the induced voltage and the torque angle change to maintain the power delivered constant. Ideally, input torque controls the power delivered and excitation current controls the operating power factor.

A simplified (and idealized) equivalent circuit for an FMGS operating in parallel with the power grid is shown in Figure 4-6. The FMGS is represented by a voltage source $\hat{E}_{S}$ in series with an equivalent reactance $x_{S}$. The voltage $\hat{E}_{S}$ is a function of the current delivered $\hat{I}$ and the rotor current $\hat{I}_{r}$. The grid is represented by an ideal voltage source $\hat{E}_{L}$ in series with a reactance $x_{L}$. For an infinite bus, $x_{L}$ should be taken as zero.

With FMGS, the phase angle $(\delta)$ between the two voltage sources ( $\hat{E}_{S}$ and $\hat{E}_{L}$ ) representing the generator and the power system is not affected by changes in the prime-mover torque. It can be controlled externatiy by advallcing or retarding the phase of the rotor applied voltage with respect to the grid voltage. An increase in the generator speed will increase the amplitude of $\hat{E}_{S}$ without a change in $\delta$.

It is prudent to operate dispersed solar thermal electric plants pumping power into power lines in a manner that is optimum from the viewpoint of the plants. In the case of dish-electric transport with FMGS, this translates into maintaining $\hat{\mathrm{E}}_{s}$ and $\hat{\mathrm{I}}$ in-phase as shown in Figure 4-6. Assuming the system to 


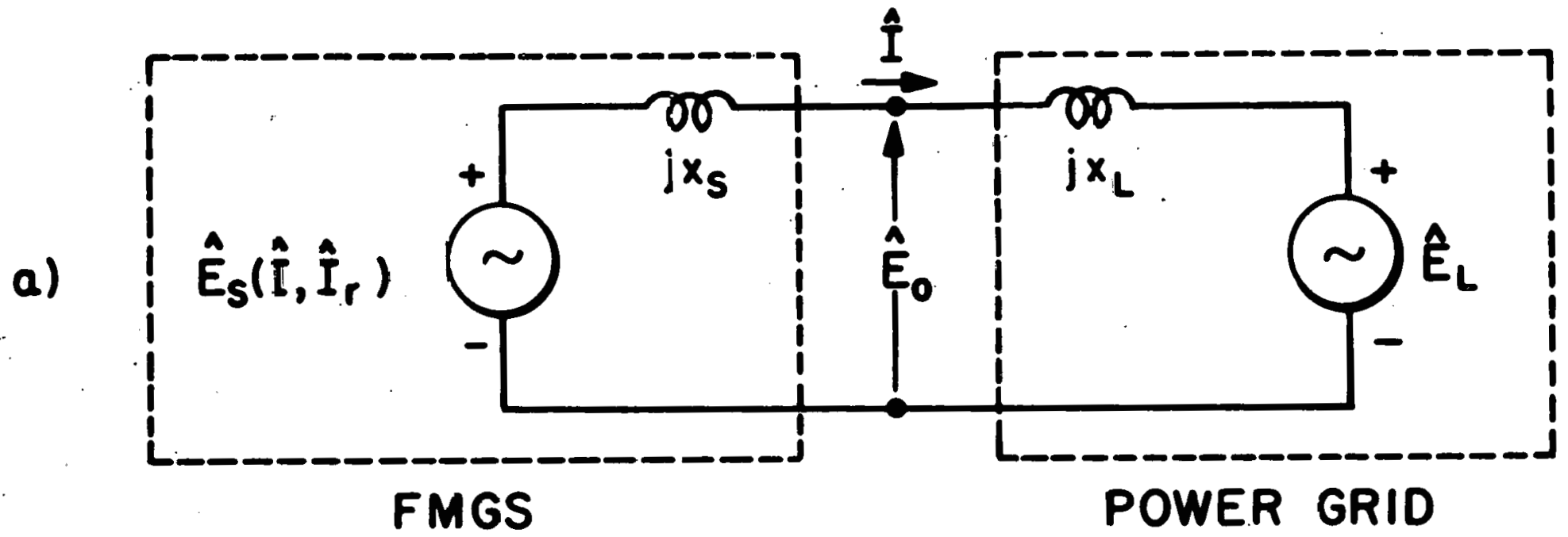

b)

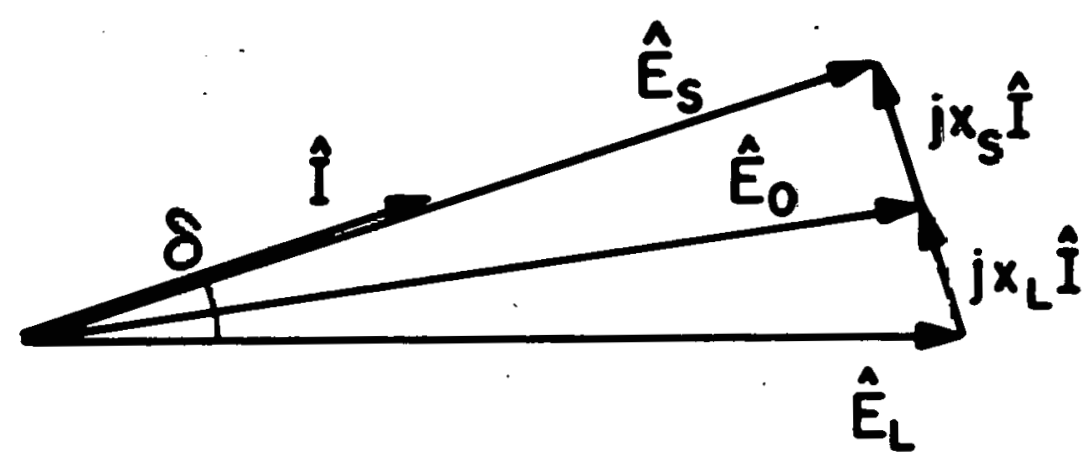

Figure 4-6. Idealized Circuit Model for an FMGS Pumping Pocer into a Power Grid. 
be operating in this manner, an increase in the magnitude of $\hat{E}_{S}$ without a change in $\delta$ will alter operating conditions in two ways: a) magnitude of $\hat{I}$ will increase and b) $\hat{I}$ will lag $\hat{E}_{S}$. Net result of these two changes will be to increase the power delivered and slightly decrease the efficiency of the system. A suitable increase in $\delta$ will, however, bring $\hat{E}_{S}$ and $\hat{I}$ back in-phase and alter the power output to match the new operating conditions. If excitation current magnitude is increased with input torque constant, the system will slow down to a new value of speed at which input-output power balance is maintained with the increased excitation current and the new efficiency value. Thus, the power pumped into the power line can be varied by controlling either the magnitude or the phase (or both) of the excitation voltage applied to the rotor terminals.

\section{E. MONITORING REQUIREMENTS}

Optimum operation of the plant will require the monitoring of key parameters so that appropriate control signals can be generated. Some of the important variables involved are listed below.

a. Input solar insolation.

b. Heat engine operation - working fluid temperatures, pressure, flow rates, rotational speed.

c. FMA - output current, output power, machine temperature.

d. Interface hardware - power pumped into the utility grid, power factor.

Some type of power management system is necessary to ensure that the sum total of all the powers generated by the individual solar generation units is properly fed into the utility system. This may require the employment of microprocessors and associated hardware and software.

One feature of FMGS that should be considered in designing the power management system is that reverse power flow back into the FMA is not possible. 
Either the FMA is pumping power into the paralleling bus (see Figure 3-4) or it is simply floating, with zero current output. Therefore, the excitation should be so adjusted that the power output of the FMA matches the solar insolation incident on the corresponding dish.

Delineation of further details should await the selection of the heat engine, operating mode (constant or variable speed), torque-speed characteristics and other particulars. 


\section{SECTION $V$}

\section{NEEDED TECHNOLOGY}

\section{A. GENERAL}

Although the concept of employing field modulation techniques to control the output frequency of a variable-speed generator has been discussed in the literature for at least 20 years, most of the significant advances leading to successful and efficient multi-kilowatt-scale prototypes have evolved as a result of the work carried out at Oklahoma State University since 1970. The prototypes fabricated so far have, of necessity, been subject to several constraints, depending on the sponsor and the application for which they were intended. Analytical work related to this system has progressed to the point that most of the major factors influencing its operation have been delineated. In the following paragraphs, further work needed to judiciously apply field modulated generator systems to solar thermal electric conversion is described.

\section{B. MILESTONES TO BE REACHED IN PROTOTYPE DEVELOPMENT}

All the prototypes fabricated thus far had slip rings to carry the excitation current to the rotating field coil housed in the laminated rotor. However, when the rotational speeds of machines approach and exceed 18,000 r/min, it is not realistic to employ wound rotors connected to external circuits via slip rings and brushes. This is also the speed range in which generators directcoupled to Brayton cycle engines will be required to operate. 
One approach to eliminate slip rings is to adopt a magnetic circuit arrangement similar to the ones employed in "inductor" and "homopolar" alternators (see Figure 2-7). As discussed earlier, the need to modulate complicates the magnetic circuit configuration. It is necessary to undertake the detailed design, fabrication and testing of an FMGS of this type in the 10 to $15 \mathrm{~kW}$ rating, operating in the speed range of 10,000 to $20,000 \mathrm{r} / \mathrm{min}$ (or higher). The testing should include the determination of the torque-speed curves under different control modes so that the characteristics of the generatur can be matched to the characteristics of the prime-mover (Brayton cycle engine).

The prototype discussed in the paragraph above should be field tested by integrating the dish, Brayton cycle engine and the field modulated generator. This will yield a wealth of data that can be used to improve the overall perfurrlance of the system. Since the ultimate output of the solar plant is required to be three-phase ac, it will be worthwhile to fabricate three dishelectric units and test them as a triplet, with a three=phase output.

\section{MILESTONES TO BE REACHED IN ANALYSIS AND THEORY}

Inductor-type field modulated generators employ a varying air-gap rather than a conventional north and south pole structure. In addition to poor magnetic circuit utilization, such an arrangement will result in a flat-topped field form and will result in non-sinusoidal induced voltages (at the basic machine frequency) in the stator windings under both no-load and full-1nad conditions. Therefore, the task of designing such a system should be coupled with the analytical examination of the influence of non-sinusoidal waveforms on the operation of the parallel-bridge rectifier system and the field modulated generator system. This should be done in several steps - first without 
bridge-input capacitors and later with bridge-input capacitors. Resistive loads should be studied first, and later, the results should be extended to include reactive loads.

Even in the case of the wound rotor FMGS (with slip rings), it was observed that certain variations in the magnetic circuit design resulting in a flat-topped field form yielded significant dividends in the form of reducing excitation requirements and improving efficiency and power output capability. A flat-topped field form was obtained by designing a uniformly slotted round rotor with a winding arrangement that resulted in magnetic neutral planes in the centers of teeth rather than in the centers of slots. This phenomenon should be investigated analytically with suitable experimental verifications to establish appropriate design criteria.

The development of a mathematical model for the FMGS needs further work to reduce it to a form suitable for studying the dynamics of the combined system (insolation, dish, tracking, engine and generator) so that control and operational philosophies can be evolved.

Dynamic behavior of solar thermal electric systems employing field modulated generators and operating in parallel with conventional utility grids require further critical study and evaluation. 


\section{SECTION VI}

\section{COMPARISON WITH OTHER OPTIONS}

\section{A. GENERAL}

As discussed in Chapter I, if the heat engine is operated in a variablespeed mode and if utility grade ac is of interest for direct insertion into an existing utility grid (without an intermediate energy storage and reconversion system), the following choices for electric power generation appear viable.

1. $A C-D C-A C$ link employing a conventional alternator.

2. $A C-D C-A C$ link employing a permanent magnet gencrator.

3. Cycloconverter.

4. Field modulated generator system.

In this chapter, an attempt is made to compare these options in terms of their overall efficiency, size, reliability, availability, economics and operational features. Simplified schematics of these four options are shown in Figure 6-1.

\section{B. EFFICIENCY AND SIZE CONSIDERATIONS}

Assuming the efficiencies of the collector, receiver and the heat engine combination to be the same (equal to $0.8 \times 0.9 \times 0.4=0.288$ ) with all four options, one need only to consider the ratio of the electrical output to the mechanical input (plus any excitation inputs) from the heat engine to compare the different electric generation schemes. In the discussion that follows, efficiency values at rated conditions are used. A detailed study should employ the efficiency versus output curves rather than a single point on the curve. 


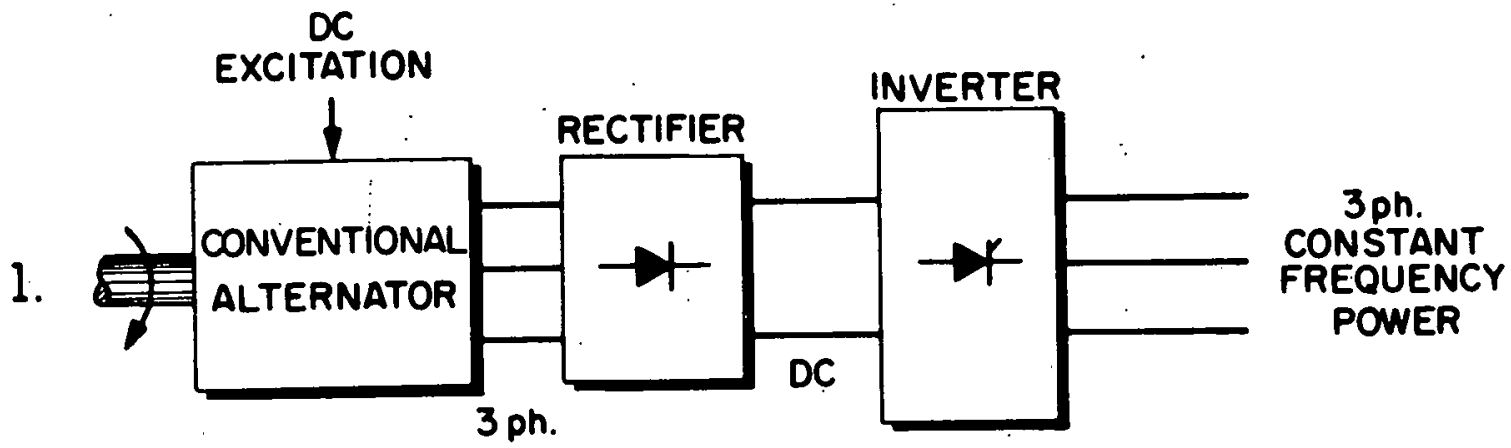
VARIABLE FREQUENCY
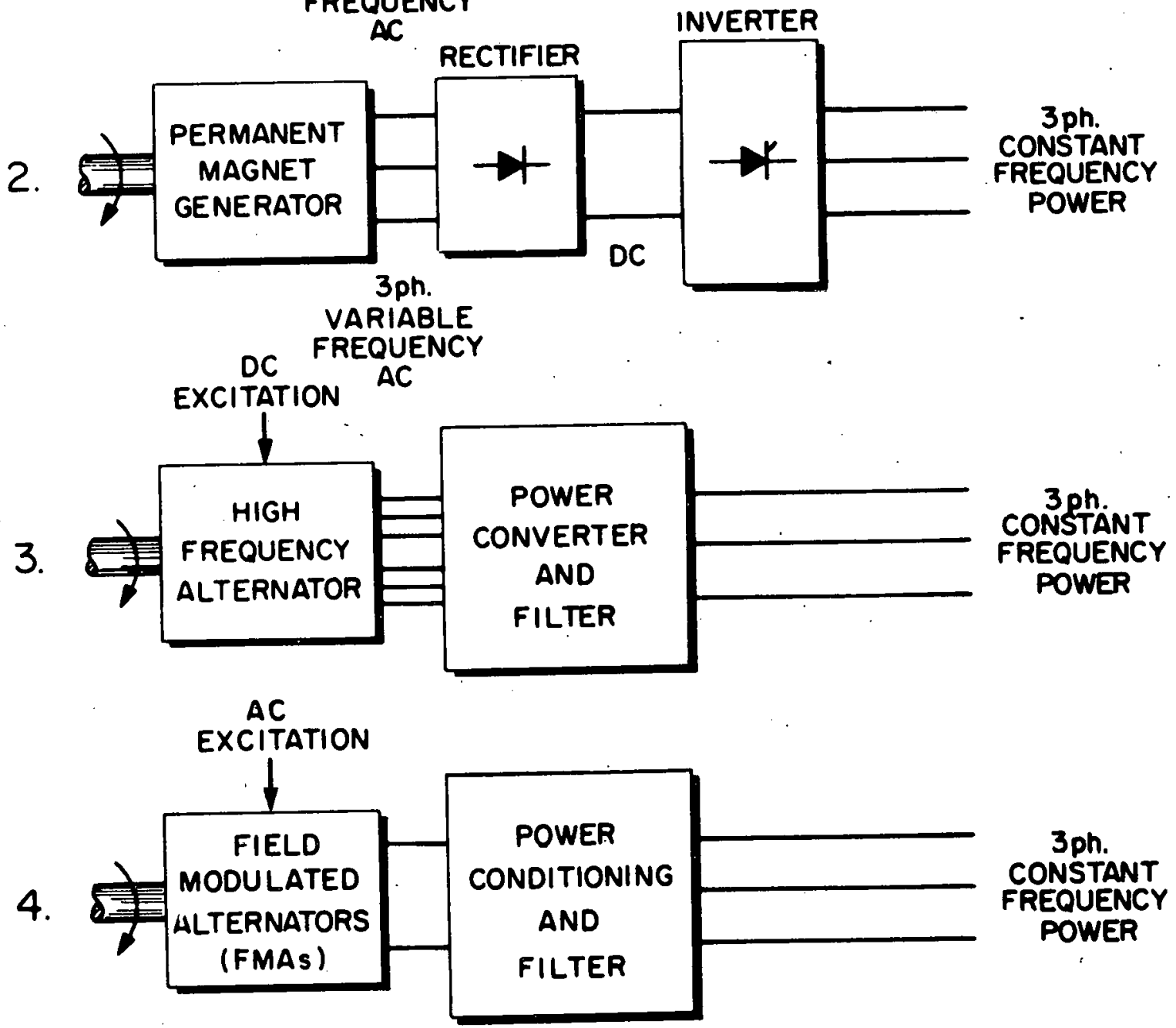

Figure 6-1. Simplified Schematics of VSCF Generation Options for HighSpeed Prime-Movers. 
Option 1:

$$
n_{M E}=n_{A} \cdot n_{R} n_{I}
$$

where

$$
\begin{aligned}
& n_{M E}=\text { Mechanical-to-electrical power efficiency } \\
& n_{A}=\text { Alternator efficiency } \\
& n_{R}=\text { Rectifier efficiency } \\
& n_{I}=\text { Inverter efficiency }
\end{aligned}
$$

High-frequency alternators feeding rectifier loads experience additional losses due to the harmonic content in the stator currents when conventional six-diode double-way rectifiers are employed. To offset this, an alternator of larger rating (110 to $115 \%)$ is recommended. Typical full-load efficiency that can be expected is around $85 \%$. However, it must be pointed out that the efficiency can be improved by employing a parallel-bridge rectifier system.* Assuming a rectifier efficiency of $95 \%$ and an inverter efficiency of $95 \%$, the value of $\eta_{M E}$ is $76.7 \%$. If the alternator efficiency is improved to $90 \%$, then the new value of $n_{M E}$ becomes $81.2 \%$.

\section{Option 2:}

This option has become viable recently due to the availability of powerful rare-earth (Samarium Cobalt) permanent magnets. However, there are still major problems associated with the permanent magnet generator (PMG) design and fabrication related to the rotor. Physical size of the PMG will probably be a little $(\simeq 120 \%)$ larger than equivalent conventional machines and it is reasonable to expect an efficiency of about $80 \%$. for the generator (aiternator) alone. With an

${ }^{\star}$ R. Ramakumar, et al., "Uperation of Alternators with Parallel-Bridge Rectifier Systems," IEEE Transactions on Power Apparatus and Systems, Vol. PAS-92, No. 5, pp. 1679-1687; September/0ctober 1973. 
efficiency of $95 \%$ each for the rectifier and the inverter, an $n_{M E}$ value of $72.2 \%$ is indicated for this option.

\section{Option 3:}

Cycloconverters tend to present a low power factor $(\simeq 0.7)$ to the highfrequency al ternator. In addition, the machine currents are rich in harmonics due to the chopping up of the waveforms in the frequency down conversion process. These factors lead to an alternator rating substantially higher (140 to 150\%) than the overall output required. Overall efficiencies $\left(n_{M E}\right)$ of 75 to $82 \%$ are achieved for variable-speed operation, the lower value corresponding to the highest speed.

\section{Option 4:}

In the FMGS option, overall efficiency can be improved by processing the outputs of a number of alternators through one common inverter. In this mode of operation, $n_{M E}$ for a group of solar generation units is expected to be in the 85 to $90 \%$ range, depending on the specific voltages and currents involved.

Physical size of an FMG will be a little (120 to 130\%) larger than a conventional alternator operating at the same speed and output conditions. The reason for this can be understood by referring to Figure 6.2 in which a regular sine wave and a modulated sine wave are shown. Since the peak flux density (and voltage) in a machine is fixed by the magnetic circuit characteristics, it is obvious that the magnetic circuit utilization is poor with modulation. This is partly compensated by the fact that higher peak currents can be allowed without exceeding the limit on the stator copper losses. Rotor iron losses will be slightly higher due to ac excitation. Employment of a parallel-bridge rectifier system at the machine output terminals leads to nearly sinusoidal currents (modulated, of course) in the stator windings. These facts, coupled with the 


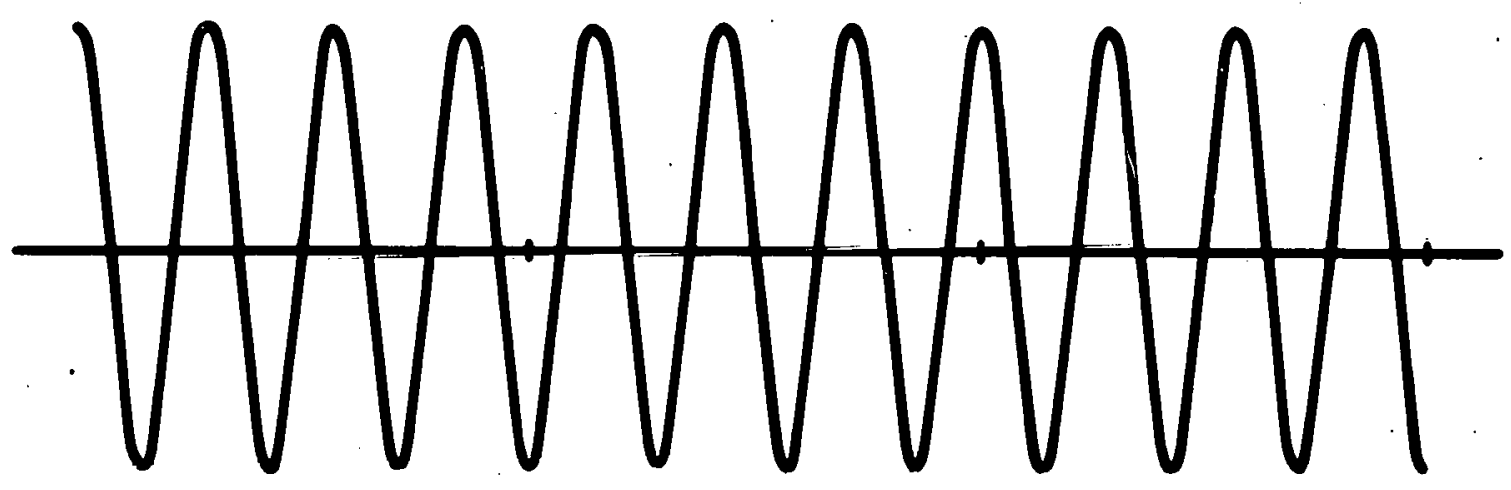

a. SINE WAVE

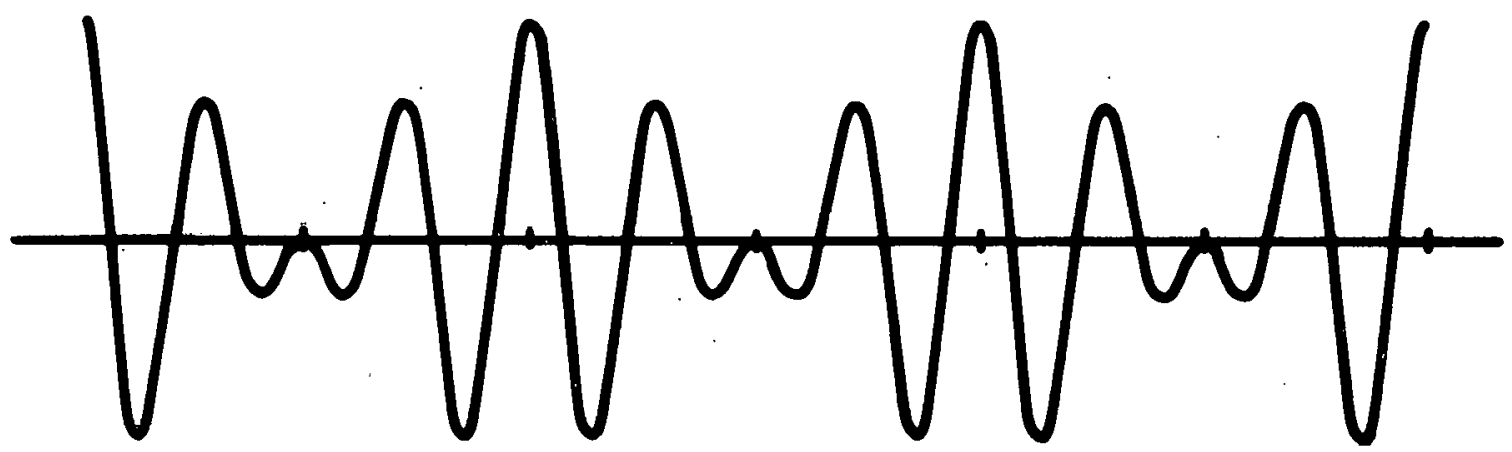

b. modulated sine waVe

Figure 62 . Sine and Múlulded Sine Waveforms. 
employment of proper stator and rotor tuning capacitors, result in the higher efficiencies without substantial penalties in size.

\section{RELIABILITY}

It appears that the PMG option (No. 2) is the most reliable of the four being discussed, primarily due to the absence of rotor windings. At the same time, most of the problems with PMG's have been in the rotor design and fabrication. All the options have solid-state electronic circuitry associated with them and the differences are primarily in the number of devices involved and the way in which they are interconnected. Unless a very detailed reliability analysis is undertaken, it is difficult to clearly order these options in terms of the ir reliabilities.

\section{AVAILABILITY}

Rectification and inversion technologies are fairly mature and for this reason no significant breakthroughs are required to adopt any of the options considered. However, the FMGS technology is the least mature of all and Chapter $V$ has outlined the major milestones to be reached for proper application of FMGS to solar thermal electric conversion. Cycloconverters are already available in the small-scale commerical market. Very high speed (over 18,000 r/min) permanent magnet generators are not yet commercially available.

Success of the dish-electric transport concept is primarily dependent on a proper marriage between the heat engine and the power conversion component. Therefore, no matter which option is selected, extensive analysis, design, fabrication and field testing will be necessary before any replication on a large scale is undertaken. 


\section{E. ECONOMICS AND OPERATIONAL FEATURES}

The economics of any electric energy conversion system eventualiy boils down to the cost of the energy generated (cents per kWh). While the cost per $\mathrm{kW}$ of any one component has a bearing on the ultimate energy cost, the only logical way to compare different options is in terms of the cost of the energy generated. Higher overall efficiencies have the potential to decrease the collector costs and a design optimization exercise is necessary to compute and minimize the generation cost.

The technologies of the four options shown in Figure 6-1 are at different levels of maturity and therefore only some qualitative remarks are in order. In the absence of an intermediate energy storage and reconversion system, the ability of the FMGS option to collect and process the outputs of an array of solar generation units by employing a common power conditioning system appears attractive both from the economic and the reliability points of view. The fact that all the outputs are locked into synchronism with the exritation source and that the output frequency is slaved to the line frequency should lead to simpler operating procedures. Once the initial matching of the heat engine and the FMA is accomplished, there is nothing in this option that points to unusually high costs over and above any of the other options.

Dish-electric transport wi th FMGS appears to have the potentiai for the highest overall power conversion efficieney. If the efficiency versus output curve can be made flat all the way down to about $25 \%$ of rated output, high energy efficiencies can be realized.

If it is necessary to have an intermediate energy storage (battery bank) and reconversion system, options 1 and 2 may have a slight edge over the other two because of the presence of $d c$ at some point in the link. On the other hand, 
if direct ac link is preferred, the FMGS option with group control (discussed in (hapter IV) appears to have the potential for reducing the cost of the electrical energy generated. 


\section{SECTION VII}

\section{SUMMARY AND CONCLUDING REMARKS}

\section{A. GENERAL}

This study, initiated in September, 1978, was intended to investigate the feasibility of FMGS for inclusion in the design of 15 kWe solar generation units constituting a dispersed solar thermal generation system employing dishelectric transport. In November 1978, a paper summarizing some preliminary ideas on this approach was prepared and presented in the Focus on Solar Technology: A Review of Advanced Solar Thermal Power Systems, held in Denver, Colorado, under the sponsorship of the U.S. Department of. Energy. A copy of this paper is attached as Appendix C.

\section{B. SUMMARY}

In Chapter II of this report, the state-of-the-art of FMGS is reviewed. Additional information on this topic is included in the form of two papers, copies of which are attached as Appendices A ard B. The application of FMGS to dispersed solar thermal electric generation is discussed in Chapter III. Schematics and block diagrams are used to illustrate dish-electric transport with FMGS. Efficiencies, dish sizes and power flows are discussed for a 15 kWe unit and for a $10 \mathrm{~m}$ diameter dish. A 10 MWe plant (conceptual) will have three three-phase modules, each module consisting of three groups (one for each of the three phases) and each group will be formed by an array of 75 solar generation units. Each unit will consist of a dish and an FMA (alternator and PBRS). 
The output of the units forming a group will be processed by one common power processor. With a collector-receiver efficiency of $72 \%$, this approach has the potential to yield overall power conversion efficiencies of slightly over $25 \%$.

The control, interface and monitoring requirements are outlined in Chapter IV. There are two possibilities -- individual control and group control. The latter will probably be more practical and cost effective. There seems to be no special problems involved in interfacing with a utility grid. The nature of the FMGS makes this problem rather simple. The milestones to be reached in prototype development, analysis and theory are briefly discussed in Chapter V. Since the FMGS technology is not as mature as some of the competing technologies, some additional research and development is needed to judiciously apply FMGS to solar thermal electric conversion.

The FMGS option is compared with three other options in Chapter VI. Because of the large number of parameters involved, many of the comparisons made are rather qualitative. As far as the overall efficiency is concerned, the FMGS option appears to be the best of all. This fact alone should make this option attractive, not to mention the convenient operational and other features.

\section{CONCLUDING REMARKS}

The concept of dish-electric transport with FMGS appears to be sufficiently attractive to warrant further development and investigation. This approach is most suitable when the heat engine rotational speeds are high (typical of Brayton Cycle engines) and, in particular, if the engines are operated in the variable speed mode and if utility grade ac is required for insertion into the grid without an intermediate electric energy storage and reconversion system. Predictions of overall efficiencies based on conservative efficiency figures for the

FMGS are high $(25 \%)$ and should be encouraging to those involved in the development of cost-effective dispersed solar thermal power systems. 


\section{SWIEEECO Record. IEEE Catalog NO. 72 CHO 595-9, April 1972.}

\section{DESCRIPTION AND PERFORKANCE OF A FIELD MODULATED FREQUENCY DOWN CONVERTER}

R. Ramakumar
H. J. Allison

H. L. Hughes

School of Elect. :cal Engineering

Oklahoma State University

Stillwater, Oklahoma 74074

\section{ABSTRACT}

Using the techrique of fleld modulation and solid-state alternator output processing, a new type of rotary energy conversion device for obtaining a desired constant frequency output independent of the speed of the prime-mover has been developed and tested. This paper describes a 10 kw prototype field modulated frequency down converter system designed, built and successfully tested at Oklahoma State University. Experimentally obtained performance characteristics are presented and discussed.

\section{INTRODUCTION}

Many types of rotary energy conversion devices combining specially designed alternators and solid-state circuitry have been developed in the past few years. This increased interest is primarily due to the advent of economic and reliable solid-state devices such.as rectifiers and silicon controlled rectifiers. The primary objective of such systems is to provide reliable power at the desired frequency for civil, aircraft, milltary or space applications employing small light-weight mobile units. At present cycloconverters are leading the way in this class of power sources.

A new type of frequency down converter has been developed using the technique of modulating the field of a high-frequency $\left(f_{r}\right)$ altemator at the desired low frequency $\left(f_{m}\right)$. It is belleved that this technique results in a very economfal system for obtaining a desired constant frequency output independent of the prime-mover speed. Because of the independence of the output frequency from the rotary speed, high-speed turbines can be used as prime movers and the overall physlcal size can be consider ably reduced without any reduction in efficiency and ucher porformance criteria.

A $10 \mathrm{kw}$ prototype field modulated generator system is described in this paper. Important. characteristics such as efficiency, rotor Input requirements and regulation are discussed using experimentaliy obtained characteristics. In addition, oscillograms of voltages at several points in the system under no-load and loaded conditions are presented to illustrate the operation of the system.

\section{PRINCIPLE OF OPERATION}

A conventional three-phase synchronous machinel of basic frequency $f_{r}$ will have induced voltages of frequencies $\left(f_{r}+f_{m}\right)$ and $\left(f_{r}-f_{m}\right)$ when excited with an alternating current of frequency $f ; f>f$. When such three-phase voltages are individually full wave rectified and their outputs tied in paz $=-1 e l$, an output voltage containing the following components results: a d-c component a full-wave rectified sine wave at the frequency $f_{m} ; v\left|\operatorname{Sin} \omega_{m} t\right|$ there $\omega_{m} \equiv 2 \pi f_{m}$.

The d-c component is, in general, proportional to the reciprocal of the modulation frequency ratio $m$, where $m=f / f$. For values of $m$ greater than 10 , this component becomes negligibly small. The ripple will also be small for $\mathrm{m}>10$ and can be made even smaller by making the high frequency voltage waveform across the phases to have a flat top or approach a square wave. This ripple can be easily filtered out of the output voltage waveform. The resulting full-wave rectified sine wave can be converted to a sine wave voltage at the modulating frequency $f_{\text {by }}$ bsing a suitable switching circuit employing controlled rectifiers.

\section{DESCRIPTION OF THE SYSTEM}

Figure 1 shows a simplified schematic of the frequency down converter system ${ }^{2}$. 'It is built around a high-speed high-reactance high-frequency three-phase alternator. The rotor is of the wound rotor type with leads brought out to a conventional siip ring arrangement, although salientpole structure is equally suited for this purpose. Both rotor and stator are laminated to minimize the iron losses. The six stator leads are brought out and three full-wave bridges are connected as shown, one across each of the phases. The outputs of the bridges are tied in parallel across the load through a silicon controlled rectifier switching system. Tuning capacitors $C$ are connected across each of the stator windings to decrease the excitation requirements (both watts and vars) at the rotor terminals. This is achieved by causing the alternator to operate into a load of a highly capacitive nature irrespective of the power factor of the load supplied at the low frequency ( $f_{f}$ ) output terminals. The sinall oupaciton $S_{\text {, }}$ and the inductor $L$ prevent any rapid voltage variations that may occur at the machine terminals from damaging the silicon controlled rectifiers. The main switching process is accomplished by the four controlled rectifiers, SCRI through $\mathrm{SCR}^{4}$. The commutating circuit consisting of $\mathrm{L}_{2}, \mathrm{C}_{2}$ and the controlled rectifiers SCRS and SCRG aid in this switching process, especially when the load is not purely resistive. At the start of one half of the low frequency cycle, SCRI, SCR4 and SCR5 are triggered together. Capacitor $C_{2}$ charges up to the peak value of the full-wave rectified voltage appearing across the parallel bridge arrangement. At the end of this half cycle, SCR2, SCR3 and SCR6 are triggered together and simultaneously SCRI, SCR4 and SCR5 are shut off. The voltage across capacitor $C_{2}$ now is of such a polarity (top + and bottom -) as to help turn off SCRI and SCR4. 
In this process, capacitor $C_{2}$ discharges and starts to recharge in the opposite direction through SCR6 to the peak value of the voltaige as before. At the end of this secopd half cyclo, the voltage across capacitor $C_{2}$ (top -, botto: + ) will ald in shutting off SCR2 and SCR3. This cherging and discharging of $C_{2}$ is repeated once eviry half cycle. The size of $C_{2}$ depends on the accuracy of the timing of the $S_{C R}{ }^{2}$ trigger signals and on the reactive nature of the load. The small inductance $\mathrm{L}_{2}$ is provided as a safeguard against sudden voltage variations from appearing across SCRS and SCR6. The main filtering of the owitched output is performed by the tuned circuit consisting of the filter capacitor $C_{3}$ and the output autotransformer. Inductance $L_{3}$ prevents any voltage spike on one side of it from appearing on the other side. In addition to filtering, capacitance $C$ enables the handing of lagging power factor loads by the system.

The fleld is excited by an a-c power source of frequency $f$. Since this frequency flxes the output frequency, care must be exercised in the design of this part of the aystem. In case the system is required to be completely self starting, an inverter-dc source comblnation muet bo uoed lu exuite the field. The de power might come from an exciter alternator-rectifier unit mounted on the same shaft as the main generator. The volt-ampere capacity required of the excitation source can be greatly decreased by partial tuning of the fleld circuit whlch is accomplished by the capacitor $C_{5}$. In series with capacitor $C_{5}$ are a small inductance $\mathrm{L}_{4}$ and a back-to-back diode combination. As long as the watts input to the rotor winding is kept low (by the use of stator tuning capacitors $C$ ), the rotor input current lags the input voltage by nearly $\pi / 2$. The current through the serles combination of $\mathrm{C}_{5}, \mathrm{~L}_{4}$ and diodes leads the input voltage by nearly $\pi / 2$. Thus the current through the back-to-back diode combination is nearly $180^{\circ}$ out of phase with the rotor input current. The voltage picked up across this dlode combination is a square wave with zero crossings colncident with the zeros of the rotor winding current. This square wave is fed to a high-frequency transformer with six secondaries. The output of each secondary is used to trigger one of the six controlled rectifiers. The switching action of the full-wave bridges across stator windings causes the waveform of the voltage across the phases to approach a modulated square wave. This introduces hamonics in the armature reaction flux, sone harmonlcs are fed back into the rnton cirouit, and these should be kept to a minimum under rated operating conditions. Inductance. $L_{4}$ absorbs these high-frequency voltage variations across $R_{1} R_{2}$ and helps $1 n$ obtaining a less corrupted square wave trigger signal. Capacitance $C_{4}$ helps to de-tune these harmonic components in the field current.

The $10 \mathrm{kw} 220$ volto oingle phise 60 Hertz prototype designed and built has sixtoen poles and runs at around 7000 RPM. This corresponds to a frequency. $f$ of about 930 Hertz. For a modulating frequency of 60 Hertz, $m$ is between 15 and 16 . The d.c. component associated with this value of $m$ is essentially negligible and causes no problem in the switching action of the SCR circuitry. The rotor diameter is 6 inches and active iron length is 2.5". Overall dimensions of the generator are: dlameter 9.75" and length 7.75". The electronics associated with the system can be arranged compactly.

\section{PERFORMANCE RESULTS}

The efficiency of the generator for three values of stator tuning capacitors is shown in Flgure 2, plotted against output power. It is sedn that the efficiency stays nearly constant frow half the rated outpit onwards. The main factor in the decrease of efficiency with no stator tuning is the added field input power required. Figure 3 shows the rotor input power for the three values of $C$. With $C=0$, the trigger signal will not have the proper phase relationship to the rotor input current and this will result in serlous corruption of the output waveform at high outputs. Stator tuning capacitors significantly improve the performance of the system.

The desirability of rotor tuning is brought out in Figure 4 in the plots of field winding current and the current requiren to bo oupjlied by the Field excitation source. Rotor tuning reduces the volt ampere capacity required of the excitation source.

One of the many interesting features of the fleld modulated frequenoy down cunverter is the variation of the rotor winding reactance (at the frequency $f_{f}$ ) with the value of the stator tuning capacitors and with the output power. This is illustrated in Figure 5 . Consider the case $C=0$. As the output power is increased, stator current increases also and armature reaction decreases the air gap flux per ampere of field winding current. This is the same as saying that the effective inductance (reactance) of the rotor winding decreases as the output power is increased. With stator tuning, the leading currents drawn by the capacitors result in self excitation and an increase in the air-gap flux per ancere of field winding current. This results in an increase in the effective rotor inductance (reactance). The effect of armature reaction in decredsing the effective inductance as the output is increased is similar in all cases.

The voltage regulation of the frequency down converter is improved by the variation of the effective rotor reactance with output power. If the voltage $V_{R}$ acruss the rotor terminals $R_{1}$ and $R_{R}$ is held conetant, the rleld winding current increases as the output power increases. This change is in the proper direction and consequently the system has a builtin "self regulating" property. Figure 6 shows the variation of the output voltage from rated output rated voltage conditions as the output power is decreased. It can be seen that with $C$. $5 u \Gamma$, the output voltage stays essentially constant down to about 40 percent of rated load. Smaller values of $C$ do not result in this desirable characteristic. It is possible to exploit this property by properly choosing $C$ to obtain nearly constant output voltage from low load to full load conditions.

The basle $h$ lgh-frequency ( $f_{n}$ ) voltage waveform generated by the machine is shown in Figure 7 for 
d.c. excitation. Since the switching action of the parallel bridge arrangement will form a nearly square wave of voltage across each generatur phase, the non-sinusoidal nature of this waveform should not be of serious concern. With field modulation and $C=0$, the voltage across one phase is shown in Figure 8 . This has the character of a double side band suppressed carrier (DSB) signal. With $C=5 \mu \mathrm{F}$ and zero output power, some of the harmonics in the voltage waveform are partially tuned which results in the waveform shown in Figure 9. However, under loaded conditions, the parallel bridge arrangement results in the formation of a square wave voltage across each phase as shown in Figures $10 a, b$, and $c$ for $c=0$, $C=2.5 \mu \mathrm{F}$ and $C=5 \mu \mathrm{F}$.

A full pitch search coil in the stator was used to observe the air-gap flux density waveform. Figures $11 \mathrm{a}$ and $\mathrm{b}$ show the voltage across the search coil under no-load conditions for $C=0$ and $c=5 \mu \mathrm{F}$. While there is a correlation between oscillograms of Figure 8 and Figure lla, the presence of capacitor currents in the stator windings and the resulting stator impedance drops is manifested in the difference between the waveforms of Figure 9 and Figure llb. Oscillograms of the airgap flux density waveform under rated load conditions with $C=5 \mu \mathrm{F}$ is shown in Figure 12. This should be compared with Figure $10 \mathrm{c}$ to observe the effect of stator impedance and diode switching leading to the formation of the square wave voltage waveform. Figure 13 shows the oscillogram of the field winding current at rated output and $c=5 \mu \mathrm{F}$. Th feedback into the rotor is minimal. The waveform if the low frequency output voltage with $C=5 \mu l$ ander no-load and full load conditions are shown in Figures $14 \mathrm{a}$ and $\mathrm{b}$. In spite of the higli.f distorted voltage waveform across one phase $\mathbf{s}$. IWn in Figure 9, the tuned circuit across the cutput results in the sinusoidal waveform of Figure 14a under no-load conditions. The output voltage waveform on load is observed to be a good sinusoid for most of the practical purposes.

\section{APPLICATIONS}

The generating system described in this paper has several advantages and potential applications. since the output frenuency is independent of the prime-mover speed, variable speed prime-movers such - the ones available in aircrafts or unregulated nigh-speed turbines and wind energy devices can be usec o drive the generator. The system is physically wuch smaller than conventional units of similar capabilities and as such is ideally suited for mobile applications, especially when it is married to a high-speed turbine to form an integral unit. The output frequency can be varied in steps or slowly over a range of values to make it a useful power source for variable speed drives and ground transportation.

\section{CONCLUDING REMARKS}

The field modulated generator system (FMGS) described in this paper has several interesting and useful features. In addition to being smaller in size and weight, it has inherently better regulation and independence from rotor inertia effects. The principle of operation appears to be applicable to systems of any size. The efficiency of the system is similar to those of conventional systems of equivalent rating. Whereas a conventional synchronous machine operating in parallel with bus bars can receive or deliver power (motor or generate) to the supply, FMGS can operate only as a generator because the bridge rectifiers will prevent any power flow from the bus bars to the generator. The behavior of the FMGS operating in parallel with an existing power system under normal and fault conditions is yet to be completely explored. The results obtained from the prototype are promising and further development, testing and design optimization are underway.

\section{WIFERENCES}

1) Allison, H. J., R. Ramakumar and W. L. Hughes, "Field Modulated Down Frequency Converter Analysis - Design - Performance", Proceedings of the Frontiers of Power Technology Conference, Stillwater, Oklahoma, September 30, 1971; pp. 3-1 to $3-18$.

2) Hughes, W. L., H. J. Allison and R. Ramakumar, "Field Modulated Alternator System and Control Therefor", U. S. Patent Application.

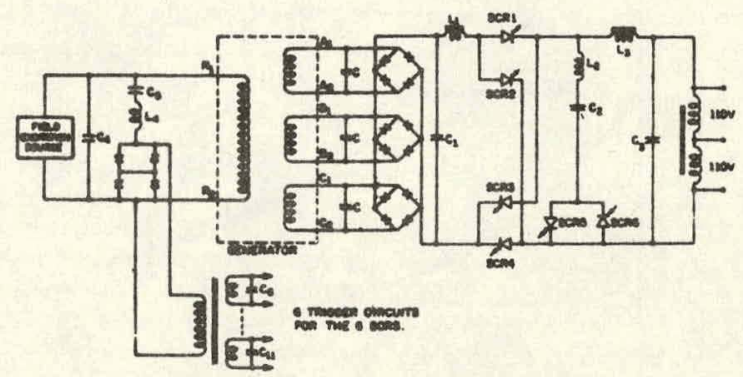

Fig. 1. Schematic of the frequency down converter system.

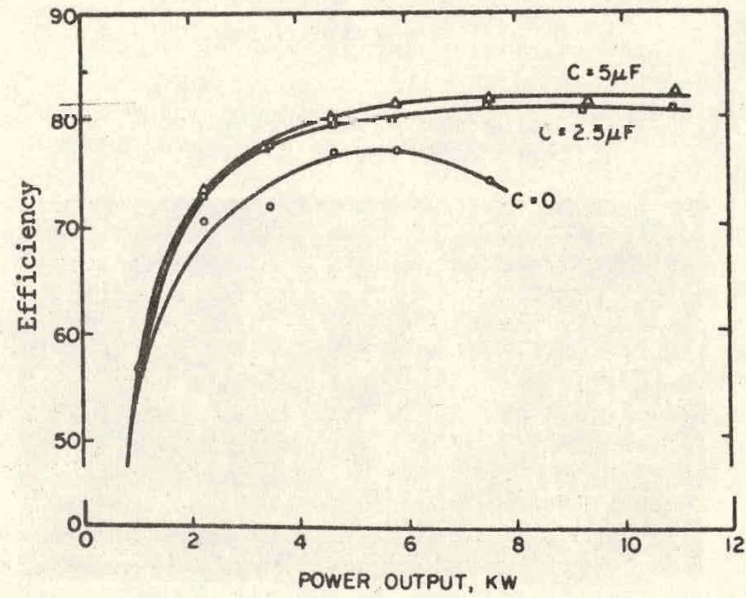

Fig. 2. Efficiency versus output characteristic. 


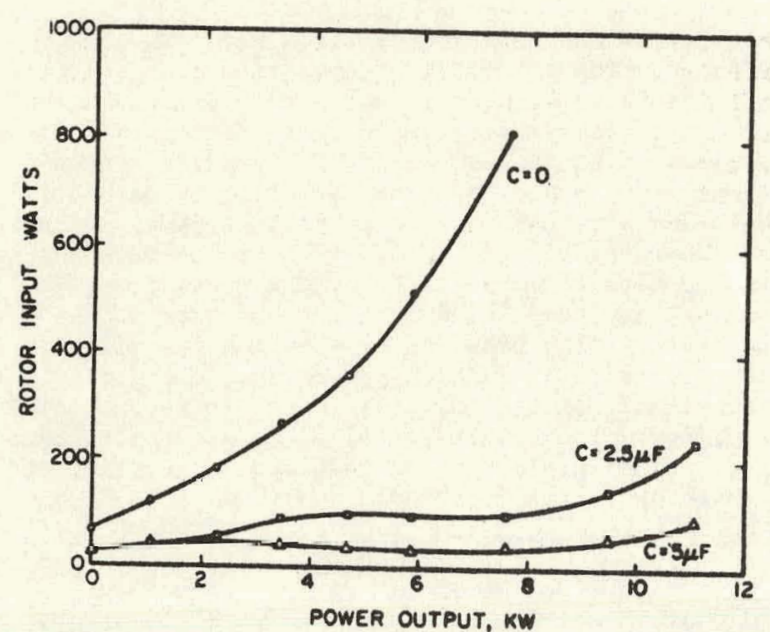

Fig. 3. Variation of the rotor input power with output.

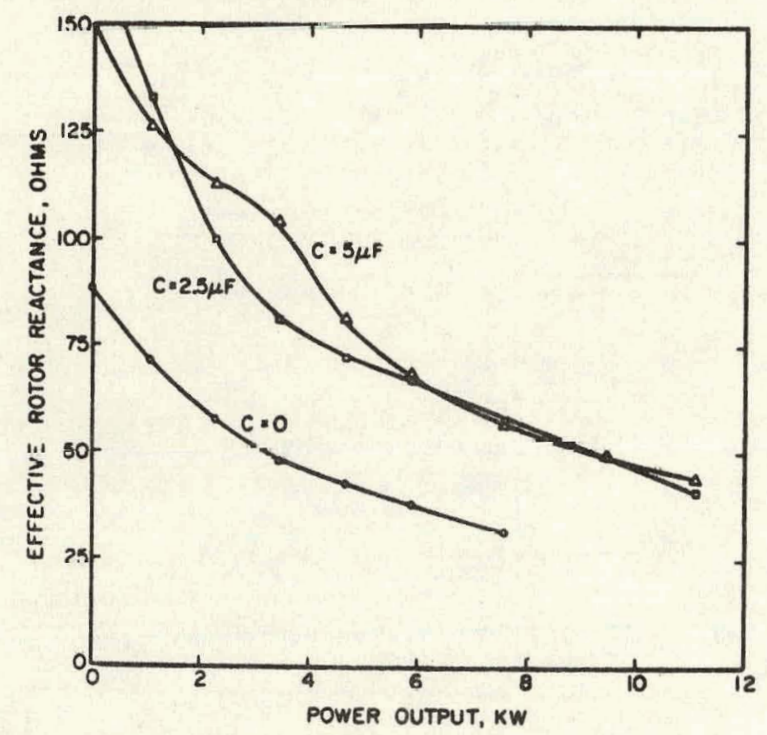

Fig. 5. Plot of rotor winding reactance for difference values of $c$ and nutput.

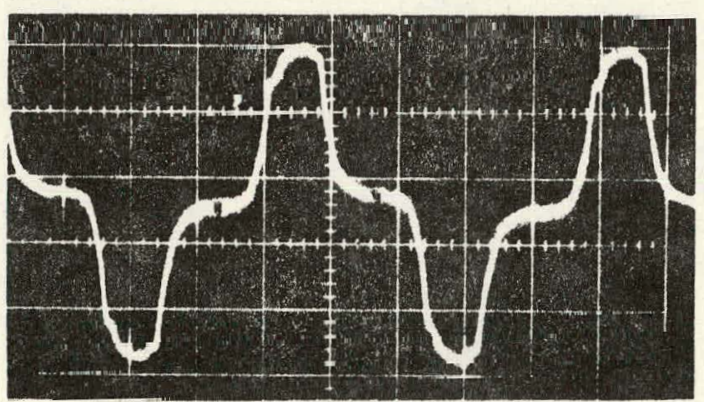

Fig. 7. High-frequency voltage waveform for d.c. excitation.

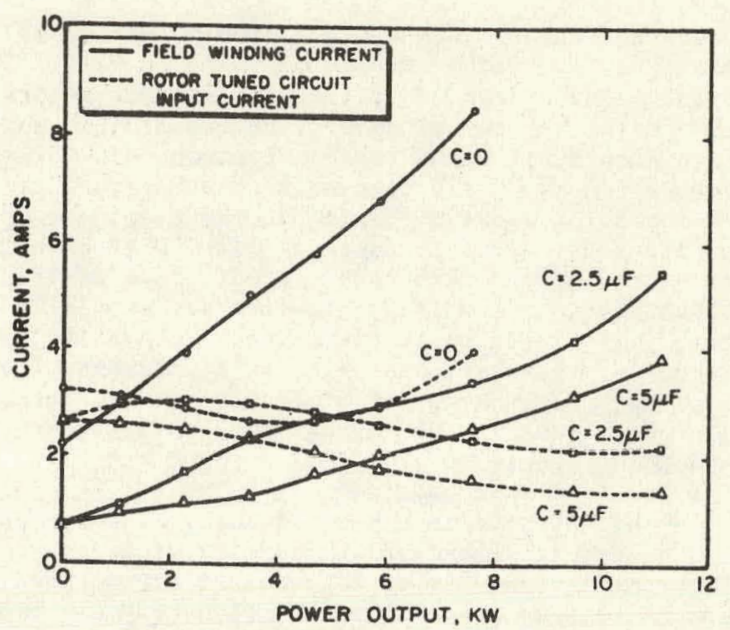

Fig. 4. Variation of field winding and rotor circuit input currents with sutput.

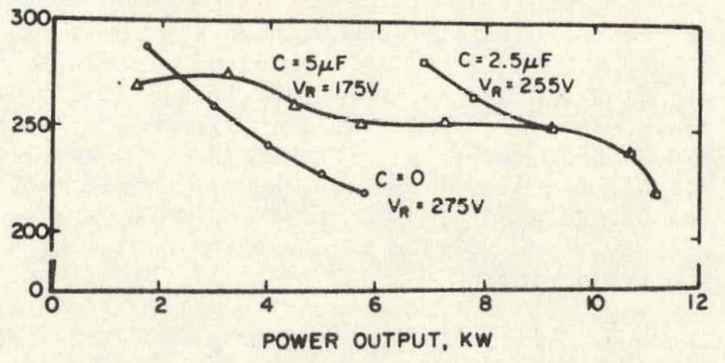

Sig. 6. Voltage regulation characteristics.

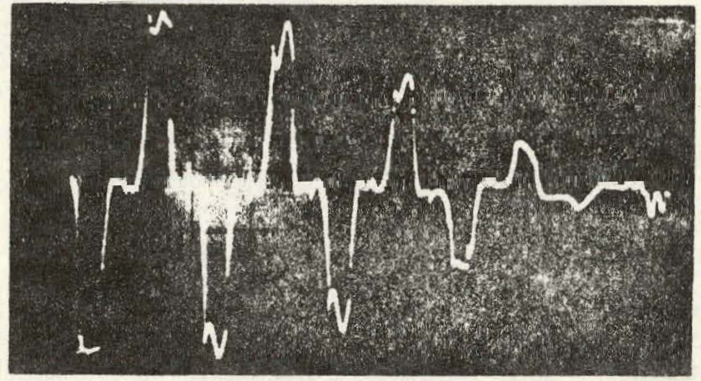

Fig. 0. Nu-luad phase voltage waveform with field modulintinu, $c 0$.

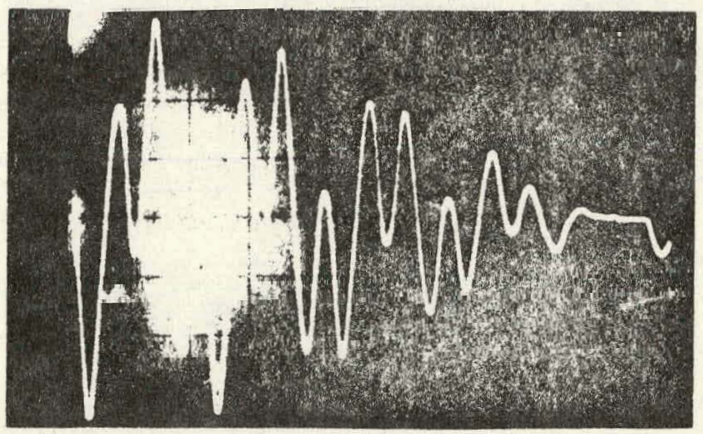

Fig. 9. No-load phase voltage waveform with field modulation; $C=5 \mu \mathrm{F}$. 

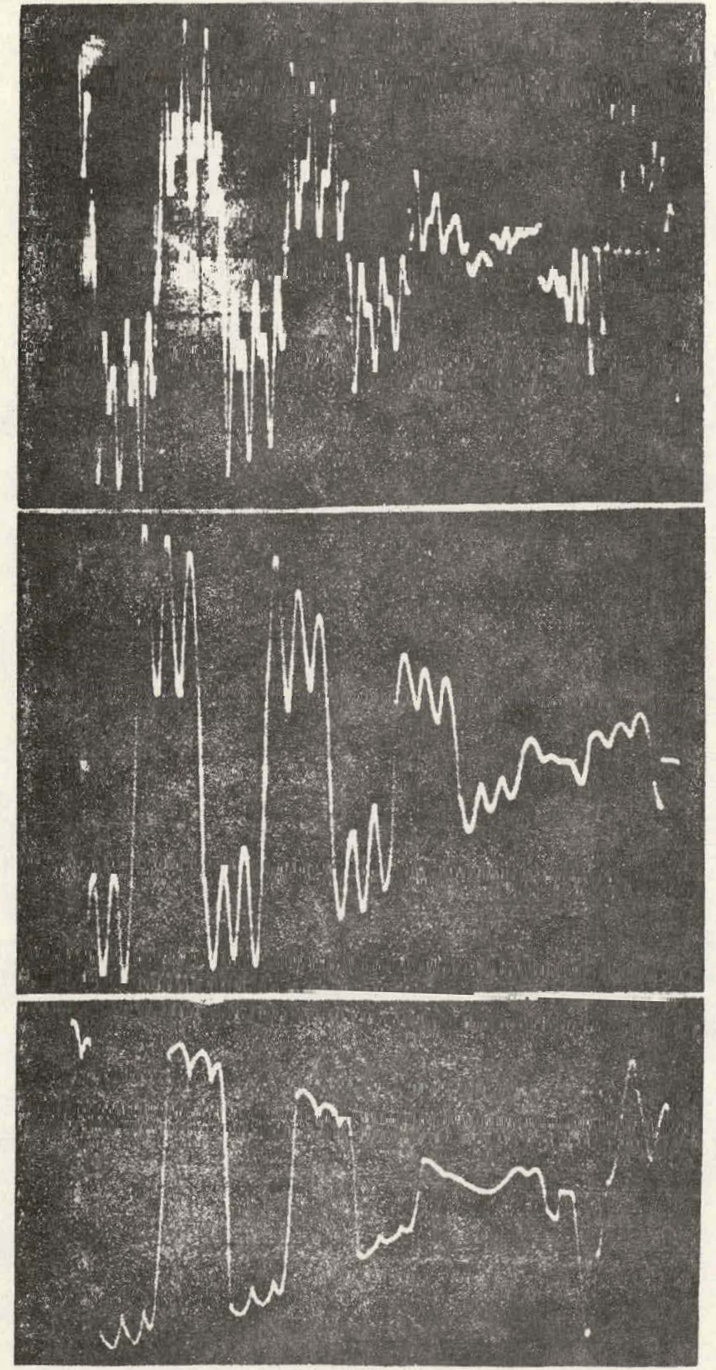

Fig. $10 a, b$ and $c$. Phase voltage on load for $C=0,2.5$ and $5 \mu \mathrm{F}$.

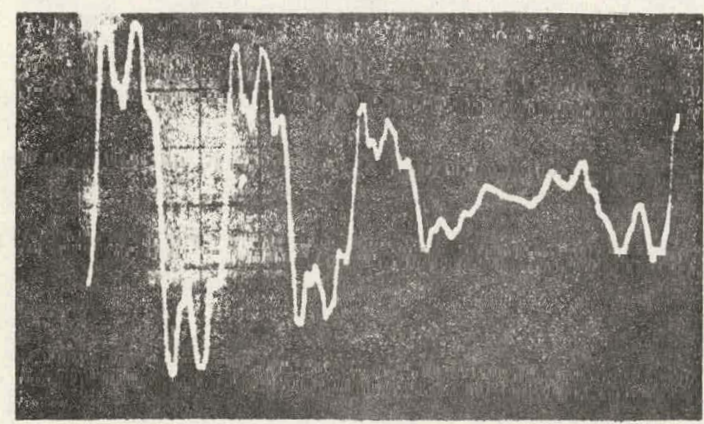

Fig. 12. Search coil voltage under full load conditions; $C=5 \mu \mathrm{F}$.
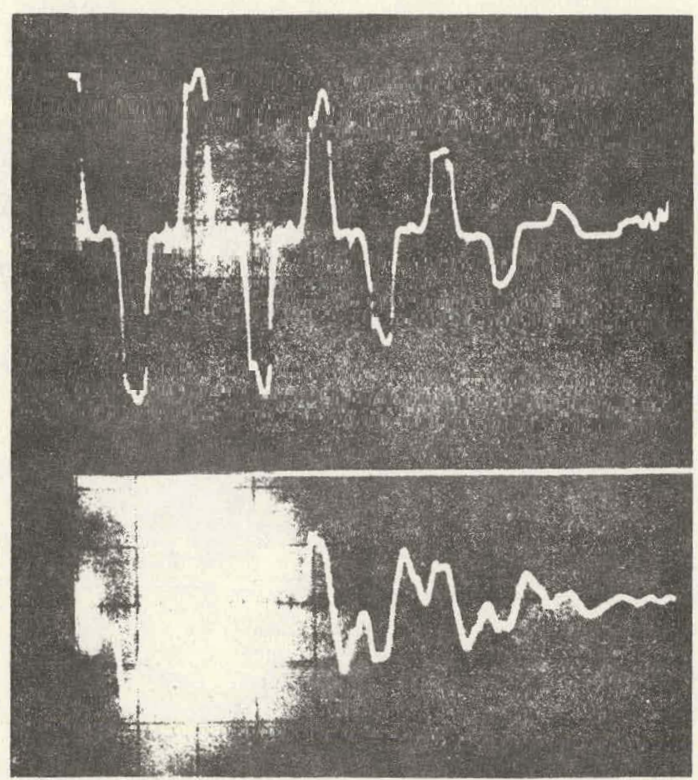

Fig. 11 a and b. Oscillogram of search coil voltage under no-load conditions for $\mathrm{C}=0$ and $5 \mu \mathrm{F}$.

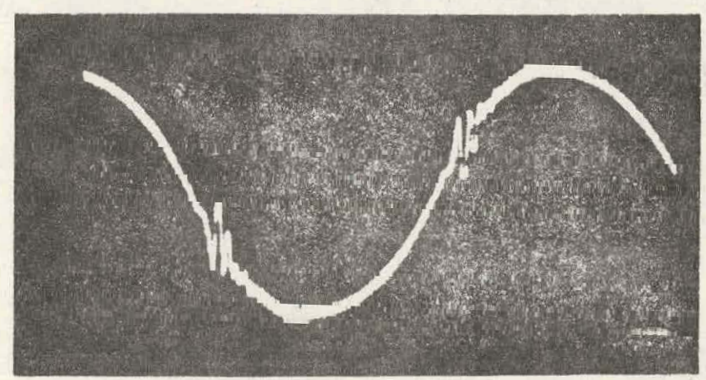

Fig. 13. Oscillogram of the field winding current at rated output and $C=5 \mu \mathrm{F}$.
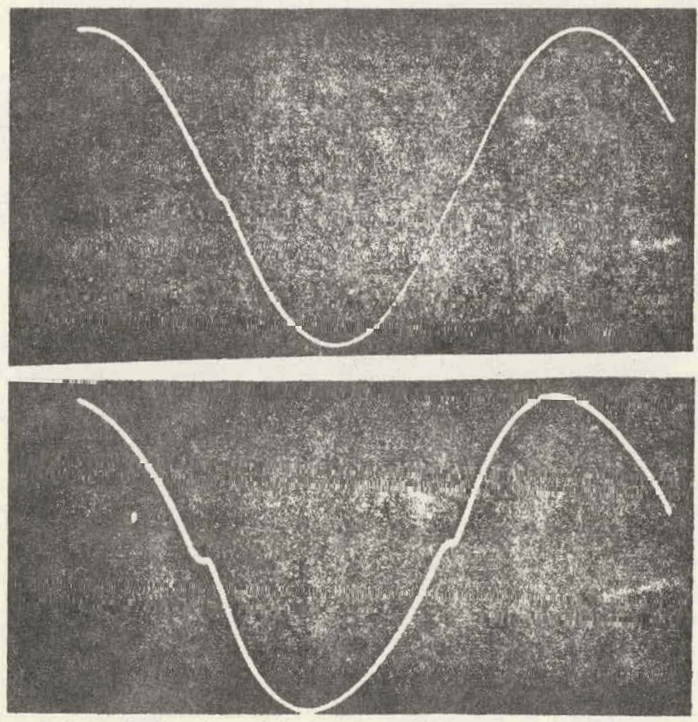

Fig. 14. Output voltage waveform

a) No-load b) Fuil load $(C=5 \mu \mathrm{F})$. 


\section{APPENDIX-B}

Performance of the Three-Phase $60 \mathrm{~kW}$ FMGS Experimenta1 Prototype 
A SELF-EXCITED FIELD MODULATED THREE-PHASE POWER SYSTEM

R. Ramakumar
Member, IEEE
H. J. Allison

Member, IEEE
W. L. Hughes

Fellow, IEEE

\section{School of Electrical Engineering \\ Oklahoma State University \\ Stlliwater, Oklahoma 74074}

\section{ABSTRACT}

Variable-speed constant-frequency generators can be developed using the principle of field modulation and solid-state output processing. This paper describes a three-phase $60 \mathrm{~kW}$ self-excited field modulated generator system prototype designed, fabricated and successfully tested at Oklahoma State University. Some of the experimentally obtained performance results are presented and discussed. Voltage control, frequency control and application aspects of such systems are also considered.

\section{INTRODUCTION}

Power generation at a constant frequency, independent of the shaft speed of the alternator, has intrigued miany researchers over the years. Previous attempts to develop such a generation system include the application of the synchronous flux principlel, solid state frequency changers ${ }^{2}$, cycloconverters ${ }^{3}$ and the use of specially designed exciter heads ${ }^{4}$. Each of these techniques has shortcomings of one form or other. Some of the systems are complex, expensive and unreliable. others have an overall efficiency which is too low to be useful for large-scale exploitation.

The application of the field modulated frequency down conversion principle 5 provides an alternative solution to this problem. This technique results in a viable system for obtaining a desired constant (or adjustable) frequency output independent of the primemover speed.

After a brief discussion of the principle of field modulated frequency conversion, this paper presents a self-excited three-phase system configuration and discusses its control aspects and application possibilities. The $60 \mathrm{~kW}$ three-phase prototype built and tested is described and some of the experimentally obtained performance characteristics are documented.

\section{Flela Modulated Frequency Conversion 6}

A field modulated generator system essentially employs a three-phase high-frequency alternator to generate single-phase power at the required low frequency. The system uses an electromagnetic modulator in the form of exciting the rotating field coil with alternating current at the desired low-frequency instead of the conventional direct current. A parallelbridge rectifier system connected across the machine stator terminals results in an output which consists of a sinail dc component, a full-wave rectified sine wave

\section{CONFERENCE PAPER}

C 74 318-2. A paper recommended by the IrEeE Rotating Machinery Comittee of the IEEE Power Engineering Society for presentation at the IFEE PES Summer Meeting 6 Energy Resounces Conf., Anaheim, Cal., July 14-19, 1974. Manuscript submitted August 28, 1973; made available for printing April 4, 1974.

Prioe: Menibers \$1.50

Normembers $\$ 2.00$

At Meeting: $\$ 1,00$ at the frequency of modulation and a small ripple at six times the basic machine frequency. If the ratio of the basic electrical rotational frequency to the modulation frequency is greater than ten, the dc component becomes negligibly small. The required low frequency output is obtained from the parallel-bridge rectifier output by using a four thyristor switching circuit followed by a suitable filtering arrangement. The voltage at the input to the thyristor switching circuit is essentially a full wave rectified sinusoid at the required low frequency. The thyristors switch at the approximately zero voltage points of this waveform to produce the desired output. This switching technique represents a significant advantage over the switching requirements of conventional cycloconverter and inverter circuits which must have the capability of switching thyristors at high voltage and power levels.

\section{Single-Phase System 7}

A simplified single-phase schematic of the frequency down conversion system is shown in figure 1. It combines a high-speed high-reactance high-frequency three-phase alternator and suitable electronic switching and output processing elements. The rotor of the alternator is laminated to handle ac excitation and the rotor winding leads are brought out through a conventional slip-ring arrangement. It is possible to eliminate the slip rings by introducing an additional air-gap as in the case of certain types of eddycurrent couplings. Both wound rotor and salient-pole configurations are suitable for field modulated power generation.

A parallel-bridge rectifier system consisting of three full-wave bridges, one across each of the three stator windings, with their outputs tied in parallel is used at the machine terminals. The output of this rectifier system is fed to the main switching circuit formed by the four thyristors SCRI through SCR4. The commutating circuit consisting of SCR5, SCR6, $L_{2}$ and $C_{2}$ aid in turning off two of the four thyristors at the end of each half cycle of the output. Filtering of the output is performed by the tuned circuit consisting of the filter capacitor $C_{3}$ and the output autotrans former.

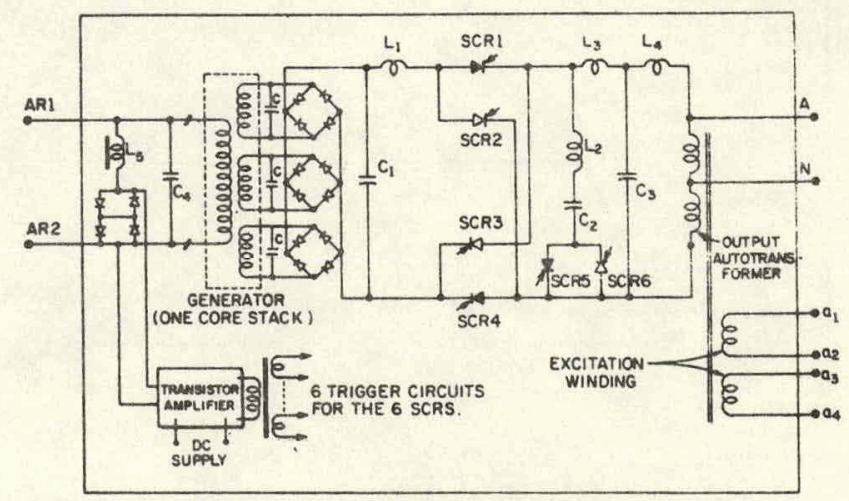

Fig. 1. Simplified Single-Phase Schematic of the Field Modulated Frequency Converter. 
The field excitation voltage is applied across the terminals AR1, AR2. This voltage must lead the output voltage by $\pi / 2$ because of the inductive nature of the rotor winding. In the three-phase version, the excitation voltages are obtained by connecting a lowpower frequency control inverter in series with voltages fed back from the output via the excitation windings wound on the same core as the output autotransformers. This is explained further in later section.

At the start of a low frequency cycle, SCRI, SCR4 and SCR5 are triggered. After a time lapse equal to one-half period corresponding to the modulation frequency, SCR2, SCR3, and SCR6 are triggered together and Simultaneously SCR1, SCR4 and SCR5 are shut off by the commutating circuit. The triggering instances correspond to the current zeros of the rotor winding current and are sensed by the circuit consisting of the inductor $L_{5}$ in series with a back-to-back diode combination. These instances also correspond to the zero voitage points of the parallel-bridge rectitier output.

The three statop tuniny capacitors C connected across the stator windings help to decrease the excitation watts and vars required at the rotor terminals. Capacitor $C_{4}$ partially tunes the field circuit and cunsiderably decreases the voltamperes required of the excitation source.

\section{Three-Phase Configuration ${ }^{8}$}

Generation of three-phase power requires three separate core stacks (magnetic circuits) on a single shaft, each one modulated separately while maintaining the proper phase difference between the corresponding single-phase outputs. The electronics associated with each phase is identical to the single-phase system discussed earlier. The excitation source will now be either a dc to three-phase inverter with proper voltage controls or the system could be self excited as discussed in the following section.

This technique can be extended to multiphase (including two-phase) systems in the same way.

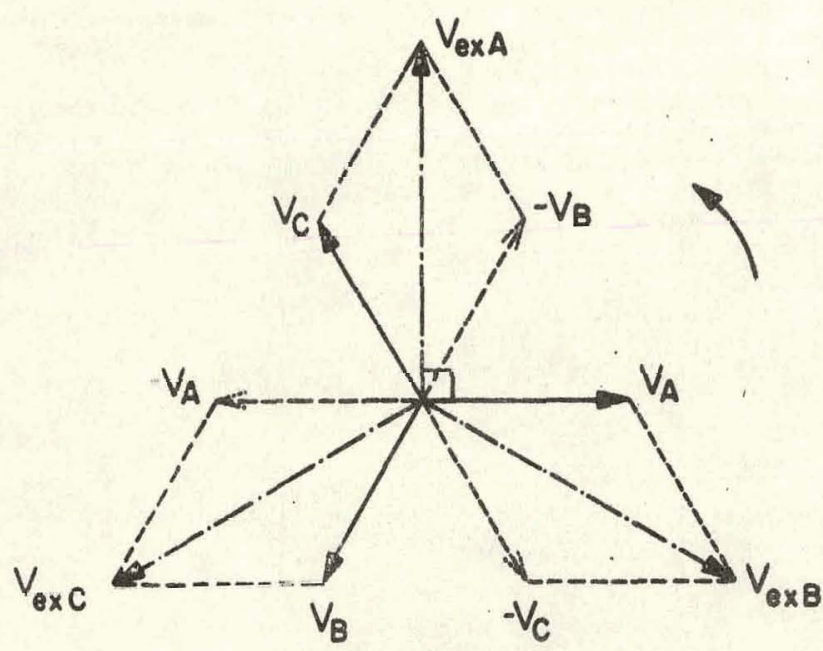

Fig. 2. Vector Diagram of Three-Phase Voltages.

\section{Excitation System}

As suggested previously, thyristor switching in the output of each phase of the field modulated power system occurs at the current zeros of the corresponding rotor current. The highly inductive character of the rotor winding requires that the excitation voltage applied to the rotor must lead the output voltage of that phase of the system by $\pi / 2$. The excitation required for a three phase field modulated system is, therefore, a set of three-phase voltages in quadrature with the output phase-voltages of the system. It is apparent that the required excitation for such a system can be derived from the output of the system by suitably adding voltages in-phase and in phase-opposition to the output phase-voltages. This unique characteristic of a three-phase field modulated power system makes it possible for such a system to be partially self-exciting as described in the following paragraph.

As shown in Figure 2, $V_{\text {exA }}$ is the excitation voltage for phase $A_{2}$ and it leads $V_{A}$ by $30^{\circ}$. $V_{\text {exA }}$ is obtained by adding $V_{C}$ and $\left(-V_{B}\right)$. Similarly, $V_{e x B}$ is obtained by adding $V_{A}$ and $\left(-V_{C}\right)$, and $V_{\text {exC }}$ is ohtained by adding $V_{B}$ to $\left(-V_{A}\right)$. The excitation windings on the output autotransformers enable one to obtain the three excitation voltages as shown in Figure 3. The voltage build up phenomenon is initiated by a low power inverter, inductively coupled into the feedback loop. The inverter also fixes the output frequency, in much the same manner as a "tickler" coil fixes the frequency of an electronic oscillator. Voltage control for the system is achieved by adjusting the amount of feedback through the feedback control variac.

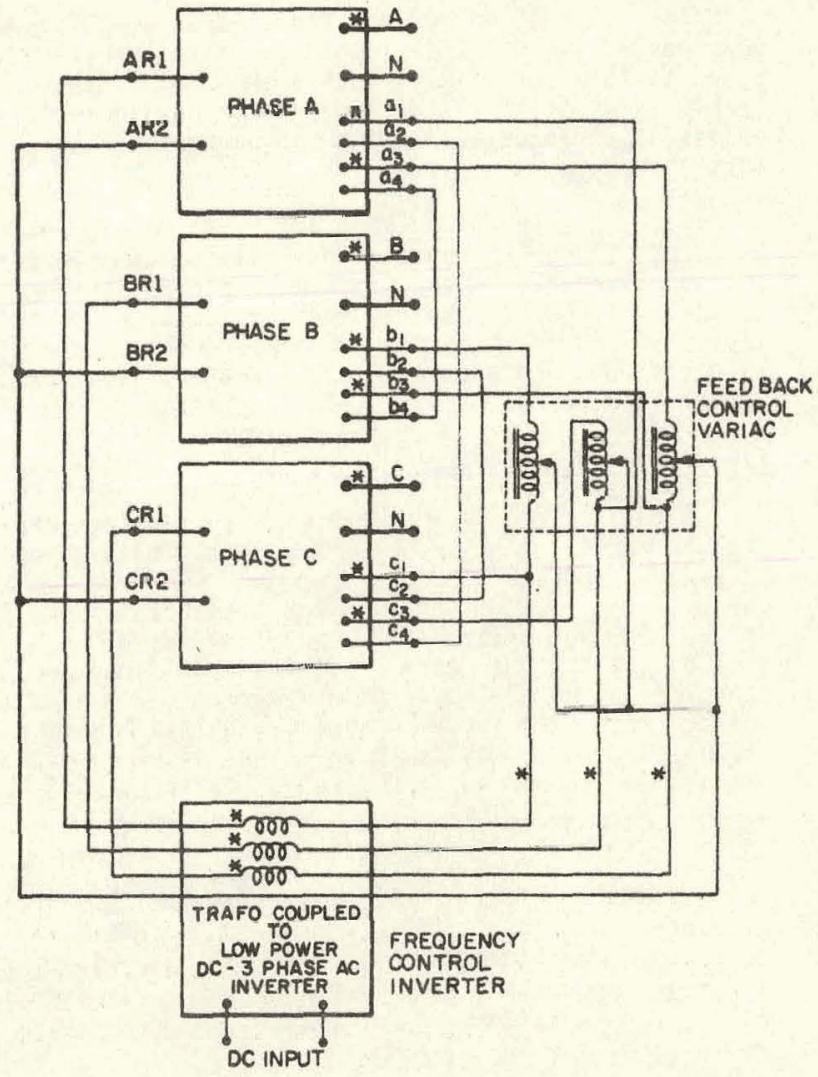

Fig. 3. Three-Phase Self Excitation Scheme. 


\section{Overall System Layout}

Figure 4 shows the overall three-phase system layout. Three core stacks and four slip rings are mounted on a single shaft, coupled to a high speed prime-mover. More than 90 percent of the excitation voltamperes are derived from the output and the remaining small fraction is supplied by the frequency control inverter. The voltage regulator is essentially a servo controlled three-phase autotransformer variac, responding to the error signal derived by comparing the output voltage with a fixed reference voltage.

If there is a large unbalance in the three-phase load, it is not possible to maintain the raced outpul voltage on all three phases simultaneously using a ganged three-phase variac. This problem can be overcome by using three separate single-phase servo-controlled variacs, each one maintaining the voltage of a particular phase at the desired value.

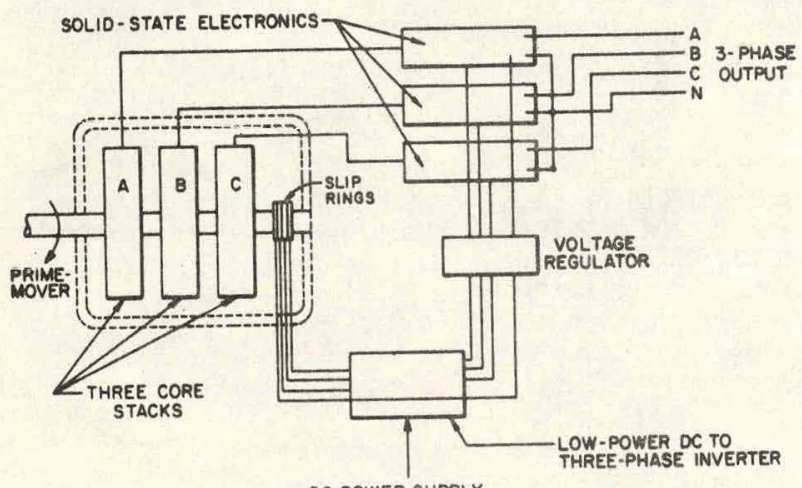

DC POWER SUPPLY

Fig. 4. Layout of the Three-Phase System.

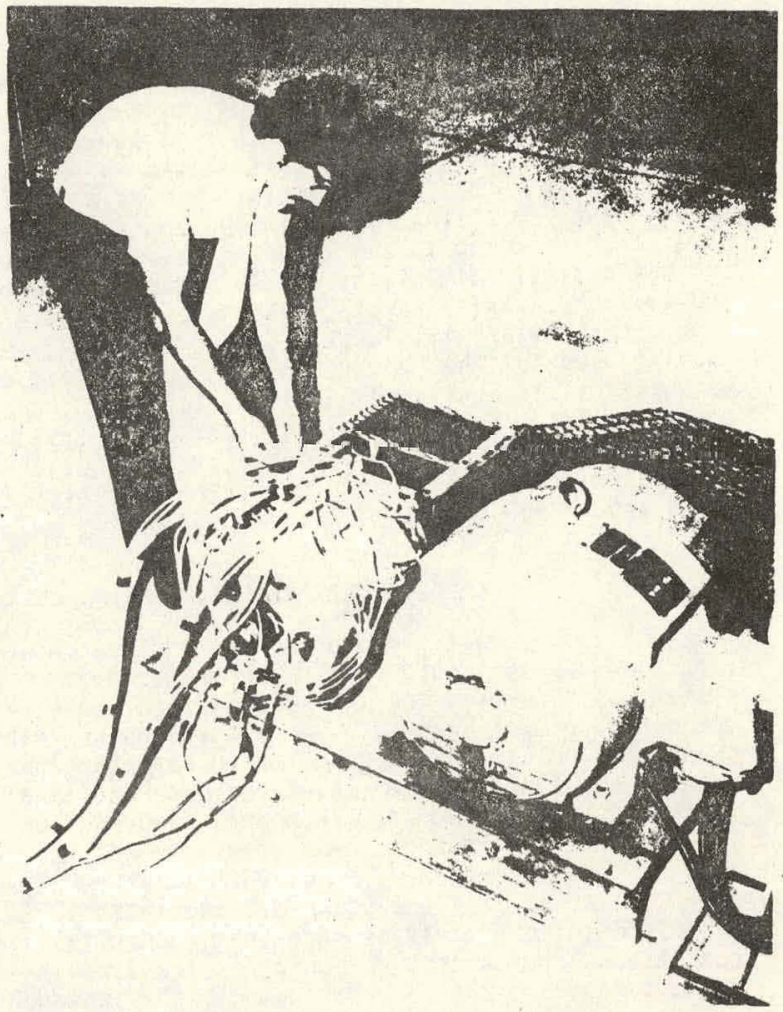

Fig. 5. Photograph of the Generator Belt Driven by an Induction Motor.

\section{DESCRIPTION OF THE $60 \mathrm{~kW}$ PROTOTYPE}

Figures 5 and 6 are photographs of the $60 \mathrm{~kW}$ three-phase field modulated generator prototype and the electronics breadboard designed, fabricated and tested at 0klahoma State University. The system is rated at $60 \mathrm{~kW}$, three-phase $120 / 208$ volts, $50 / 60 \mathrm{~Hz}$, 167 amperes per phase. The machine itseif is an 8pole $400 \mathrm{~Hz}$ three-phase alternator, running at 6000 $\mathrm{r} / \mathrm{min}$. The lower frequency output is obtained by the field modulation technique. The experimental prototype system is belt driven by a $150 \mathrm{hp}$ induction motor at approximately $6000 \mathrm{r} / \mathrm{min}$.

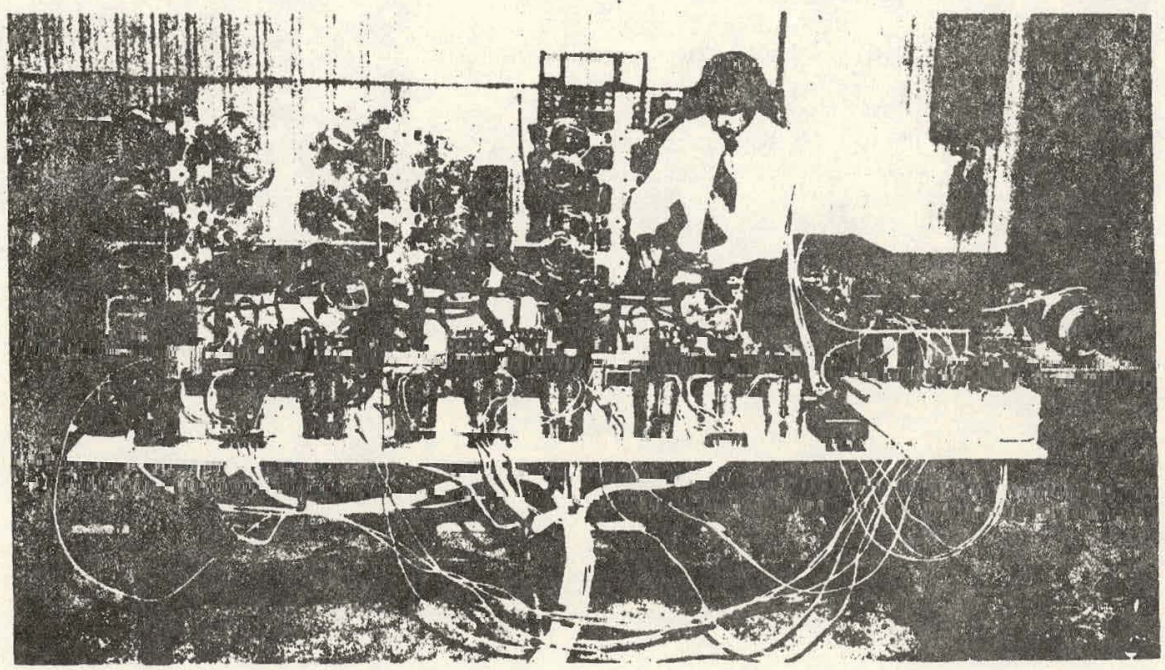

Fig. 6. Photograph of the Solid-State Controller Bread Board. 
The stator and rotor cores are fabricated from $14 \mathrm{mils}$ non-oriented silicon steel laminations. The stator laminations have 12.15 inches outer diameter and 8.9 inches inner diameter. The rotor has salient poles and a sinusoidal afrgap with a minimum value of $25 \mathrm{mils}$. Each of the three core stacks has an axial length of 1.5 inches. The stator houses a 54 slot three-phase fractional-slot winding and the salientpole rotor is wound in the standard way. The generator has overall dimensions of 13.5 inches diameter and 18 inches axial length. The size of the electronic controller will largely depend on the type of cooling used for the power handling solid-state components. It is estimated that the electronics can be compacted into a box of size 2 feet by 5 feet by 1 foot, with forced air cooling. The total weight of the system (excluding the prime-mover) is estimated to be around 900 pounds.

\section{PERFORMANCE RESULTS}

The experimental prototype was tested using a lamp bank as the load (unity power factor). The system was operated in the self-excited mode, with frequency control provided by a three-phase variac supplfed from utility mains. The $60 \mathrm{~Hz}$ output phasevoltage and line-voltage waveforms under no-load and fill-load condiliuns are shown in Figures 7 and 8 . The harmionic content of these waveforms was measured using a Hewlett-Packard Model 302A Wave Analyzer. The results of this anaiys is are tabulated in Table I. From this data it is seen that under full-load conditions the largest harmonic in the line-to-line voltage is less than one percent of the fundamental and that the deviation of the rms line-voltage from the rms value of the corresponding fundamental is within one-half percent.

The voltamperes supplied by the frequency control inverter (or its counterpart) and the total voltamperes required by the rotor circui?, are tabulated in Table II. It is seen that the rnntrol in verter is required to supply only a small fraction and that the self-excitation process provides the bulk of the excitation voltamperes required.

The system was specially designed to operate over a small speed range (around $6000 \mathrm{r} / \mathrm{min}$ ) such as the one encountered with unregulated turbines. However, basically the output frequency is independent of the shaft speed of the generator. To illustrate this point, the generator was driven at a considerably different speed range with a significant droop. The results are tabulated in Table III and the waveforms are shown in Figures 9 and 10 . An examination of these waveforms shows that the harmonic content at the higher speed range is similar to that obtained at the lower speed of operation, thus demonstrating the basic characteristic of the machine to operate at a constant output frequency essentially independent of speed.

Figure 11 shows the variation of the feed-hack. portion af the rotor applied voltage (refer Table II) with the power output per phase. This relationship is very nearly linear and is amenable to a fairly simple control scheme.
The overall efficiency of the test set up, ratio of $60 \mathrm{~Hz}$ power output to the motor input power, under full load conditions was measured to be 77 percent. With an estimated efficiency of 85 percent for the induction motor and the belt drive, the efficiency of the generator system is slightly above 90 percent. This value is very comparable to the efficiencies of more conventional systems having similar ratings.

a.

b.

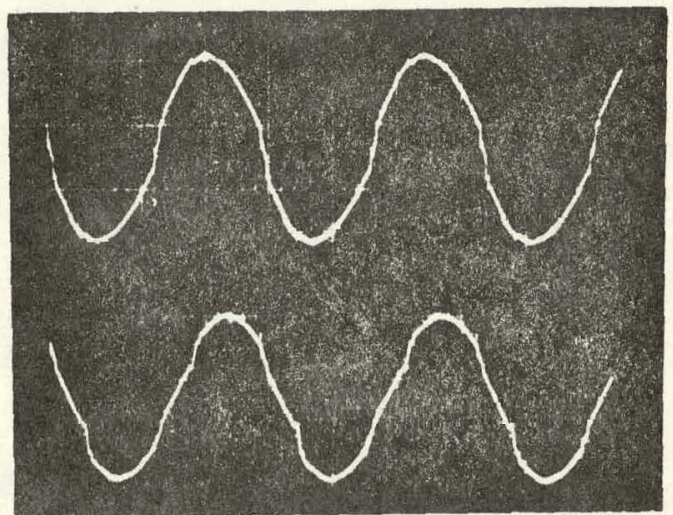

Fig. 7. No-Load Waveforms.

a. Line-Neutral Voltage; $100 \mathrm{~V} / \mathrm{cm}$. $5 \mathrm{~ms} / \mathrm{cm}$.

b. Line-Line Voltage; $200 \mathrm{~V} / \mathrm{cm}, 5 \mathrm{~ms} / \mathrm{cm}$.

a.

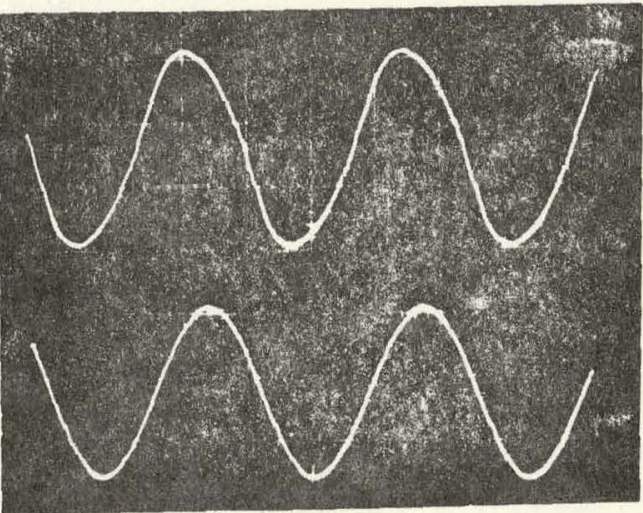

Fig. 8. Full-1 nad Waveforms

a. Line-Neutral Voltage; $100 \mathrm{~V} / \mathrm{cm}$., $5 \mathrm{~ms} / \mathrm{cm}$.

b. Line-Line Voltage; $200 \mathrm{~V} / \mathrm{cm} ., 5 \mathrm{~ms} / \mathrm{cm}$. 
TABLE I

Harmonic Content of the Output Voltage Waveforms

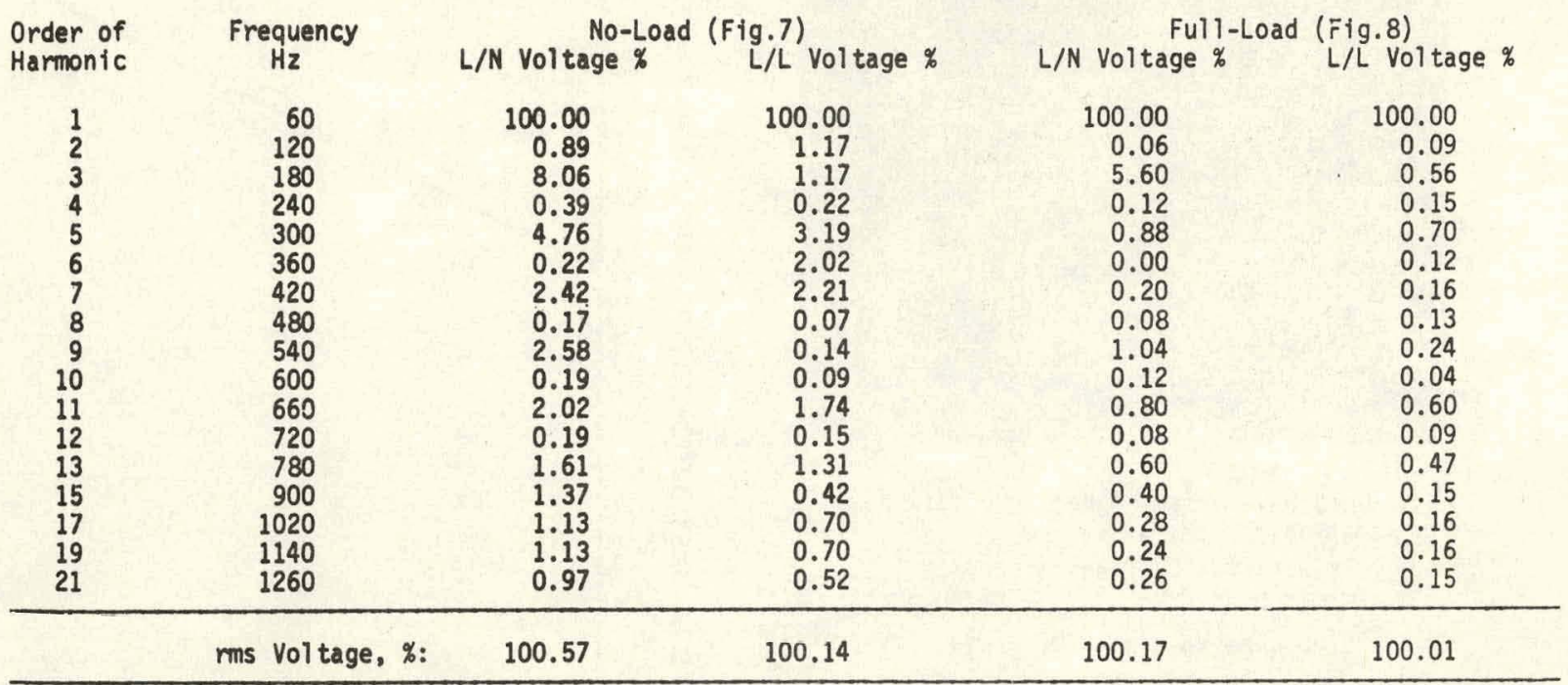

TABLE II

Excitation Parameters for Different Outputs $60 \mathrm{~Hz}$ Output Voltage $=120 \mathrm{v} /$ phase; Maintained Constant

\begin{tabular}{|c|c|c|c|c|c|c|c|}
\hline $\begin{array}{l}\text { Total } \\
\text { Power } \\
\text { Output, } \\
\text { KW }\end{array}$ & $\begin{array}{c}\text { Power } \\
\text { Output, } \\
\text { KW } \\
\text { Per-Phase }\end{array}$ & $\begin{array}{l}\text { Frequency } \\
\text { Control } \\
\text { Inverter } \\
\text { Voltage } \\
\text { Per-Phase } \\
\end{array}$ & $\begin{array}{c}\text { Rotor } \\
\text { Applied } \\
\text { Voltage } \\
\text { Per-Phase }\end{array}$ & $\begin{array}{l}\text { Rotor } \\
\text { C.ircuit } \\
\text { Input } \\
\text { Current } \\
\text { Per-Phase } \\
\end{array}$ & $\begin{array}{l}\text { VA } \\
\text { Supplied } \\
\text { by Control } \\
\text { Inverter } \\
\text { Per-Phase }\end{array}$ & $\begin{array}{l}\text { Total VA } \\
\text { required by } \\
\text { the rotor } \\
\text { Per-Phase }\end{array}$ & $\begin{array}{c}\text { Generator } \\
r / \mathrm{min} \text {. }\end{array}$ \\
\hline $\begin{array}{r}0.00 \\
25.20 \\
33.48 \\
42.12 \\
52.20 \\
60.00\end{array}$ & $\begin{array}{r}0.00 \\
8.40 \\
11.16 \\
14.04 \\
17.40 \\
20.00\end{array}$ & $\begin{array}{l}20 \\
20 \\
20 \\
20 \\
20 \\
20\end{array}$ & $\begin{array}{l}194 \\
230 \\
245 \\
262 \\
274 \\
292\end{array}$ & $\begin{array}{l}6.9 \\
3.2 \\
2.4 \\
2.6 \\
3.9 \\
5.6\end{array}$ & $\begin{array}{r}138 \\
64 \\
48 \\
52 \\
78 \\
120\end{array}$ & $\begin{array}{r}1339 \\
736 \\
589 \\
681 \\
1069 \\
1633\end{array}$ & $\begin{array}{l}6100 \\
6060 \\
6055 \\
6050 \\
6045 \\
6020\end{array}$ \\
\hline
\end{tabular}

TABLE III

Excitation Parameters for Different Outputs (Higher Speed Operation) $60 \mathrm{~Hz}$ Output Voltage $=120 \mathrm{v} /$ phase; Maintained Constant

\begin{tabular}{|c|c|c|c|c|c|c|c|}
\hline $\begin{array}{l}\text { Total } \\
\text { Power } \\
\text { Output, } \\
\text { KW }\end{array}$ & $\begin{array}{c}\text { Power } \\
\text { Output } \\
\text { KW } \\
\text { Per-Phase }\end{array}$ & $\begin{array}{l}\text { Frequency } \\
\text { Control } \\
\text { Inverter } \\
\text { Voltage } \\
\text { Per-Phase }\end{array}$ & $\begin{array}{c}\text { Rotor } \\
\text { Appl ied } \\
\text { Voltage } \\
\text { Per-Phase }\end{array}$ & $\begin{array}{l}\text { Rctor } \\
\text { Circuit } \\
\text { Input } \\
\text { Current } \\
\text { Per-Phase }\end{array}$ & $\begin{array}{c}\text { A } \\
\text { Supplied } \\
\text { by Control } \\
\text { Inverter } \\
\text { Per-Phase }\end{array}$ & $\begin{array}{l}\text { Total VA } \\
\text { required by } \\
\text { the rotor } \\
\text { Per-Phase }\end{array}$ & $\begin{array}{c}\text { Generator } \\
r / m i n .\end{array}$ \\
\hline $\begin{array}{r}0.00 \\
25.20 \\
33.48 \\
42.12 \\
52.20 \\
60.00\end{array}$ & $\begin{array}{r}0.00 \\
8.40 \\
11.16 \\
14.04 \\
17.40 \\
20.00\end{array}$ & $\begin{array}{l}30 \\
30 \\
30 \\
30 \\
30 \\
30\end{array}$ & $\begin{array}{l}120 \\
153 \\
174 \\
195 \\
216 \\
240\end{array}$ & $\begin{array}{l}4.8 \\
2.0 \\
2.5 \\
3.5 \\
4.6 \\
6.0\end{array}$ & $\begin{array}{r}144 \\
60 \\
75 \\
105 \\
138 \\
180\end{array}$ & $\begin{array}{r}576 \\
306 \\
435 \\
683 \\
994 \\
1440\end{array}$ & $\begin{array}{l}8100 \\
7960 \\
7880 \\
7790 \\
7710 \\
7570\end{array}$ \\
\hline
\end{tabular}


a.

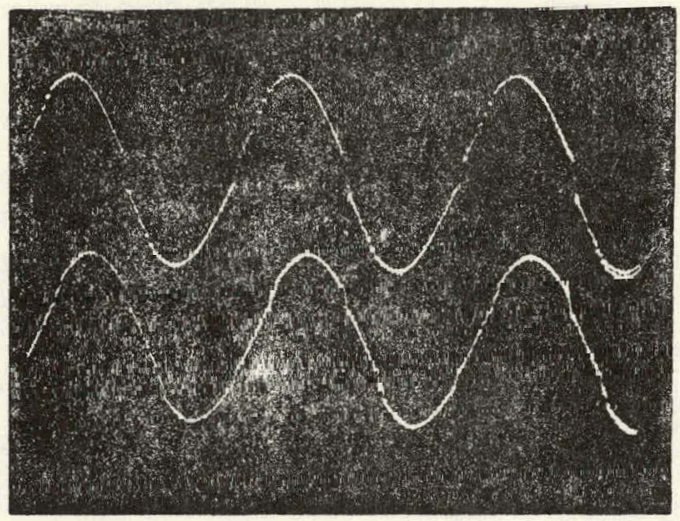

Fig. 9. No-Load Waveforms (higher speed of operation).

a. Line-Neutral Voltage; $100 \mathrm{~V} / \mathrm{cm}$., $5 \mathrm{~ms} / \mathrm{cm}$.

b. Line-Line Voltage; $200 \mathrm{~V} / \mathrm{cm}, 5 \mathrm{~ms} / \mathrm{cm}$.

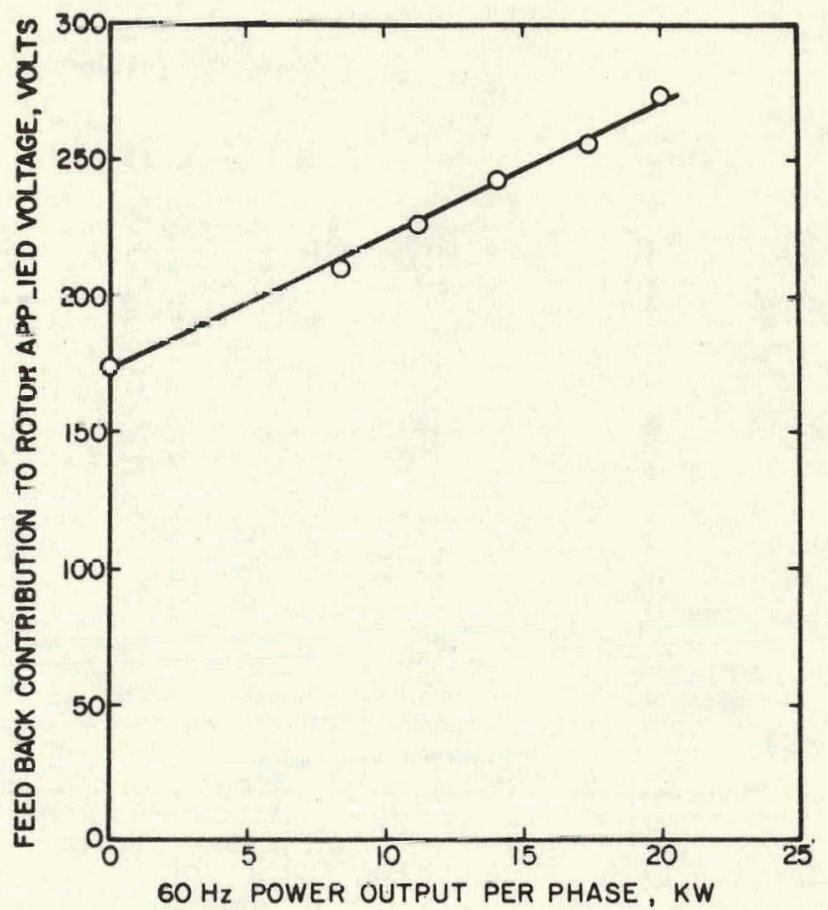

Fig. 11. Variation of the Feedback Portion of Rotor Applied Voltage with Power Output. a.

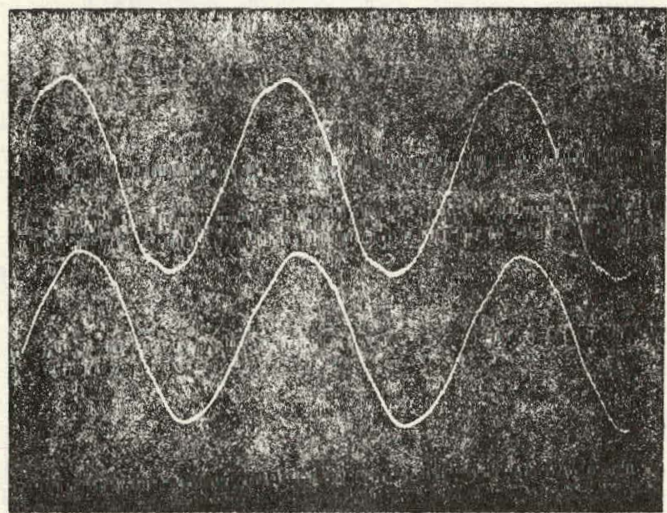

Fig. 10. Ful1-Load Waveforms (higher speed of operation).
a. Line-Neulral Voltage; $100 \mathrm{~V} / \mathrm{cm}$. $5 \mathrm{~ms} / \mathrm{cm}$.
b. Line-Line Voltage; $200 \mathrm{~V} / \mathrm{cm} ., 5 \mathrm{~ms} / \mathrm{cm}$.

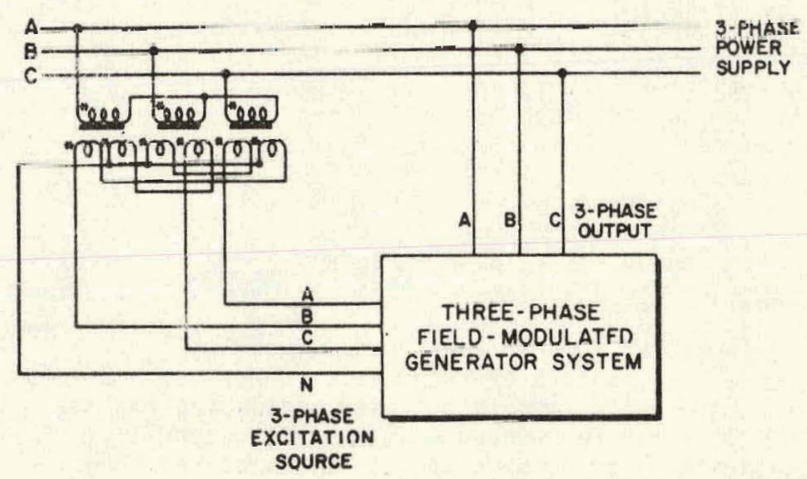

Fig. 12. Schematic of an application of the Field Modulated Generator System. 


\section{APPLICATIONS}

The variable-speed constant (adjustable) frequency feature of field modulated generator systems lends 1 tself to many useful applications. Light weight portable $60 \mathrm{~Hz}$ power sources can be bullt by operating the generator at higher frequencles $(1000 \mathrm{~Hz}$ or higher) and high speeds. High speed unregulated prime movers can be used in such power systems. By varying the modulation frequency in steps or smoothly over a suttable range, a variable-voltage, varlablefrequency power source for supplying ac variable speed drives is obtained 90 . When.driven by high-speed gas turbines, such systems appear to be well sulted for prime-mover carrying vehicles, such as urban cars, mass transit systems, and off-highway vehicles.

A specific application of the system described in this paper under investigation at Oklahoma State University is associated with the conversion of the variable energy avallable in the winds to constant frequency ac energy. When a power network is already present and wind energy is proposed as an additional source to augment the generating capacity of the power system, the avaflable supply itself can be used as the excitation source, as shown in Figure 12. Such a procedure greatly simplifies the electronics associated with the system and the problems associated with synchronizing the wind driven part of the system to the existing power lines.

\section{CONCLUDING REMARKS}

The self-excited field modulated three-phase power system described in this paper has many significant features which can have an impact on the power systems of the future. Since the generator operates at a high frequency and speed, it is much smaller and lighter than conventional generators having the same power rating. The unique self exciting feature of the machine reduces the voltamperes required to drive the machine to full output to a minimal level (approximately 300 VA for $60 \mathrm{~kW}$ output). Unbalanced loads, up to the rated power in one or two phases only, can be supplied by this system without any major operational difficulties similar to the ones experienced. With conventional three-phase synchronous machines. This is due to the fact that the load on each phase of the proposed system is reflected as a balanced load on all three phases of the corresponding core stack only. These features, coupled with the ability of the systen to provide fixed or variable output frequencies independent of shaft rotational speed give promise for the applications described in this paper for such a system.

Further work is in progress which will test various other aspects of the system described, and construction of a complete system including the control circuits for tes: under actual working conditions as a separate power source and as a source pumping power into an existing grid are underway.

\section{REFERENCES}

1. K. M. Chirgwin and L. J. Stratton, "VariableSpeed Constant-Frequency Generator System for Aircraft," AIEE Transactions, pt. II (Applications and Industry), Vo1. 78, November 1959. pp. 304-310.

2. K. M. Chirgwin, L. J. Stratton and J. R. Toth, "Prectse Frequency Power Generation from an Unregulated Shaft", AIEE Transactions, pt. II (Applfcations and Industry), Vol. 80, January 1961, pp. 442-451.

3. L. J. Lawson, "The Practical Cycloconverter", IEEE Transactions on Industry and General Appli cations, Vol. IGA-4, No. 2, pp. 141-144, March/ Aprif 1968.

4. E. F. Lindsley, "New Alternator Delivers 60Cycle Power at Any Speed", Popular Science, July 1973, pp. 38-40.

5. W. L. Hughes, H. J. Allison and R. Ramakumar, "Field Modulated Alternator System and Control Therefor." U. S. Patent No. 3,727,122.

6. H. J. Allison, R. Ramakumar and W. L. Hughes, "A Field Modulated Frequency Down Conversion Power System," IEEE Transactions on Industry Applications, Vol. IA-9, No. 2, March/April 1973, pp. 220-226.

7. R. Ramakumar, H. J. Allison and W. L. Hughes, "Description and Performance of a Field Modulated Frequency Down Converter," 1972 SWIEEECO Record, IEEE Catalog No. 72 CHO 595-9 SWIECO, Dallas, Texas, April 1972, pp. 252-256.

8. R. Ramakumar and H. J. Allison, "Design-Fabrication and Layout of a $60 \mathrm{~kW}$ Three-Phase Field Modulated Generator System." Proceedings of the Frontiers of Power Technology Conference, Oklahoma State University, Stillwater, Oklahoma, pp. 16-1 to 16-9, October, 1972.

9. W. L. Hughes, H. J. Allison, and R. Ramakumar, "A Varlable Frequency Power Source for Ground Transportation." Proceedings of the 7th Intersociety Energy Conversion Engineering Conference (IECEC). pp. 996-1002, 1972,

10. R. Ramakumar, H. J. Allison, and W. L. Hughes, "Varlable. Speed Drive Applications of Fieid Modulated Frequency Down Converters," 1973 SWIEEECO Record, IEEE Catalog No. 73 CHO 719-5-SWIECO, Houston, Texas, Apri\} 1973, pp. 162-165.

\section{ACKNONLEDGEMENTS}

The. study reported in this paper was supported by USAF Aeronautical Systems Division Contract No. F 33657-72-C-0645. The authors wish to thank Mr. Bruce W. Broding and Mr. B. Thomas Haug for their involvement in the fabrication and testing of the prototype system. 


\title{
APPENDIX C
}

APPLICATION OF FIELD MODULATED GENERATOR SYSTEMS

TO DISPERSED SOLAR THERMAL ELECTRIC GENERATION

\author{
Paper Presented \\ in \\ Focus on Solar Technology \\ Denver, Colurado \\ November, 1978
}


APPLICATION OF FIELD MODULATED GENERATOR SYSTEMS

TO DISPERSED · SOLAR THERMAL ELECTRIC GENERATION*

\author{
R. Ramakumar \\ Oklahoma State University, Stillwater, OK 74074
}

\title{
ABSTRACT
}

This paper gives a brief introduction to field modulated generator systems and discusses some preliminary thoughts on their application to dispersed solar thermal electric generation.

\section{INTRODUCTION}

Field modulation refers to varying the magnetic field in the air-gap of a rotating machine as desired by varying the excitation current to obtain a variety of desired outputs. The concept of employing field modulation techniques to control the output frequency of a generator has been discussed in the literature for at least twenty years [1-4]. However, most of the early attempts were not highly successful either for the lack of high-speed highpowered solid-state switching devices at that time or due to low overall efficiencies resulting from line-to-line short circuits at the machine terminals during commutation or both.

The first successful multi-kilowatt-scale field modulated generator system (FMGS) was developed, designed, fabricated and tested at Oklahoma State University (OSU) during the early seventies. The key to the success was the employment of a parallel-bridge rectifier system (PBRS) at the machine terminals, thus eliminating the line-to-line short circuits. This feature, coupled with the use of capacitors at the bridge-inputs, reduce the excitation requirements, improve the regulation and the overall efficiency. Over the past eight years, several $10 \mathrm{~kW}$ and $20 \mathrm{~kW}$ single-phase prototypes and a three-phase $60 \mathrm{~kW}$ prototype have been built and tested. Design details and performance characteristics of these systems arc well documented in the literature [5-9].

Overall efficiency (ratio of $60 \mathrm{~Hz}$ output to mechanical input, accounting for excitation losses) of the $10 \mathrm{~kW}$.prototype was nearly constant at $82 \%$ from $110 \%$ down to $40 \%$ of the rated output. For the $60 \mathrm{~kW}$ prototype, this figure was slightly over $90 \%$. For the purpose of comparison, it should be noted that, in the case of an AC-DC-AC system, with an alternator efficiency of $90 \%$ and an inverter efficiency of $90 \%$, the overall efficiency is only $81 \%$.

* This paper presents the results of one phase of research carried out for let Propulsion Laboratory, California Institute of Technology. This work was jointly sponsored by the Department of Energy and the National Aeronautics and Space Administration under interagency Agreement and Contract No. NAS 7-100. 
A functional block diagram of the basic FMGS scheme is shown in Figure 1. Assuming the machine waveform to be sinusoidal, voltage waveforms at various points are also shown. The excitation current is sinusoidal at the modulation (low) frequency and low-frequency envelope switching is employed for demodulation. All the experimental prototypes built and tested so far at OSU are based on this principle.

A slight variation of the basic scheme to completely eliminate the SCR switching circuit has been discussed in the literature [10]. A functional block diagram and the associated waveforms for this scheme are given in Figure 2. This requires two identical machines or two core stacks mounted on the same shaft and excited as shown in Figure 3 . On a close examination, it can be seen that the unidirectional current flow throught he PBRS circuitry makes this scheme unworkable.

With very-high-speed machines (above $20,000 \mathrm{r} / \mathrm{min}$ ), it is desirable to el iminate the need for slip rings to supply the cxcitation. An approach to accomplish this is shown in Figure 4. Because of the need to modulate the field, the magnetic circuit becomes slightly more involved. The stator winding will be in two halves, one on each side of the exciting coil, and they can be connected in series or in parallel as desired.

\section{APPLICATION TO DISPERSED SOLAR THERMAL ELECTRIC GENERATION}

One of the advanced dispersed solar thermal electric generation systems under consideration by the Jet Propulsion Laboratory consists of a multitude of $15 \mathrm{kWe}$ solar-electric units coupled together on the electrical side. Since electrical transmission has the potential for efficient and economic transport of energy, this particular concept appears viable, deserving further study.

Several alternatives are available for converting the mechanical energy output of the heat engine into electrical energy. Application of FMGS is one of the options under investigation at present. The nature of the basic FMGS scheme suggests the use of a single-phase unit with each dish. The outputs of an array of dishes can be paralleled (at the PBRS output terminals) and processed through a common inverter. To obtain a three-phase electrical output from a dish collection field, the units are divided into three equal groups, with each group modulated by one of the three phases and contributing to the output of that phase. The units belonging to a group can be scattered throughout the field to smooth out the effect of cloud cover and other statistical variations.

\section{CONCLUDING REMARKS}

FMGS appears to provide a viable alternative for constant frequency ac puwer generation from an unregulated high-speed shaft such as a Brayton cycle heat 
engine. It has potential for light weight, high efficiency and attractive electrical characteristics under both steady-state and transient (fault) conditions. Furhter work is underway to estimate cost projections, determine the monitoring and control requirements for parallel operation with a utility grid and to identify the technologies needed for successful introduction of this device in advanced dispersed solar thermal systems of the future.

\section{REFERENCES}

1. B. M. Benton and R. P. Judkins, "Frequency Control Device for Generators, "U.S. Patent, No. 2,896,150, dated July 21, 1959.

2. L. J. Johnson, "Apparatus for Producing Alternating Current," U.S. Patent, No. 3,001,124, dated September 19, 1961.

3. A. K. Wickson, "A Simple Variable Speed Independent Frequency Generator," AIEE Conference Paper No. CP 59-915, presented at the Summer and Pacific General Meeting and Air Transportation Conference, Seattle, Washington, June 1959 .

4. T. Bernstein and N. L. Schmitz, "Variable Speed Constant Frequency Generator Circuit Using a Controlled Rectifier Power Demodulator." AIEE Conference Paper No. CP 60-1053, presented at the Pacific General Meeting, San Diego, Califurnia, August 1960.

5. R. Ramakumar, H. J. Allison and W. L. Hughes, "Description and Performance of a Field Modulated Frequency Down Converter," 1972 SWIEEECO Record, IEEE Catalog No. 72 CHO 595-9 SWIECO, Dallas, Texas, pp. 252256, Apri1 1972.

6. H. J. A1lison, R. Ramakumar and W. L. Hughes, "A Field Modulated Frequency Down Conversion Power System," IEEE Conference Record of 1972 Seventh Annual Meeting of the IEEE Industry appplications Society, IEEE Catalog No. 72 CHO 685-8-IA. Philadelphia, Pennsylvania, pp. 769-774, October 1972; IEEE Transactions on Industry Applications, Vo1. IA-9, No. 2, pp. 220-226, March/Apri1 1973.

7. W. L. Hughes, H. J. Ali ison and R. Ramakumar, "Field Modulated Alternator System and Control Therefor," U.S. Patent, No. 3,727,122, Apri1 10, 1973.

8. R. Ramakumar, H. J. Allison and W. L. Hughes, "A Self-Excited FieldModulated Three-Phase Power System," IEEE Summer Power Meeting and Energy Resources Conference, Paper No. C 74 318-2, Anaheim, California, July 1974.

9. R. Ramakumar et al., Final Report, "Development and Adaptation of Field Modulated Generator Systems for Wind Energy Applications." Submitted to the Energy Research and Development Administration and the National Science Foundation, Washington. D.C. , Contrar.t. No. ERDA/NSF-AER 7500647, September 1976. NTIS Accession No. PB 272495/AS.

10. W. L. Hughes, H. J. Allison and R. Ramakumar, "Apparatus for Providing AC Electrical Energy at a Preselected Frequency," U.S. Patent, No. $3,663,945$, May 16, 1972 . 


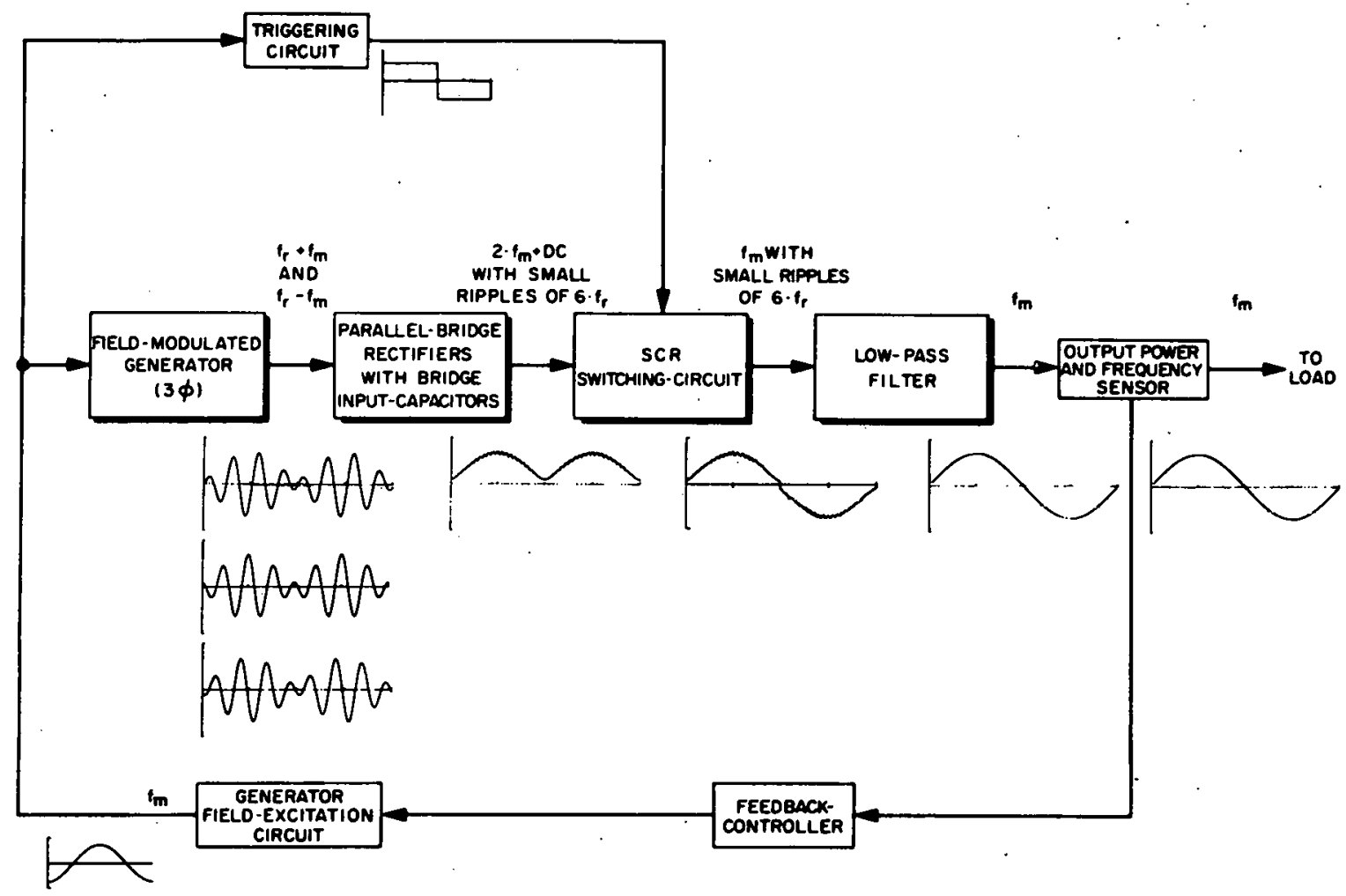

Figure 1. Functional Block Diagram of the Basic FMGS Scheme.

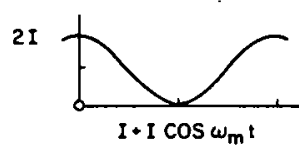

EXGITATIONN CIIRRENT WAVEFORMS

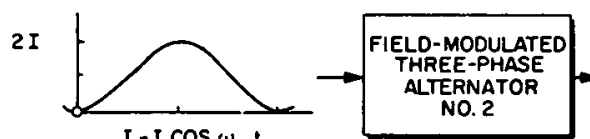

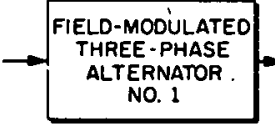

IDENTICAL MACHINES

NO. 2
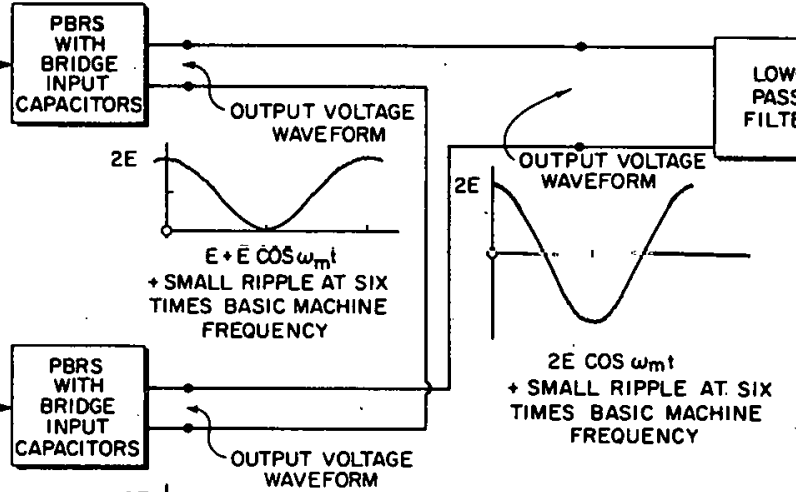

PASS
FILTER

2E $\cos \omega_{m t}$

+ SMALL RIPPLE AT. SIX TIMES BASIC MACHINE FREQUENCY

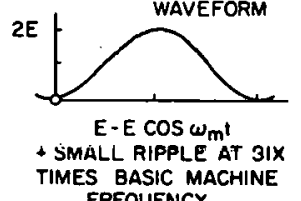

FREQUENCY

Figure 2. Functional Block Diagram of an Alternate Scheme With Field Modulation and no SCRS. 


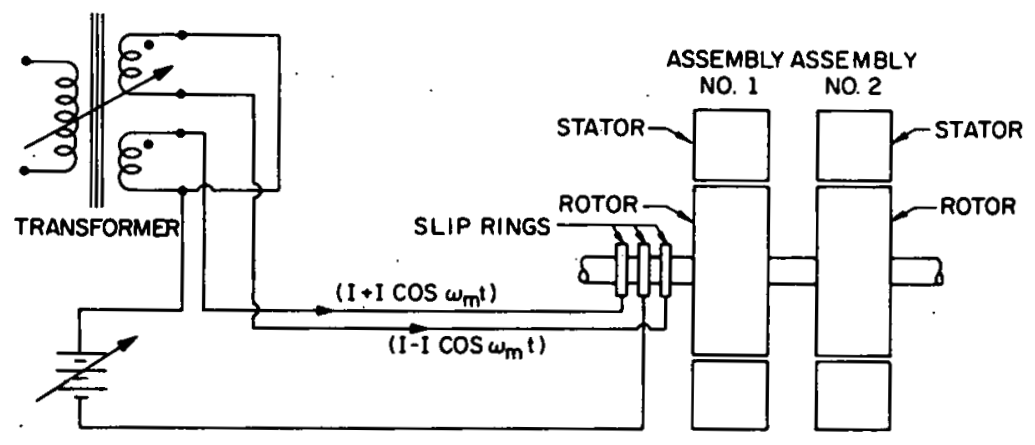

Figure 3. An implementation of the Alternate Scheme of Figure 2.

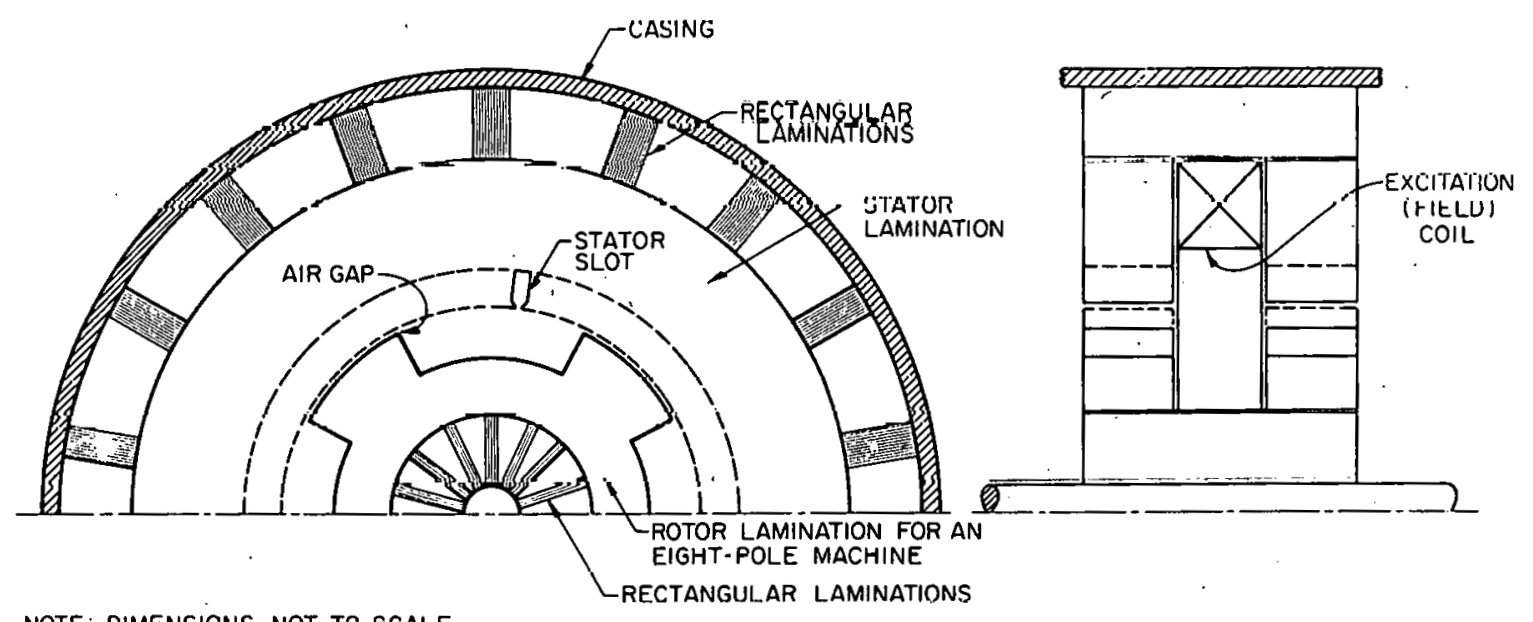

NOTE: RIMENGIONG NOT TO SCAIEE

Figure 4. Inductor-type Magnetic Circuit to Eliminate Sliprings. 